\title{
Participation in sustainability transitions: A case study of engagement in Ottawa's Energy Evolution Strategy
}

\author{
by
}

Daniel Atlas

A thesis submitted to the Faculty of Graduate and Postdoctoral Affairs in partial fulfillment of the requirements for the degree of

Master of Arts

in

Political Science

Carleton University

Ottawa, Ontario

(C) 2021, Daniel Atlas 


\begin{abstract}
This thesis engages with the issue of how cities are responding to the challenge of climate change through participatory processes intended to enable sustainable energy transitions. It focuses on municipal-level energy transition planning in the city of Ottawa, Ontario Canada, using a case study of participation in Ottawa's Energy Evolution Strategy. This Strategy aims to have the city reach net-zero greenhouse gas emissions by 2050 . This thesis draws on 14 semi-structured interviews with Energy Evolution participants and city staff as well as other primary sources such as reports and meeting minutes. It examines democratic engagement in Energy Evolution informed by two theoretical frames which, together, provide a holistic view of participation in sustainability transitions. Constructivist science and technology studies (STS) theory is used to analyze the creation of the participatory process. Informed by STS theory, I show that Energy Evolution was purposefully created and only partially framed as participatory. It was stakeholder focused, invited, professionally facilitated, and maintained a technocratic focus on energy transitions. I also assess the process against specific normative criteria, informed by the theory of ecological democracy. I show that Energy Evolution was only partly participatory in the way that is envisioned by ecological democracy theorists. Informed by this analysis, I argue for the increased role of diverse non-state actors in transitions processes, noting that for such processes to be effective, these actors require a deeper understanding of, and influence on, participatory processes in institutional spaces that are empowered to make these important environmental decisions.
\end{abstract}




\section{Acknowledgements}

I would like to thank the individuals and organizations who made this thesis possible. First, the ongoing encouragement and support of my two supervisors kept me pushing through. I am grateful to my supervisor Peter Andrée. Our early conversations led to my decision to begin this process. You encouraged me to get out and involved in the community. And your insights and detailed feedback pushed me to elevate this work.

Second, I would also like to extend my gratitude to my co-supervisor James Meadowcroft for coming onboard to this project. You provided valuable suggestions, pushed me with tough questions but you were also a calming and reassuring force when needed.

Thank you to Ecology Ottawa and the Ottawa Eco-Talent Network for being open and welcoming to me. Without these two organizations, I never would have adopted this work. I am also thankful to the interviewees for their involvement in this study and their trust in me. Without you, this project would not have been possible.

I would like to thank my loved ones for their support during this time. And last, I would like to thank the workers, farmers and producers (who are mostly unknown to me) for sustaining me throughout this process. 


\section{Table of Contents}

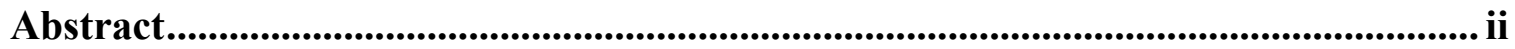

Acknowledgements ......................................................................................................ii

Table of Contents .......................................................................................................................... iv

List of Abbreviations ............................................................................................. vii

List of Tables ........................................................................................................ii

List of Figures................................................................................................................................ ix

List of Appendices....................................................................................................................... $\mathrm{x}$

Chapter 1: Thesis Introduction ................................................................................................... 1

Chapter 2: Literature Review............................................................................................ 7

2.1 Participation in Municipal Environmental Decision-Making................................................

2.2 Sustainability Transitions (ST) Research ………………………………………..... 10

2.3 Participation in Sustainability Transitions....................................................................... 13

2.4 Conclusions: Participation in Transitions Decision-Making .............................................. 17

Chapter 3: Theoretical Approach ............................................................................................ 19

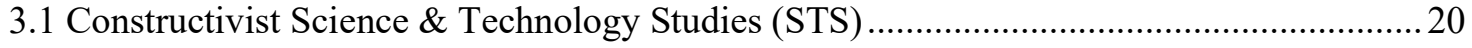

3.2 Ecological Democracy ……………………………………………………………..2

3.3 Conclusions: Constructivist STS \& Ecological Democracy in Conversation ...................... 34

Chapter 4: Methodology............................................................................................................ 37

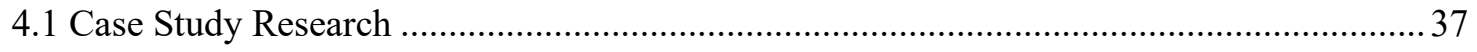

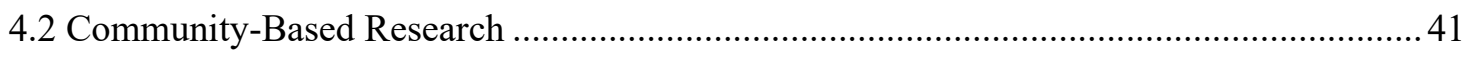

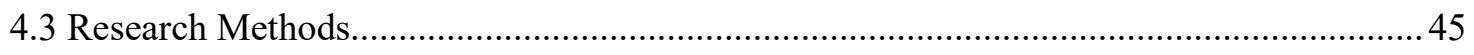

4.4 Conclusions: Analyzing Participation in Energy Evolution in Practice ............................. 49

Chapter 5: The Case Study of Energy Evolution................................................................ 51

5.1 The City of Ottawa: Context, Energy Mix \& Jurisdictional Responsibilities .....................52 


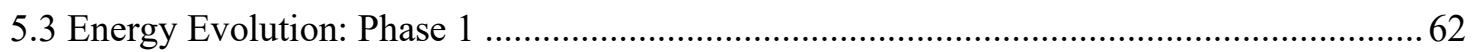

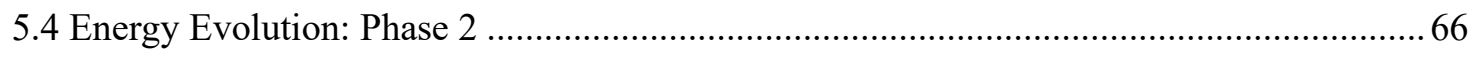

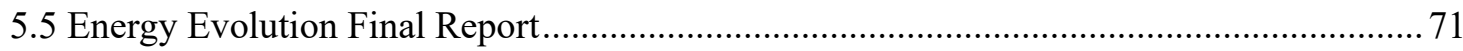

5.6 Conclusions: Examining a case study of Ottawa's Energy Evolution process .................... 75

\section{Chapter 6: Analysis Part I - Participation 'in the making' in Ottawa's Energy}

Evolution Strategy ..................................................................................................................... 77

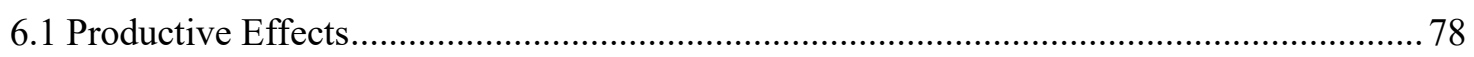

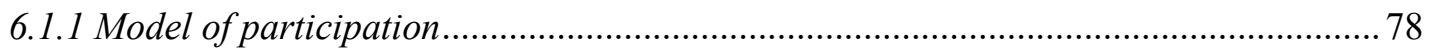

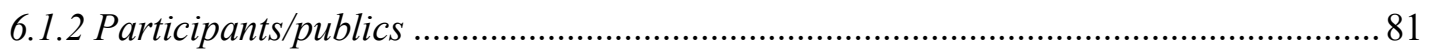

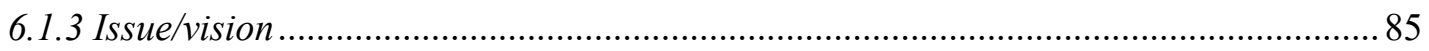

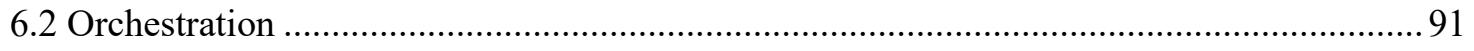

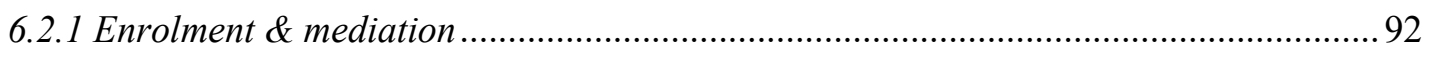

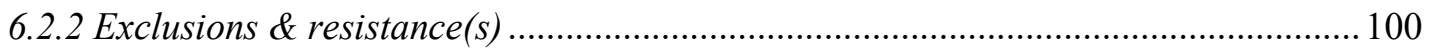

6.3 Conclusions: The Manifestation of Participation in Ottawa's Energy Evolution Strategy 105

\section{Chapter 7: Analysis Part II - Participation in Ottawa's Energy Evolution Strategy} in Contrast to Ecological Democracy ..................................................................... 111

7.1 Participatory Space in Ottawa's Energy Evolution process ......................................... 113

7.2 Influence \& Accountability in the Energy Evolution Participatory Process ..................... 126

7.3 The Consequentiality of the Energy Evolution Participatory Process............................... 135

7.4 Conclusions: Energy Evolution \& Ecological Democracy ........................................... 144

\section{Chapter 8: Conclusion - Energy Evolution \& Participation in Sustainability}

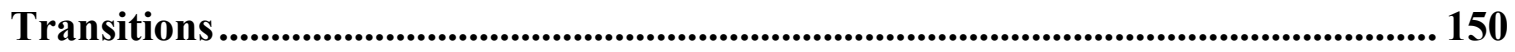

Section 8.1 Lessons for Transitions from Ottawa's Energy Evolution Process ...................... 152

8.1.1 Energy Evolution's participatory process .......................................................... 152

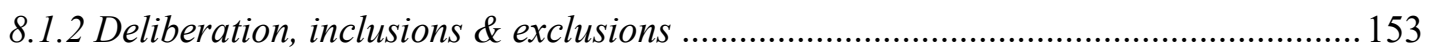




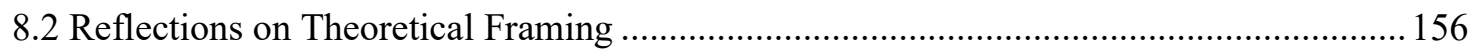

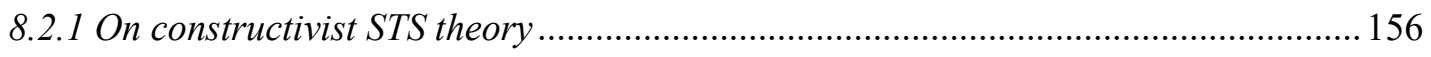

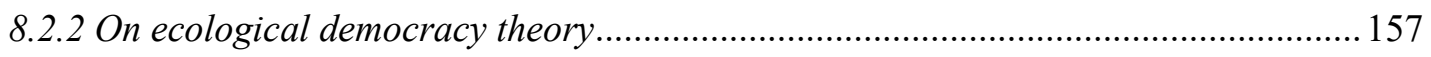

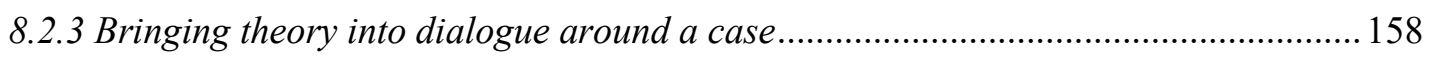

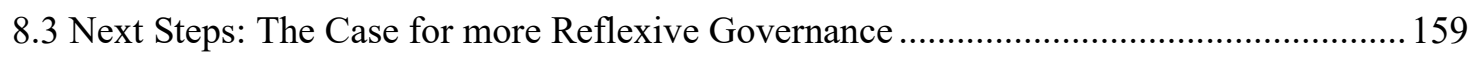

Appendices ........................................................................................................................... 162

Appendix A: List of community stakeholders involved in Sounding Board discussions and technical workshops in "Ottawa's Community Energy Transition Strategy: Phase 1" (City of Ottawa Planning, Infrastructure and Economic Development 2017, p. 1-2)......................... 162 Appendix B: List of community stakeholders involved in overall Sounding Board discussions and technical workshops in “Energy Evolution: Ottawa’s Community Energy Transition

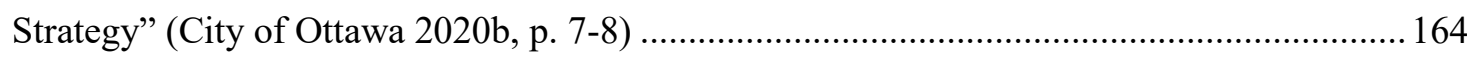
Appendix C: List of sample interview questions for Sounding Board members (with prompts

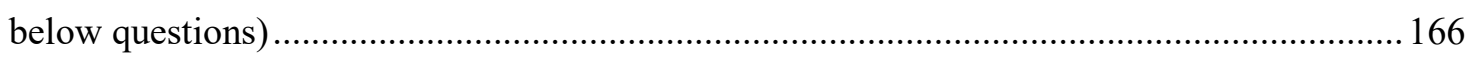
Appendix D: List of sample interview questions for City of Ottawa staff (with prompts below

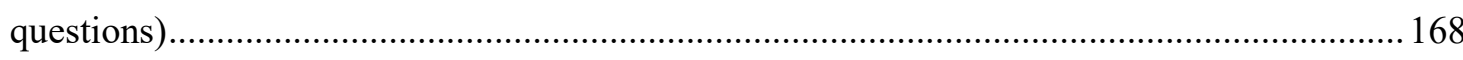
Appendix E: List of individuals/organizations that provided support for Energy Evolution: Ottawa's Community Energy Transition Strategy Final Report (EPWWM, 2020a) .............. 170

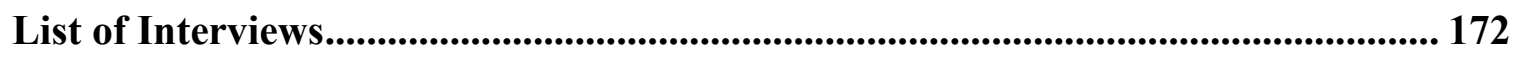

References ........................................................................................................................... 173 


\section{List of Abbreviations}
ANT
Actor-network theory

AQCCMP Air Quality and Climate Change Management Plan

BAP Business as planned

CBO Community-based organization

CBR Community-based research

CO2 Carbon dioxide

ECPC Environment and Climate Protection Committee

EE Energy Evolution

ENGO Environmental non-government organization

EPWWM Standing Committee on Environmental Protection, Water and Waste

Management

GHG Greenhouse gas

IPCC Intergovernmental Panel on Climate Change

OETN Ottawa Eco-Talent Network

RNG Renewable natural gas

SSG Sustainability Solutions Group

ST Sustainability transitions

STS Science and technology studies 


\section{List of Tables}

Table 1. Main analytical themes of participatory collectives ................................... 48

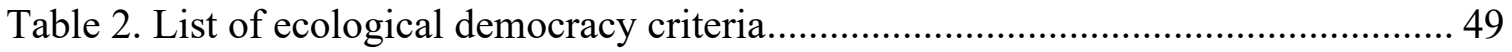

Table 3. General timeline of key Energy Evolution events ......................................... 61

Table 4. Summary of City of Ottawa GHG emissions projections for BAP, $80 \%$ scenario

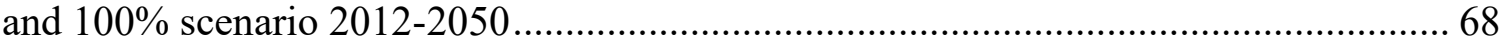

Table 5. Early Energy Evolution Sounding Board Members (2016) by organization type

Table 6. A summary of Ottawa's Energy Evolution participatory collective in relation to

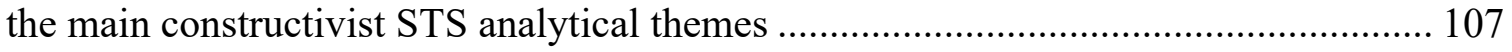

Table 7. Summary of the Energy Evolution participatory process against the norms of

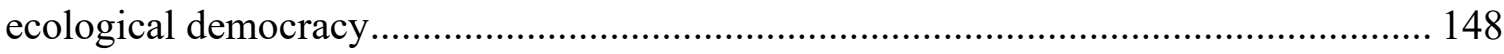




\section{List of Figures}

Figure 1. "A socio-material collective of participation, which emerges through the coproduction of subjects $(\mathrm{S})$, objects $(\mathrm{O})$ and procedural formats $(\mathrm{P})$ in relation the setting and extant orders (outer circle).". Reprinted from "Participation in transition(s):

Reconceiving public engagements in energy transitions as co-produced, emergent and diverse" by J. Chilvers \& N. Longhurst, 2016, Journal of Environmental Policy and Planning, 18(5), p. 590. Copyright 2016 The Author(s). Published by Informa UK Limited, trading as Taylor \& Francis Group.

Figures $2 \&$ 3. Figure 2: "Projected community-wide GHG emissions by sector in the 80\% scenario" (left), Figure 3: "Projected community-wide GHG emissions by sector in the $100 \%$ scenario" (right). Reprinted from "Project status update on Energy Evolution: Ottawa's community energy transition strategy" 2019, City of Ottawa, p. 9-10. Copyright 2020 by City of Ottawa.

Figure 4. "Ottawa's climate change framework". Reprinted from "Climate Change Master Plan” 2020a, City of Ottawa, p. 6. Copyright 2020 by City of Ottawa.

Figure 5. "Total projected community-wide GHG emission reductions required to achieve $100 \%$ scenario incremental to BAP scenario by sector, 2016-2050 (percentages shown at 2050 are non-cumulative)". Reprinted from "Energy Evolution: Ottawa's community energy transition strategy" 2020a, City of Ottawa, p.13. Copyright 2020 by

City of Ottawa. 73 


\section{List of Appendices}

Appendix A: List of community stakeholders involved in Sounding Board discussions

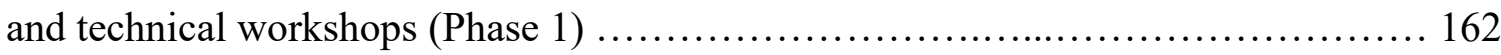

Appendix B: List of community stakeholders involved in overall Sounding Board

discussions and technical workshops.......................................... 164

Appendix C: List of sample interview questions for Sounding Board members......... 166

Appendix D: List of sample interview questions for City of Ottawa staff............ 168

Appendix E: List of individuals/organizations that provided support for Energy

Evolution's Final Report..................................................... 170 


\section{Chapter 1: Thesis Introduction}

This thesis is about participation in sustainability transitions. It focuses on municipal-level energy transition planning in the city of Ottawa, Ontario Canada using a case study of participation in Ottawa's Energy Evolution Strategy. It explores what Energy Evolution means in Ottawa, and the extent to which the creation of an energy transition strategy was participatory and democratic. This project is situated in relation to the problem of energy use patterns in a country like Canada and, specifically, the role of energy use in exacerbating global climate change.

The global energy sector faces several sustainability challenges today. The Intergovernmental Panel on Climate Change (IPCC) estimates that in 2010, the energy supply sector contributed 35 per cent of total anthropogenic global greenhouse gas (GHG) emissions and is the largest total sectoral contributor of GHGs (Bashmakov et al., 2014). The energy sector is also faced with a number of deep disparities between: the promise of widely distributed energy and the fact that nearly one billion people globally that do not have access to electricity; the gap between scientific evidence showing the need for rapid cuts in GHG emissions compared to energy related emissions hitting historic global highs in 2018; expectations of renewables-driven energy transitions and current energy systems which are highly reliant on fossil fuels; as well as the gap between well-supplied oil markets and unease over geopolitical tensions and global uncertainties (International Energy Agency [IEA], 2019). Energy sustainability poses a wicked environmental problem that includes both technical and social justice dimensions. This thesis is grounded in the assumption that both dimensions need to be addressed simultaneously given that the stabilization of GHG concentrations at low levels requires a 
fundamental transformation of the energy supply system to more sustainable and equitable modes of energy production and consumption.

The sustainability transitions (ST) approach is well-suited to address the complexities of environmental problems such as energy sustainability as it conceptualizes 'socio-technical' systems as a complex configuration of elements that include technology, policy, markets, consumer practices, infrastructure, cultural meaning and scientific knowledge. Major shifts in these systems are identified as socio-technical transitions (Geels, 2012). These shifts encompass long-term, multi-dimensional and fundamental transformation processes of socio-technical systems to more sustainable modes of production and consumption (Markard et al., 2012). As these systems are both societal and technical, transitions represent processes of social change in response to social challenges that are inherently political and require understanding power relations (Avelino et al., 2016). To date, however, the academic field of ST is generally technology-focused. Most studies overlook the role of the public, and of democratic engagement, in transition processes (Chilvers \& Longhurst, 2016). And historically, debates on how to manage policy transitions to sustainability have been "curiously silent on democratic matters, despite their potential implications for democracy" (Hendriks 2008, p. 341). But there is continued interest in participation in transitions, with attention to the contribution of non-state actors such as citizens, communities, cities and city networks to a sustainable future (Hoff et al., 2020), as well as questions of how public input and involvement ought to be designed, structured and organized so it facilitates a transition to a sustainable energy future (Renn et al., 2020). Further, with a growing number of research funding programmes requiring explorations of participation, 
"analytical approaches to critically scrutinise participation processes in their complexity seem ever more important" (Fritz \& Binder 2018, p. 2). The field of ST thus continues to need more studies that examine that examine how power is manifest in transition planning, with a view to exploring how decision-making processes can become less distorted, more inclusive, ecologically accountable and responsive in addition to attention to examining the details of participatory processes and how they can be used to forward sustainability transition goals. This study intends to fill this gap, drawing on the theories of constructivist science and technology studies (STS) (Chilvers \& Longhurst, 2016) and ecological democracy (Dryzek, 2009; Schirmer et al., 2016) to examine participation in municipal-level energy transition planning in the city of Ottawa.

On April 24, 2019, Ottawa City Council declared a climate emergency for what they deem as the purposes of naming, framing and deepening the commitment to protecting its economy, ecosystems and community from climate change (City of Ottawa, n.d.-a). This action was consistent with efforts being undertaken around the world. Cities are recognized as having an important part to play in sustainability transitions (Roelich et al., 2018), as they are responsible for roughly two-thirds of global primary energy consumption and they play a key role in transforming energy systems (Petersen, 2018). And local governments are increasingly engaging in innovative ways of governing to enable sustainability transitions (Smedby \& Quitzau, 2016). For the City of Ottawa, Energy Evolution encompasses the shift away from the dependence on fossil fuels toward more sustainable modes of living. Energy Evolution is designed to manage energy consumption, promote the use of renewable energy and advance local economic development opportunities. It has been developed in collaboration with dozens of local 
businesses and organizations. Energy Evolution is intended to be a community-wide initiative with a vision to transform Ottawa into a thriving city powered by clean, renewable energy (City of Ottawa, 2020b). This project uses 14 semi-structured interviews with participants and city staff to conduct a case study of Ottawa's Energy Evolution Strategy from 2014 to 2020, focusing primarily on the period from 2016 to 2020 when Energy Evolution hosted over 45 meetings with more than 200 stakeholders representing approximately 90 organizations (Standing Committee on Environmental Protection, Water and Waste Management [EPWWM], 2020b).

This research project does not undertake a technical analysis of the merits of the Energy Evolution Strategy. Rather, it aims to critically interrogate the micro-political processes of participation in sustainability transitions on a municipal scale, informed by the theories of constructivist STS and ecological democracy. Constructivist STS provides an open-ended view of participation, holding that publics, issues and procedural formats of participation are constructed via the performance of collective participatory practices (Chilvers \& Longhurst, 2016). Ecological democracy is a term for a set of decisionmaking procedures that deepen democratic practice by better including actors affected by ecological risks in policy processes (Eckersley, 2005). Ecological democracy is a normative goal that is specifically suited to the climate change challenge, as its procedures seek to integrate different perspectives, assimilate feedback, and give rise to values that are oriented to the community as a whole, inspiring decision-making that takes into account a variety of interests (e.g., future generations and non-human nature) and generates creative situations which are self-critical and self-correcting (Dryzek, 2013). 
Informed by the theories of constructivist STS and ecological democracy, this project asks: What does Energy Evolution mean in Ottawa and to what extent are the processes for creating an energy transition participatory and democratic? This research question can be broken down into two main research sub-questions, each informed by specific elements of my theoretical framework. These are: 1) How is participation in this process manifest? and 2) How does the participatory process in Ottawa stand up against the procedural norms of ecological democracy? In response to my first research subquestion, this work argues that the Energy Evolution process was purposely created and only partially framed as participatory. In response to my second question, it argues that it was only partly participatory in the way that is envisioned by ecological democracy theorists. On the role of this participatory process in relation to the City's stated goal of achieving a transition to renewable energy sources, this thesis argues that participation in this process helped move the energy transition conversation in Ottawa forward, but that other factors will make or break the goal of implementing a sustainable energy transition. Further, this case study affirms the need for ecologically reflexive governance processes that are inclusive and empowering for a variety of actors to address environmental problems and enable the transition to sustainable energy sources.

This thesis is divided into eight chapters. Following this introductory chapter, the second chapter provides a literature review of relevant works that focus on environmental decision-making, the context of this work within the broader field of sustainability transitions and the need to build on small-scale case studies and participatory processes relevant to ST. The third chapter introduces the two theoretical frames used in this work: constructivist STS and ecological democracy. The fourth chapter foregrounds the 
methodological choices undertaken in this study, explaining the philosophical basis of the research methodology (a single case study approach and community-based research) and the practical research methods used in this work. The fifth chapter provides a contextual background and a chronological timeline of the development of Ottawa's Energy Evolution Strategy. Chapter six engages with constructivist STS theory to respond to my first research sub-question exploring two analytical themes of productive effects and orchestration. Chapter seven draws on ecological democracy to respond to my second research sub-question by analyzing the participatory space, level of influence and accountability, and consequentiality of the process. This thesis concludes by summarizing my arguments and findings using these two theoretical frames. This chapter also considers the strengths and limitations these frames each brought to this study and discusses the implications of this project's results for future research. 


\section{Chapter 2: Literature Review}

The engagement with a participatory process of energy transition planning Ottawa encompasses questions of how to approach effective environmental decision-making, how to foster a transition to more sustainable modes of energy production and consumption and how we can adopt participatory approaches that might push forward these goals.

This literature review chapter is divided into three parts. First it outlines the rise of participation in environmental decision-making. It acknowledges that researchers have been dealing with questions of participation in environmental decision-making for a long period of time and addresses the need to continue this academic inquiry. Second, it briefly situates the context of this work within the broader field of sustainability transitions (ST), outlining the wider gap that this project intends to fill, including: an engagement with power and a wider range of small-scale actors and under looked avenues for transitions. Third, it examines the need to build on an emerging ST literature of the value of exploring emerging and relevant small-scale case studies and participatory processes to energy transitions via three key studies. This chapter concludes by summarizing the relevancy of this three-part review to this study.

\subsection{Participation in Municipal Environmental Decision-Making}

Participation in environmental decision and policy-making emerged as a focus for government activity in the late 1960s and early 1970s as a result of social movements that argued for local empowerment and civic activism where citizens and local communities were entitled to information about the environmental risks to which they were subject, and had a right to be involved in environmental decisions affecting them (Meadowcroft, 
2004). Governments rationalized the democratization of environmental decision making via a need to secure legitimacy for decisions. Dryzek (2013) refers to this style of environmental problem-solving as 'democratic pragmatism', noting that it generally occurs within the confines of the basic institutional structure of liberal capitalist democracy. With the rise of this approach, governments began to regularly introduce public enquiries and consultation, more transparent administrative mechanisms and formal procedures such as environmental impact assessments, environmental mediation (i.e., alternative dispute resolutions), policy dialogues, lay citizen deliberation, public inquiries and right-to-know legislation (Dryzek 2013; Meadowcroft, 2004).

This type of environmental problem solving involves both participants from within and outside government, and can occur in the context of committee meetings, legislative debate, hearings, public addresses, legal disputes, rule-making, project development, media investigations and policy implementation and enforcement (Dryzek, 2013). Participation is not a singular phenomenon. There are several different types of participation. Meadowcroft (2004) traces three 'strands' with longstanding roots that developed in relation to environmental decision-making since the 1970s. The ‘citizenship' strand emphasises the individual citizen's ability to engage in environmental decisions which affect their future via access to information, participation in debates and the creation and implementation of environmental policy. The 'community centred' strand emphasises local communities and their entitlement to participate in decisions that affect their development via the management of their own affairs, contribution to environmental decision-making processes in the larger political units they belong to and involvement in determining outcomes on issues that directly impact them. Last, the 
'stakeholder' strand emphasises the common interests of groups aligned via social interaction and the participation of these stakeholders together in solving environmental problems. Stakeholders should work together to develop solutions to environmental problems in which they are entangled (Meadowcroft, 2004).

At the same time governments began to incorporate public participation mechanisms into environmental decision-making, academics became engaged with how to deal with questions of how to incorporate publics into participatory processes. One seminal work dealing with this (on a general level) is Arnstein's (1969) typology or 'ladder' of eight levels of participation that range from non-participation to full citizen power. Arnstein's (1969) work makes the point that there are different scales and ranges of power between the have-nots and the powerholders in participatory processes. Studies of local environmental participatory processes trace back to a similar time period, and thus are a long-standing field of inquiry (e.g., Elder, 1982; Gariepy, 1991). The literature is highly diverse, dealing with several areas and different themes. For example, previous environmentally focused case-studies have evaluated the effectiveness of deliberative processes (Petts, 2001) and how public participatory processes can promote social learning (Petts, 2007). Other works examine discourses and ideologies surrounding participation, such as Webler, Tuler and Krueger's (2001) case study of a forest planning process in northern New England and New York. Their research shows that individuals hold different ideas on what a good public participation process entails. One conclusion that can be drawn from such work is the need for research that examines in greater detail the way public participation actually occurs in practice. More recent studies such as Uittenbroek et al.'s (2019) study of three cases of adaptation planning in the Netherlands 
outlines that both government actors and citizens need to show a willingness to participate in participatory processes and both actors can affect the design and objectives of public participation. They argue there is a lack of empirical studies on how participation is practiced and how participation processes are designed.

This project aims to explore the creation, practice and normative goals of participatory processes in relation to objectives of sustainable futures via energy transitions. Previous studies on participation in environmental-decision tell us that participation emerges in different ways. In addition, there are a range of actors involved in participatory processes and there is a need to study the complexity and design of participatory processes. But environmental problems are not a simple question of government inclusion of participants in their decision-making capacities. Rather, there has been an increased focus on the complexity of environmental problems in relation to social systems in an emergent sustainability transitions (ST) literature.

\subsection{Sustainability Transitions (ST) Research}

Whereas the previous literature focuses on participation in specific environmental decisions, over the past twenty years a research community has developed around addressing sustainability problems across a variety of specific domains (e.g., energy, transportation and food), with a goal of initiating sustainability transitions (ST) that aim to fundamentally restructure societal systems of consumption and production (Farla et al., 2012). ST research is an interdisciplinary field of study that incorporates a wide range of disciplines, such as: innovation studies, history evolutionary economics, sociology and science and technology studies in examining socio-technical systems and transitions (Chilvers \& Longhurst, 2016; Markard et al., 2012). It is a particularly useful field in 
addressing "wicked environmental problems", which are policy or planning dilemmas that are complex, uncertain, non-definitive and lack a single and risk-free solution (Rittel $\&$ Webber, 1973). These problems are characterized by complex integrated social, cultural, economic, political, as well as environmental dimensions (Sharp et al., 2021). The socio-technical approach to transitions is well-suited to address the complexities of environmental problems it conceptualises socio-technical systems (e.g., energy, water and/or transportation sectors) as a configuration of elements that include technology, policy, markets, consumer practices, infrastructure, cultural meaning and scientific knowledge. Major shifts in these socio-technical systems are identified as socio-technical transitions (Geels, 2012), or long-term, multi-dimensional and fundamental transformation processes where established socio-technical systems shift to more sustainable modes of production and consumption (Markard et al., 2012) that can challenge overall stability, lock-in and path dependence. While there are numerous theories and branches of inquiry found in ST, transitions management (TM) (Kemp \& Loorbach, 2006; Loorbach, 2010) is more attentive to participation than others. It focuses on processes to influence governance activities so that they lead to accelerated change toward sustainability, by for example, looking at how to coordinate actors to compete with dominant actors and practices (Loorbach \& Rotmans, 2010). It is also policyoriented and prescriptive, suggesting that policy makers can shape transitions, one idea being to change governance by bringing actors from a wide range of areas to cooperate (Köhler et al., 2019).

Whereas the rising popularity of ST has lent to its growth, several critiques of the field as a whole have arisen. Some critiques relevant to this project are that the socio- 
technical transitions framework is overly focused on elites and technology (Lawhon \& Murphy, 2011). In doing so, studies privilege the perspective of actors such as corporate leaders, innovators, scientists and state agents, but exclude other relevant actors such as consumers, activists and workers. Critics argue that this narrow focus on a subset of actors who shape transitions is at odds with the challenges of developing pluralistic and participatory institutions for transitions governance (Lawhon \& Murphy, 2011). Studies have also overemphasized socio-technical transitions at the macro or systems level, which have come at the expense of a more actor-oriented and agency-sensitive analyses (Farla et al., 2012). This approach, for example, looks at how strategies, resources and capabilities of individuals, firms and other organizations can impact the overall system and trigger transformation processes (Farla et al., 2012). Further, with ST researchers largely focusing on policy in the past, there have been calls to engage with the politics and political process of sustainability transitions (Meadowcroft, 2011). This includes an argued engagement with the political circumstances that make policies possible, via the domains of 'interests', 'institutions' and 'ideas' (Meadowcroft, 2011). Last, transitions studies often have a bottom-up bias and represent a 'point source approach', which conceptualises transitions as a singular disruptive process with new technologies as driving force and an overfocus on radical innovations may lead transition scholars to underestimate the potential of incremental or small-scale change (Geels, 2018).

Collectively, these critiques argue that avenues for sustainability transitions are possible via a wider range of actors, where power is distributed across diverse societal subsystems and among many societal actors in modern society (Meadowcroft, 2007). As a result, transitions research must be more sensitive to the role of spatial and geographical 
factors, with attention to the role power plays in guiding transitions toward more sustainable outcomes (Lawhon \& Murphy, 2011) and provide an understanding of the struggles of actors with competing interests and which kinds of resources they can mobilize in support of their goals, which will provide a better assessment of the conditions for sustainability transitions to materialize (Farla et al., 2012). This work contends with these gaps, as it examines a possible route toward sustainable futures via participation and democratic engagement in small-scale transition processes.

\subsection{Participation in Sustainability Transitions}

This project builds on an emerging area in the ST literature of the value of exploring geographically and politically-situated case studies. It builds on previous case studies that examine transitions on a small-scale level. This point is well articulated in the work of Roelich, Bale, Turner and Neall (2018). These authors contend that the literature on sustainable energy transitions is dominated by the socio-technical systems theory (STS) and the multilevel perspective (MLP), which understand ST in term of large-scale systemic change. Roelich et al. (2018) argue for increasing recognition that sustainable energy transitions are always geographically and politically situated. Their case study of the creation of municipal energy companies in fives cities in the UK outlines the importance of spatial, political and temporal aspects of energy transitions. They point to a growing body of work which emphasizes the organizational processes through which municipalities develop sustainable energy and climate strategies, and encourage more of it. Such research would aim to examine the municipal scale to understand who governs urban energy transitions, and which processes either push or constrict these low-carbon transitions. 
One early study on participation and deliberation related to sustainability transitions is Hendriks' (2008) work on democratic and inclusionary processes surrounding energy reform processes and transitions management in The Netherlands. This work assesses the openness and accessibility of network governance to those potentially affected by decisions. The practice of network governance is conceptualized by Hendriks (2008) as proactive and affirmative, emphasizing the openness and accessibility of networks to those affected by decisions, including the marginalized, disempowered, silent and silenced. For Hendriks (2008), networks comprise of a set of interdependent policy actors who form around a policy issue or program and network governance refers to an attempt to manage or co-ordinate networks. Network governance requires arrangements that are open and accessible to functional and descriptive representatives from potentially affected publics, enables participants to meaningfully engage and influence decisions, and minimizes external and internal forms of exclusion (Hendriks, 2008). Using interviews, Hendriks' (2008) analysis finds that network arrangements are "colonized by elites at the exclusion of many potentially affected groups and individuals" (p. 1010). In other words, in Dutch energy reforms, partnerships are dominated by industry and government elites, at the expensive of broader democratic engagement and processes (Hendriks, 2008). As a result, a series of strategies are proposed on how to make network governance more accountable and accessible to affected publics, including proactive intervention which entails providing resources and effective opportunities for policy actors, marginalized groups and citizens to participate in issues and decisions that affect them (Hendriks, 2008). While this work does not 
examine networks, it intends to build on notions of democratic participation, deliberation and inclusion/exclusion in public processes related to sustainable energy transitions.

There has been a continued interest in participation in sustainability transitions, with recent works, for example, exploring large questions of how the involvement of publics should be designed, structured and organized to facilitate a sustainable energy transition (Renn et al., 2020). And there are explorations of the role of non-state actors in transitions, such as citizens communities, cities and city networks (Hoff et al., 2020). One recent study which explores these themes is Lyytimäki et al.'s (2019) examination of participation in Finland's national-level initiative called, "The Commitment to Sustainable Development 2050". This work finds a sustainability narrative that emphasises a holistic and long-term management approach with an aim of widespread inclusion of various actors (the public sector, companies, civil society actors, organizations and citizens) participating on a voluntary basis. They find the Commitment 2050 process has the potential to contribute to sustainability transitions that require "longterm, multi-actor, multi-level and multi-sectoral participation" as it frames a narrative of shared and collective responsibility for voluntary action by actors, and does not focus on a single issue, but aims to "tackle a variety of societal challenges tied loosely together by the specific national interpretation of sustainable development based on widespread consensus" (Lyytimäki et al. 2019, p. 32-33). The process they studied also does not focus on a top-down approach of targets for selected social actors, but encourages different actors to identify sustainability targets that are relevant from their perspective and to develop concrete measures to achieve them (Lyytimäki et al., 2019). These authors conclude by encouraging multi-stakeholder participation from a variety of 
areas, and express concern that this is not being realised in many sustainability transition efforts. While this study explores a different approach to participation in ST, it builds on a need to understand how multiple actors across different sectors can be included in participatory spaces.

Chilvers and Longhurst (2016) examine four cases of civil society participation in UK low carbon energy transitions and also show a need to engage in the political processes of transitions. In doing so, Chilvers and Longhurst (2016) bring sustainability transitions theory into conversation with constructivist and relational Science and Technology Studies (STS) perspectives on public participation to "initiate a new way of conceiving of and thinking about participation in transitions" (p. 586). This embodies a more open definition of participation that views all forms of participation as emergent and co-produced phenomenon, which pays particular attention to the circumstances of its construction, performance, production dimensions and effects (Chilvers \& Longhurst, 2016). There are two main analytical themes in the work by Chilvers and Longhurst (2016). First, the work draws attention to the processes by which collectives of participation in transitions are orchestrated, the process by which they get made and the exclusions that occur in terms of social actors or competing visions of energy futures. Second, the approach draws attention to the way in which participatory collectives are productive in multiple ways by producing issues and visions as well as particular 'models' of participation and identities of the public (Chilvers \& Longhurst 2016). Overall, Chilvers and Longhurst (2016) find that there are instances of energy system politics via their four cases seen in the: "contestation that occurs around the framing of 
issues, subject and the way in which processes of participation exclude or are resisted" ( $p$. $601)$.

This research builds on an understanding participation 'in the making' as presented by Chilvers and Longhurst (2016), who argue this approach is important for exploring the politics of transitions. Like Chilvers and Longhurst, it uses a constructivist STS framework to analyze participation in Ottawa's Energy Evolution Strategy. More specifically, it applies Chilvers and Longhurst's (2016) analytical tools of orchestration and productive effects. Orchestration provides for the analysis of the work that goes into enrolling actors into a participatory collective and mediating them, whereas productive effects involve how the issue at stake, model of participation and public are defined in the participatory forum. The subsequent theoretical approach (outlined in Chapter 3) and methodology (Chapter 4) explain the application of this theoretical frame in further detail.

\subsection{Conclusions: Participation in Transitions Decision-Making}

Examining participation in Ottawa's Energy Evolution process begs both for an engagement with how to make good environmental decisions and how to enable the existence of sustainable futures. First, previous works on environmental decision-making highlight a need to explore how participation emerges in different ways (Meadowcroft, 2004) and show a need to engage in a detailed examination of the complexity and design of participatory processes. The emergence of the sustainability transitions literature begs the need to unpack the complexity of environmental problems. Previous case studies found in the ST literature have engaged in exploring the politics surrounding geographically situated transitions processes. They share a broad understanding of 
politics and highlight them in the transition processes (Avelino et al., 2016). This work aims to build on this burgeoning area of research in understanding the politics of sustainability transitions as the implications of sustainability discourses and the transformation processes between actors in micro-level power relations (Avelino \& Wittmayer, 2015). It addresses the need to understand geographically situated small-scale transition processes and look at what processes push or constrict transitions (Roelich et al., 2018), with a specific focus on participation. It examines democratic engagement and the extent to which participatory processes are inclusive/exclusive (Hendriks, 2008) and builds on a need to understand whether multiple actors from different backgrounds and experiences are included in participatory spaces to enable their effectiveness (Lyytimäki et al., 2019). Last, it builds on examining the construction of participatory processes related to sustainable energy transitions (Chilvers \& Longhurst, 2016). This frame, along with the use of ecological democracy are explored in the subsequent chapter outlining the theoretical frames used in this study. 


\section{Chapter 3: Theoretical Approach}

This thesis examines participation in energy transition planning via a case-study of engagement in Ottawa's Energy Evolution process. This project's theoretical framework aims to draw on, and juxtapose, two different theories of participation. First using Chilvers and Longhurst (2016), it employs constructivist science and technology studies (STS), which views participation as emergent phenomena and social experiments in themselves, allowing for an analysis of the construction and framing of the participatory process in Ottawa's Energy Evolution Strategy. Second, it uses democratic theory via ecological democracy as a normative frame via Dryzek (2009) and Schirmer et al. (2016) to evaluate whether there is a presence of deliberation, inclusion and effectiveness in the participatory process in the Ottawa case.

The use of these two theories provides a productive tension. Constructivist STS provides descriptive criteria whereas ecological democracy provides normative criteria in the evaluation of Energy Evolution's participatory process. While each theory is distinct in its approach to participation, using these two different approaches in conversation with one another is complementary. Adopting both theories to empirically evaluate this case allows for a detailed and multifaceted explanation of the characteristics, benefits and drawbacks as well as the outcomes of the participatory approach used to create Ottawa's Energy Evolution Strategy.

This chapter is divided into three sections. First, it outlines constructivist STS by situating the theoretical frame in the broader constructivist tradition in the social sciences with relevancy to this work. It then outlines Chilvers and Longhurst's (2016) constructivist STS framework and provides the analytical criteria to be used in the 
analysis of this work. This first section concludes with my first sub-research question based on the relational and co-productive perspective on public engagement in transitions. The second section outlines ecological democracy by first outlining the basis for the theoretical framework. It then provides the analytical criteria based on Dryzek (2009) and Schirmer et al. (2016) to be used in the analysis of this work. The section concludes with my second sub-research question based on the normative model of what constitutes good deliberation and participation. Last, this chapter concludes by bringing both frames into dialogue and summing up the theoretical frames and tools brought to this study.

\subsection{Constructivist Science \& Technology Studies (STS)}

The constructivist theoretical development in the social sciences rose from the latemodern interpretivist challenge to rationalist methodology and neopositivist epistemology. Instead of resting on the assumption of analyzing an objective natural world or single objective reality found in positivism, interpretivism relies on human interpretation, perception and cognition as the unit of its analysis (Green, 2002). Consistent with these interpretivist assumptions, constructivism is the idea that: "most sociopolitical phenomena are constructed by human social interaction and the resultant shared understandings of their value and meaning, as opposed to being naturally occurring" (Green 2002, p. 6-7). These sociopolitical phenomena are constructs as their shape and form is "imbued with social values, norms and assumptions, rather than being the product of purely individual thought or meaning" (Halperin \& Heath 2017, p. 46). Instead of politics existing as independent of human meaning and action, constructivists argue politics is a social construction and "states and other social institutions take specific 
historical, cultural and political forms that are a product of human interaction in the social world" (Halperin \& Heath 2017, p. 46). This is particularly useful for political science analysis in determining that reasons, preferences and interests are contextual and socially constructed or embedded in culture (Green, 2002). More specifically, constructivism offers a useful actor-oriented analysis as it holds that actors are not entirely free, but make choices as a result of interacting with others, and bring distinct historical, cultural and political realities into being (Halperin \& Heath, 2017). For constructivists, society is seen as a "constitutive realm", or an "environment that forms and influences the identifies and interests of actors and makes them who they are" (Halperin \& Heath 2017, p. 46). And this contextual, cultural and institutional environment matters for constructivists, as is provides incentives and disincentives for actor behaviour. Social interaction influences the identities of actors as the properties of actors are not intrinsic to them, but they are socially contingent and depend on social interaction such as "bargaining/negotiating, arguing" and "communicating in general" (Halperin \& Heath 2017, p. 46). These identities and interests of actors are "constituted (formed, influenced) through interaction and by the institutionalized norms, values and ideas of society" (Halperin \& Heath 2017, p. 46). And because these identities and interests of actors result from social interactions, they cannot be disconnected from the social conditions which produce them and are subject to fundamentally change as a result of political processes (Halperin \& Heath, 2017).

One particular field where social constructivism took off was in the interdisciplinary field of Science and Technology Studies (STS), traced by Lynch (2016) to Berger and Luckmann's (1966) work: The Social Construction of Reality: A Treatise 
in the Sociology of Knowledge, which argues that society is constructed via human interaction. Lynch (2016) summarizes Berger and Luckmann's (1966) argument writing that stable social institutions are human constructs, which "emerge from the individual or interactional level" by humans (p. 101). These institutions "become externalized and objectivated, eventually being taken for granted as realities" and knowledge runs from individuals to institutions and back where "new cohorts are socialized into (and through) such institutions" (Lynch 2016, p. 101). Lynch (2016) writes that following Berger and Luckmann's (1966) seminal work, variants of constructivism became more proliferated and increasingly remote from their original theory, and constructivism took on a life of its own. A decade after Berger and Luckmann's publication, social constructivism began to take hold in the sociology and social history of the natural sciences as a concept "not only for explaining religious doctrines, popular superstitions, and political ideologies, but also for explaining the emergence and current acceptance of established scientific and mathematical knowledge" (Lynch 2016, p. 105). In the 1980s and 90s, social constructivism became central to STS (as well as other prominent disciplines in the humanities and social sciences) and a recurrent theme was the deconstruction of the distinction between nature and society where the authority of science was under question and became no different from other sources of authority. For Lynch (2016), Latour's (1987) Actor-Network Theory (ANT) is the most prominent effort in STS of a "throughgoing enculturation and politicization of nature" where naturalistic scientific claims are not accepted on their own terms, but rather a wide array of human and nonhuman actors (such as: "collective agencies, non-human entities, theoretical causes, laboratory apparatus and virtually all other nominal things") are given agency beyond the 
field of human actions and are "placed in subject position in narratives about scientific and technological innovations" (Lynch 2016, p. 108). For ANT, all entities (human and non-human) stand on equal ontological footing, and the associations and relations established between them produce new actors, new ways of acting and agency (Müller, 2015). This agency is "exclusively a mediated achievement, brought through forgoing associations", and "to become capable of action, entities need to form aggregates and find allies to produce an actor-network" (Müller 2015, p. 30-31). Along with ANT, assemblage theory is at the forefront of a shift that "sees space and agency the result of associating humans and non-humans to form precarious wholes" and both theories examine the spatial dimensions of power and politics in exploring order (Müller 2015, p. 27). Müller (2015) traces assemblage as a refined concept to Deleuze and Guattari's (1987) A Thousand Plateaus: Capitalism and Schizophrenia, summarizing it as a relational mode of "ordering heterogenous entities so that they work together for a certain time" (p. 27) where agency is created by arrangements from an equal ontological stating point of all entities (including humans, non-humans and things and matters).

Assemblages as a wide variety of wholes constructed from heterogenous parts includes a wide range of entities that can be conceived of as assemblages, for example ranging from: "atoms and molecules to biological organisms, species and ecosystems" which are products of historical processes (which goes beyond human history to include other histories such as cosmological history and evolutionary history) (De Landa 2006, p. 8). Müller (2015) outlines the concept of the assemblage as providing a useful tool in engaging with the analysis of power and politics to describe "transformative, creative or deterritorializing forces and movements" (p. 29). In addition, these above influences and 
developments of social constructivism in the social sciences in fields such as STS and the changing relationship between society and science would also inform works that engage with, for example: forms of citizen-science and public knowledge (Irwin, 1995), the social construction of public talk (Irwin, 2006) and the relations of science and society including public understanding of science and citizen forms of engagement (Irwin \& Michael, 2003).

The first theoretical framework employed in this work is a constructivist and relational science and technology studies (STS) perspective based on Chilvers and Longhurst's (2016) study of participation in UK low carbon energy transitions. This theory holds that the publics, issues and procedural formats of participation do not exist naturally but are actively constructed through the performance of collective participatory practices. It provides an open view of participation that analytically focuses on collectives of participation and the construction of participation as emergent sociomaterial collectives of humans, non-human artefacts and other elements through which publics engage in addressing collective public problems (Chilvers \& Longhurst, 2016). Chilvers and Longhurst's (2016) framework is based on ANT and assemblages in conceiving forms of public engagement and participation as varied collectives of human and non-human actors, devices, settings, theories, public participants, procedural techniques and other artefacts. This STS perspective views participation as an emergent and co-produced phenomenon, and specifically looks at the circumstances of its "construction, performance, productive dimensions and effects" (Chilvers \& Longhurst 2016, p. 586). 
The theoretical basis of Chilvers and Longhurst's (2016) STS framework contains three dimensions of participation that are always co-produced through the performance of collective participatory practices where actors are included or excluded from a collective of participation via mechanisms of enrolment. These three dimensions define and shape participation by including: the construction of objects (or issues), subjects (or publics/participants) and the specific procedural formats (or configuration of the participation) in forming and defining a greater participatory collective (Chilvers \& Longhurst, 2016). Figure 1 shows how these three dimensions are complementary to one another via collective participatory practices, where the outer circle represents the setting in which the performance of participation occurs which participatory collectives are shaped by (and in turn shape the setting) (Chilvers \& Longhurst, 2016).

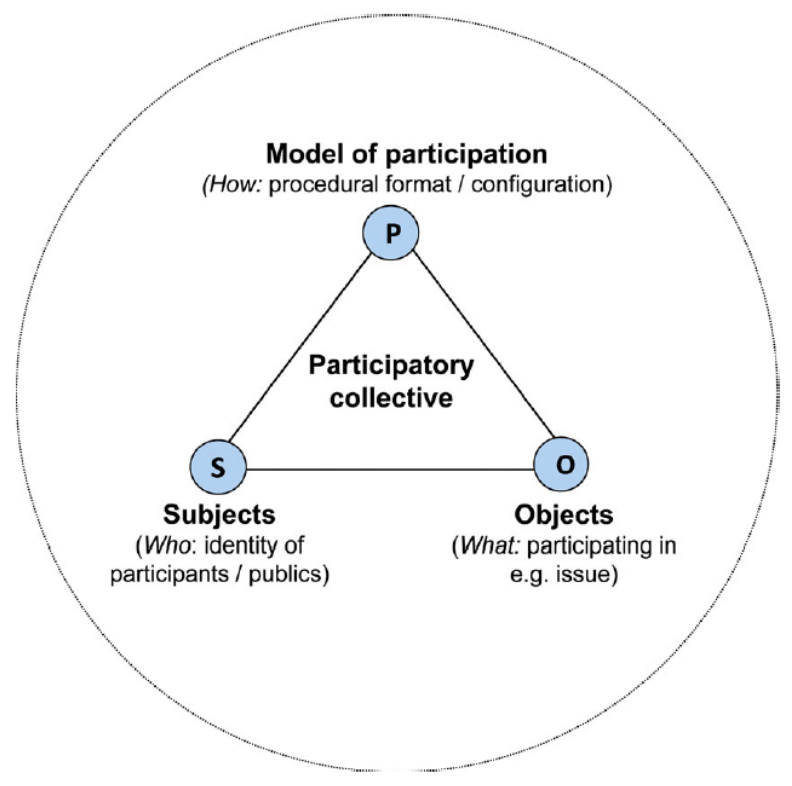

Figure 1. "A socio-material collective of participation, which emerges through the co-production of subjects (S), objects $(\mathrm{O})$ and procedural formats $(\mathrm{P})$ in relation the setting and extant orders (outer circle).". Reprinted from "Participation in transition(s): Reconceiving public engagements in energy transitions as co-produced, emergent and diverse" by J. Chilvers \& N. Longhurst, 2016, Journal of Environmental Policy and Planning, 18(5), p. 590. Copyright 2016 The Author(s). Published by Informa UK Limited, trading as Taylor \& Francis Group. 
Chilvers and Longhurst (2016) evaluate participation in energy transitions through two analytical themes utilized in this work. The first involves orchestration, or the work that goes into orchestrating a collective of participation through processes of enrolment and mediation. Enrolment refers to the way that different actors (including both human and non-human) are drawn into a particular form of participatory collective practice and definition of the issue at stake. As Chilvers and Longhurst (2016) note, mechanisms for enrolment can be highly centralized and controlled by a small number of actors in the collective, in for example citizens panels, focus groups or established deliberative participatory techniques. These are often mediated by professional facilitators who discipline participants to conform to a certain type of participation, which can involve resistance by participating actors. These are more standardized in enrolling representative samples of human subjects in creating participatory collectives. In contrast, modes of enrolment can be more fluid and built on connections where multiple actors simultaneously enrol one and other, seen in more informal and citizen-led forms of public engagement (Chilvers \& Longhurst, 2016).

Mediation involves the way a participatory collective is held together by “different devices, processes, skills, or 'technologies of participation"” (Chilvers \& Longhurst 2016, p. 591). This mediation can be done formally, for example via procedures such as an online survey or memberships to a specific group. However, Chilvers and Longhurst (2016) note that enrolment and mediation are not just human qualities, but "can be imbued in material objects, devices, or technologies in shaping heterogenous collectives and maintaining connections between actors and across sites" (p. 591). Nevertheless, while these forms can differ between participatory collectives, a 
key is that all kinds of participation are by definition exclusive and are always partial and framed in certain ways (Chilvers \& Longhurst, 2016). In addition, enrolment and mediation are also subject to forms of resistance (both 'internal' and 'external' to the participatory collective) which attempt to stabilize the three dimensions found in Figure 1 (Chilvers \& Longhurst, 2016).

The second analytical theme involves the productive effects of participatory collectives, focusing on the ways that diverse collectives of participation in low carbon energy transitions construct particular definitions of the issue at stake, models of participation and the public. First, collectives of participation can be subject to powerful framing effects surrounding the issue in question. Chilvers and Longhurst (2016) note that this is especially present in institutionally orchestrated processes where issues are often pre-defined by incumbent interests. In addition, participatory procedures have been shown to 'fix' issues in technical terms, which constructs and maintains a boundary from the social and ethical concerns of public participants (Chilvers \& Longhurst, 2016).

Second, collectives of participation produce publics, via constructing the identities of the actors involved in the process. Chilvers and Longhurst outline examples of these identities, including:

... 'innocent citizens' or 'pure publics' that are assumed to have limited prior knowledge of the issue in question or deemed to be 'representative' of a wider public; 'interested' or 'affected' publics who have a personal attachment to the object of participation, including through exposure to risk or illness; or more 'active' or 'innovative citizens' who are constructed as bringing about various forms of distributed action. (p. 592)

For Chilvers and Longhurst (2016) the relations between actors in a collective can also create (and influence) the particular model of participation at stake. This shows that the socio-material collective or the three dimensions of participation and setting in which 
participation occurs (as seen in Figure 1) are consistently complimenting and informing one another.

Numerous studies that use STS perspectives on public participation exist in social science energy research (see Hess \& Sovacool, 2020). Relevant here is Chilvers et al. (2018), who build on Chilvers and Longhurst (2016) and develop a conceptual framework for understanding ecologies of participation, and illustrate it using an empirical analysis of participation in UK energy system transitions from 2010 to 2015. Most similar to this study is Lynch et al. (2020), who also directly apply Chilvers and Longhurst's (2016) STS perspective to a participatory case called "Societal Roadmap for the Bioeconomy in the Netherlands", finding various partialities in a constructed public in their case study.

In examining Ottawa's Energy Evolution process, this work also aims to build on a theoretical framework referred to by Chilvers and Longhurst (2016) as a relational and co-productive perspective on public engagement in transitions. Its analytical criteria allows for an empirically oriented exploration of how participation gets made (Chilvers \& Longhurst, 2016), as well as an evaluation of the construction of a participatory collective via the analytical themes above as it conceptualizes all forms of participation as actively constructed and orchestrated, and not existing in a pre-given natural state (Chilvers \& Longhurst, 2016). It allows us to ask, and then offers tools for helping to address, my first research sub-question: How is participation in this process manifest?

\subsection{Ecological Democracy}

While constructivist and co-productionist STS approaches view all forms of participation as emergent phenomena and social experiments in themselves (Chilvers \& Longhurst, 
2016), ecological democracy provides a useful model of what constitutes good deliberation and participation, providing a normative tool to evaluate participatory processes.

Ecological democracy is a form of deliberative democracy based on the communicative (Habermasian) understanding of democracy, which according to Dryzek (2013) rests on the idea that "legitimate governance depends on the right, opportunity, and capacity of those subject to a collective decision (or their representatives) to participate in the consequential deliberation about that decision" (p. 236). For Dryzek (1990), communicative rationality provides the opportunity for a solution to ecological problems whereas instrumental rationality is an anathema. Instrumental rationality is associated with the Enlightenment's disenchantment of the world and invokes a Cartesian dichotomy between subject (the human mind) and everything else as objects (including the natural world and other people) to be dominated, resulting in the killing of nature (Dryzek, 1990). Communicative rationality allows for the resolution of complex problems as it promotes the "free harmonization" of actions by different individuals concerned with different facets of problems (Dryzek 1990, p. 202). But it poses two problems. First, general communicative rationality (stated by Habermas) is not conducive to harmonious relationships with the natural world, due to different ecological contexts where "individuals are likely to interpret and experience them in different ways" (Dryzek 1990, p. 203).This is solved via the recognition of the irremovable plurality in human discourse where communicative rationality is just a procedural standard for human interaction, which does not dictate substantive resolution of disputes (Dryzek, 1990). Second, if communication is simply a "property of human dealings with each other", its 
rationality may coexist easily with instrumental and dominating attitudes toward nature (Dryzek 1990, p. 203). For Dryzek (1990), Habermas believes that only in our relationships with other persons can instrumental rationality be overcome and communicative rationality flourish and we can only know language (which we have created ourselves) and that "nature will always remain estranged and separate" (p. 204). The solution to communicative rationality's tension with the natural world is not to completely negate communicative rationality, but extend it. Therefore, ecological democracy extends communicative rationality to include ecological rationality by establishing ecological principles to be applied, debated redeemed or rejected in supplementing values intrinsic to communicative rationality such as: equality, noncoercion and truthfulness (Dryzek, 1990). It recognizes that if nature is a silent participant in every conversation, it deserves the same respect we give to human participants and therefore recognizes agency and concern for the natural world and an extension of participatory communication to nonhuman entities (Dryzek, 1990). The recognition of agency in nature undercuts the instrumental rationality's Cartesian subjectobject dualism that legitimates the domination of nature by recognizing an equality with the natural world. It breaks the restriction of communicative rationality to only human entities in recognizing a non-passive world by extending it ecologically and rendering it to fit with human dealings with the environment (Dryzek, 1990).

Achieving ecological communicative rationality in practice is established via the move to a more radical democracy for proponents of ecological democracy. Simply extending democratic procedures is insufficient as mechanisms such as "policy dialogue, environmental mediation, lay citizen deliberation, governance networks, and society 
dialogues" are limited in their scope and constrained by the context in which they operate, and can involve the "co-optation and neutralization of troublemakers by powerful government and corporate officials" (Dryzek 2013, p. 234-5). Plumwood (2005) offers an apt summary of the conditions that Dryzek's ecological democracy should meet, including: robustness (the capability of performing different conditions), flexibility (adjustment to new situations), resiliency (capability of correcting severe disequilibrium), allowing negative feedback (or (“'[reacting] against human-induced shortfalls in life support capability"), coordination of responses and actions across different circumstances and boundaries and matching the scale of decision-making systems to the scale of ecological problems (p. 613). For Dryzek (2013), we ought to move to an ecological democracy because "the communicative aspect of democracy proves to do most of the work" rather than the "familiar electoral aspect" (p. 235). Ecological democracy is a form of deliberative democracy, which argues a broad range of interests can converge in the formulation of a consensus involving "collective decision making through authentic democratic discussion, open to all interests, under which political power, money, and strategies do not determine outcomes" (Dryzek 2013, p. 235).

Ecological democracy is relevant to environmental decision making because it focuses on the communicative and deliberative aspect of democracy. Deliberation is particularly fit for ecological decision-making and participation in areas such as energy transitions for multiple reasons. First, deliberation provides a good way of integrating different perspectives that inevitably attend any complex issue (such as experts, representatives of people concerned with different kinds of values and citizens who have 
local knowledge) (Dryzek, 2013). Second, deliberation is good at generating and assimilating feedback on the state of social-ecological systems, but only provided it is inclusive of discourses that interpret the various aspects of those systems. Third, values that can survive authentic democratic deliberation are those oriented to the interest of the community as a whole rather than selfish interests within the community (or outside it). The goal is to develop procedures and rules that can encourage participants to at least strive to adopt the "moral point of view" rather than seek to further their own narrowly conceived interests by bargaining (Eckersley 2004, p. 165). Fourth, deliberation inspires people to think not only about their own interests or those physically present in the decision-making process, but those who are not present. Ecological democracy asks participants in any discursive forum to examine proposed decisions and ideas from the perspective of "all significantly affected others, citizens or noncitizens, the living and the not-yet-born, human and nonhuman" (Eckersley 2004, p. 164-5). Fifth, deliberation is good at generating creative solutions to environmental problems (such as a new way to meet the concerns of parties to the dispute). Finally, deliberation has a self-critical aspect and is good at identifying its own deficiencies and correcting them if necessary. For Dryzek (2013), ecological democracy ought to be "beyond boundaries", meaning it should transcend the boundary between human social systems and natural systems ( $\mathrm{p}$. 238).

In Schirmer et al.'s (2016) case study of the deliberative quality of the Tasmanian forest peace process they identify five separate but interrelated criteria based on deliberative democracy's common core idea of ensuring a communicative process that is inclusive, deliberative and consequential (Schirmer, et al., 2016). In addition to Schirmer 
et al.'s criteria, Dryzek's (2009) work on deliberation outlines a general scheme for a deliberative system composed of five core elements. This work aims to make use of a combination of Schirmer et al. (2016) and Dryzek (2009) in outlining six key ecological democracy criteria to evaluate and analyze the amount of deliberation, inclusion and the effectiveness of the participatory process in Ottawa's Energy Evolution Strategy. The first criterion is access to deliberative public space, which encompasses an area that does not restrict who can participate, has few legal restrictions on what participants can say (which encourages a diversity of viewpoints) and recognizes that the overall success of deliberation is based on the active participation of people in the process itself (Dryzek, 2009; Schirmer et al., 2016). The second criterion is inclusive empowered space, which recognizes that the deliberative process should be inclusive for all existing discourses, in a space for actors that is "recognizably part of institutions producing collective decisions" (Dryzek 2009, p. 1385). It is important to note that this does not mean all those affected have to be physically present in the deliberative process, but their discourses or interests must be represented (for example, future generations and affected species). The third criterion is overall deliberativeness, which involves a "quality" or "nature of the dialogue", including an exchange of arguments in which actors offer reasons for their proposals (Schirmer et al. 2016, p. 290). The fourth criterion is transmission, which is some means by which public deliberative space can influence inclusive empowered space (Dryzek, 2009). The fifth criterion is transparency and accountability, where formal empowered space is accountable to public space and public scrutiny of the deliberative process provides legitimacy for collective outcomes (Dryzek, 2009; Schirmer et al., 2016). The final criterion is consequential decisiveness which outlines that a successful 
deliberative process (or the elements above) have an impact or are consequential in influencing the content of collective decisions and/or overall social outcomes (Dryzek, 2009; Schirmer et al., 2016). The proposed framework of ecological democracy provides a useful and practical normative 'measuring stick' in evaluating the quality of the participatory process within Ottawa's Energy Evolution Strategy. It allows us to ask and then offers tools for helping to address my second research sub-question: how does the participatory process in Ottawa stand up against the procedural norms of ecological democracy?

\subsection{Conclusions: Constructivist STS \& Ecological Democracy in Conversation}

Constructivist STS and ecological democracy are two distinct theoretical frames built on different traditions. While both theories focus on the analysis of participatory forums and characteristics such as inclusion and exclusion, constructivist STS provides an entirely non-prescriptive framework, while ecological democracy gives a pre-set collection of normative criteria of what constitutes good participation.

This aspect of ecological democracy is specifically critiqued by Chilvers and Longhurst (2016) who argue that deliberative democratic theories provide an overly procedural focus on methods and principles that define pre-given models of what constitutes good deliberation and participation. Rather, constructivist STS allows an exploration of how participation gets made and constructed, holding that it does not exist in a pre-given natural state. The strength of the Constructivists STS approach lies in outlining the creation and powerful framing effects found in participatory processes. While constructivist STS considers the productive effects of participation, this approach 
is not fully evaluative of participatory processes, nor does it address the political implications and consequences of participation.

Ecological democracy provides an exploration of multiple areas of participatory processes, including both the internal space of participation and the external implications it may have. However, a general critique of deliberative democracy is that it outlines a form of ideal reason which is overly optimistic, or "that there is no place in the real world like the jury room, where the better argument and reason wins" (Szulecki 2018, p. 28). In addition, there are conflicting interests, ideological commitments that can obstruct agreement and a lack of economic power and issues of ownership (i.e. capital) outlined in deliberative democratic theory (Szulecki, 2018). Nevertheless, proponents of deliberative democracy argue that it is particularly good at solving ecological problems due to its: legitimacy (which is in short-supply in technocratic decision-making), problem-solving rationality and making of better citizens (Dryzek 2007, as cited in Szulecki, 2018), with proper deliberation being central (and necessary) to the process of decision-making (Szulecki, 2018). In addition, the ecologically communicative ideal in this frame has value strictly in its high ambitions for social science (Flyvbjerg, 2006). While it may be an overly ideal theory, these high ambitions provide a significant learning process in evaluating a high-bar of deliberative ideals in accordance with participatory processes.

In sum, the use of these two different theories allows for a productive dissonance. Constructivist STS theory enables an analysis of participation as it is, or 'in the making'. It allows the analysis of the construction and framing of the participatory process in Ottawa's Energy Evolution Strategy. It provides the analytical tools of orchestration and productive effects. Orchestration involves examining the work that goes into enrolling 
actors into a participatory collective and mediating them. The productive effects of participatory collectives involve how the issue at stake, model of participation and public are defined. On the other hand, ecological democracy provides an analysis of the participatory process from a normative point of view. By providing a pre-set number of criteria, it analyzes the amount of access to participation, the presence of deliberativeness, the amount of transmission or influence that participation/participants have, and the consequentiality of the overall Energy Evolution process. The next chapter outlines the operationalization and use of these theories in this study. 


\section{Chapter 4: Methodology}

The following chapter foregrounds the methodological choices undertaken in the study of participation in Ottawa's Energy Evolution process. It is divided into four sections. The first two parts outline the philosophical basis of the research methodology. First, this chapter defends the choice to adopt an in-depth single case study and explains its utility in the analysis of Energy Evolution. Second, it traces the inception of this project to community-based research (CBR) and explains the benefits of engagement in a CBR project. Third, it describes the research methods used in the project, explaining the use of primary semi-structured qualitative interviews, theory-driven thematic coding and triangulation with primary and secondary sources of data to analyze primary interview research material. Last, it concludes by outlining how this work developed its response and synthesized analysis to the main and two-sub research questions posed in the introduction.

\subsection{Case Study Research}

This research examines the decision-making process surrounding Ottawa's Energy Evolution Strategy as a single case-study. While some critique a case study approach for its lack of generalizability and presence of subjectivity, there are multiple reasons why a case study approach is advantageous (Flyvbjerg, 2006). In this section, I rationalize the choice to develop a single-case study by elaborating on each of these reasons, showing how they informed the selection and/or analysis of my case study.

The case-study provides the advantage of closing in on real-life situations and testing views directly in relation to phenomena as they unfold in practice. Experience has shown that researchers who conduct intensive, in-depth case studies have reported "that 
their preconceived views, assumptions, concepts and hypotheses were wrong and that the case material has compelled them to revise their hypotheses on essential points" (Flyvbjerg 2006 p. 235). The case-study serves as a research tool that can challenge preconceived notions and is characterized by falsification of them rather than verification. This case-study examines the real-life participatory process in Ottawa's Energy Evolution Strategy and tests it according to constructivist and democratic theory, but as a single-N case study it is not inferior to a large-N, multiple or comparative case-study, because single case-studies are in fact multiple, linking research efforts, ideas and evidence in several different ways (Flyvbjerg, 2006) as this study accomplishes with a use of two distinct theories in contrast to examine one single case.

Second, context-dependant knowledge and experience, grounded in real-life experiences, lie at the center of a case study (Flyvbjerg, 2006) and the wealth of details a case provides are important for two key reasons. The first is the development of a nuanced view of reality. Such nuance dispels the myth that human life is nothing but "the rule governed acts found at the lowest levels of the learning process" such as contextindependent facts and rules and "in much theory" (Flyvbjerg 2006, p. 223). Second, case studies further researchers' own learning processes and skill development, as concrete experiences are achieved through "continued proximity to the studied reality and via feedback from those under study" (Flyvbjerg 2006 p. 223). Distance from the object of study and a lack of feedback can hinder the learning process and lead to academic blindness, where the effect of the research becomes unclear and untested (Flyvbjerg, 2006). This case was first developed via close engagement to the studied reality (as explained in the subsequent section on community-based research) in observing 
processes in Ottawa's political institutions to identify environmental and sustainability issues that were in deliberation and then considered academic literature and theory after that could help address these issues. This case-study combines concrete experiences, learning processes and academic theory to enliven addressing the issue of energy transitions in Ottawa.

But it is important to note that the case study is not just a useful learning process and tool for social science, but also involves the examination of power. For Flyvbjerg (2001), in the Habermasian context there must be a concrete empirical examination of the case at hand with "how communication takes place, and how power operates" (p. 94). This includes the exploration of whether communication involves consensus seeking and the absence of power, or whether communication is the exercise of power and rhetoric and whether these forms of "consensus seeking and rhetoric, freedom from domination and the exercise of power" eventually come together in individual acts of communication" (Flyvbjerg 2001, p. 94). The case study approach is particularly useful to the study of power relations, and this case-study will examine the operation of power in the participatory process surrounding Ottawa's energy transition planning. Flyvbjerg's (2001) point is specifically related to how this case study aims to use the ecological democracy framework to examine power in communication and deliberation and power relations in the constraints of pushing or constraining an energy transition in Ottawa. In sum, just as the case study is a useful in providing context dependant knowledge, experience, real-life application and explanatory research, the examination of power is central to contemporary social science and the decision-making process. 
Next, the case study is useful for both generating and testing of hypotheses but is not limited to these research activities. For Flyvbjerg (2006), the generalizability of a case study can be increased by the strategic selection of the case. Ottawa's Energy Evolution Strategy is a 'typical' case as it is an energy transition effort that involves participation, but was not intended to be innovative or test a new participatory methodology. And this case was strategically selected to reveal what worked (or did not work), who was included/excluded in this participatory forum, and the effects it had on a goal of an energy transition in Ottawa. It can also be viewed as a 'critical case', which can be defined as having a strategic importance in relation to a general problem (Flyvbjerg 2006, p. 229). A case-study that evaluates Ottawa's participatory process provides an opportunity to explore how public processes are responding to the general climate challenge and relates the importance of participatory practices to the larger problem of energy sustainability and climate change, holding that the characteristics of participation and barriers to the implementation of a energy transition in this case are likely to exist in other places where participation is tried and pose a problem for researchers.

Last, because case studies reflect a complex reality, they are difficult to summarize and should be read as a narrative. For Flyvbjerg (2006), a discipline "without a large number of thoroughly executed case studies is a discipline without a systematic production of exemplars, and that a discipline without exemplars is an ineffective one" (p. 242). Case studies inject social science disciplines with illustrative and in-depth knowledge (Flyvbjerg, 2006), which this case-study aims to contribute to. This case study brings two different ways of theorizing participation into the Energy Evolution case and 
with each other, looking at how participation manifests through a constructivist frame, as well as how the ideal of linking the technological response to issues of fairness and inclusion as presented by ecological democracy theorists are taking place in practice. This case provides a narrative of what happened in Ottawa's Energy Evolution process, but began with community-based research, explored in the next section.

\subsection{Community-Based Research}

This work began with community-based research (CBR) in partnership with Ecology Ottawa and the Ottawa Eco-Talent Network (OETN). CBR is defined as: "a partnership of students, faculty and community members who collaboratively engage in research with the purpose of solving a pressing community problem or effecting social change" (Strand et al. 2003, p. 3). CBR contains three core principles to help communities address problems. The first is collaboration and a sharing of authority. The second is promoting multiple uses of knowledge, such as both the experiential (or local) knowledge of the community and the specialized knowledge and skills of academics and students. Third, it promotes social action and change by producing information useful to community-based organizations (CBOs).

The community-based research partnership in this work with Ecology Ottawa and OETN began via expressing interest in environmental decision-making and inquiring about the organizational needs of Ecology Ottawa. This co-aligned with Ecology Ottawa's need to reimplement their 'Council Watch' program, which aims to hold City of Ottawa Councillors accountable to the public by tracking environmental decisions in Ottawa's City Hall in City Council and four environmentally-related committees. This encompasses a benefit of CBR, which allows CBOs to complete more activities that 
appear on their short-term agenda (Strand et al., 2003). In this case, the proposed research project arose by contacting Ecology Ottawa about an interest in environmental decisionmaking with OETN providing a liaising role between myself and Ecology Ottawa, in addition to consultative role by providing an advisor with past experience and expertise as a City of Ottawa staff member involved in environmental projects. Work on the Council Watch program began with attending city meetings and providing electronic documents of written summaries from meetings that include things such as: motions, voting records, speeches/comments from Councillors, presentations/comments from city staff and delegations at meetings. In addition, there was feedback provided and communication with Ecology Ottawa staff on what worked and did not with the recording sheets and observation of meetings, how to train or communicate the process to future volunteers and ideas of finished products and ideas for communications that Ecology Ottawa could output to the public. This involvement enhanced the organizational systems of the CBO for strategic planning and evaluation (Strand et al., 2003), as it allowed Ecology Ottawa to plan and (re)implement quality programs in the longer term. In this case, CBR enhanced the capacity of all parties as it allowed a learning of the community and the practical challenges it faces in relation to fostering more sustainability and environmental progression, as well as providing information, data and analysis that can help and lend academic credibility to achieving the organization's goals of environmental sustainability in Ottawa.

Overall, CBR allows the alleviation of pressures on community-based organizations and helps organizations to achieve their social change goals. But this project, however, is not immune from two major barriers to CBR. First, relevant is what 
Strand et al. (2003) call 'doing CBR in the middle', or partnering with already established organizations (such as Ecology Ottawa) that can be thought of as "one step up from the grassroots" compared to unorganized communities that are most in need of CBR (p. 73). But partnering with these grassroots organizations requires skills that few academics and students possess such as knowledge and ongoing ties to local communities, and the advantage of partnering with well-established groups is that they have clear organization, with staff and leadership who are easy to identify and contact with unlike the case with unorganized communities. However, a disadvantage that they can put distance between researchers and community members, which falls short of true community collaboration for Strand et al. (2003). Nevertheless, for Strand et al. (2003), doing CBR from the middle is most likely to conform to the basic principles of CBR (noted above) when the partner organization (like Ecology Ottawa) has demonstrated a real commitment to their constituent communities, including: ongoing efforts to be community based, willingness to recruit constituency members to be involved in planning and carrying out CBR projects and expressing real commitment to using research results to be bring about improved services to the community. The second major barrier involves the nature of the project and the community with which one is working. For Strand et al. (2003), CBR is defined by the fact that the research focus is derived from the needs of the community rather than the theoretical interests of the discipline and the use of the results are to be decided by the community members themselves (Strand et al., 2003). This research project was developed from a starting point of helping to understand how to better address environmental problems in the City of Ottawa. It first adopted the normative theory of ecological democracy to provide a frame that might be useful to Ecology 
Ottawa in achieving its goals. But it also acknowledges that this work can serve as a tool to further the theoretical interests of academic research.

While the above stages are considered essential to CBR, other stages of collaboration can also be hazy for Strand et al. (2003) as for example, community members' involvement may take the form of reviewing and approving aspects of the research design without having a hand in its development, reading and suggesting changes in the report without having to help write it or groups neither have the interest or time to participate in the development of the research instrument or analysis. This project experienced these deficiencies, as roles were sometimes unclear and connections changed over time (specifically during a pandemic). But in the case of this research, the community can be considered as fairly unorganized while the CBR partner is an agency that advocates for the community's needs which meant that leaders and staff generated ideas and provided input specifically at early and planning stages of the research, which Strand et al. (2003) note is particularly useful for sensitizing researchers to the community itself. Overall, Strand et al. (2003) caution becoming paralyzed by the imperfections from these ideal CBR principles and acknowledge that no CBR practice is perfect in design and we need to do the best we can under our relevant circumstances. Despite the relevant barriers to CBR experienced in this project, this work uses its CBR foundations as a tool for knowledge creation, discovery and dissemination and a learning process that enables capacity building towards a larger goal of environmental sustainability. 


\subsection{Research Methods}

The examination of the participatory process surrounding Ottawa's Energy Evolution Strategy surrounding one specific policy issue is a single-N or in-depth study that is illustrative of public engagement in energy transition. Primary research data were collected initially via 12 semi-structured interviews (a combination of more short, standardized questions with open, lengthier and complex questions). Interviews were conducted from summer to fall $2020 .{ }^{1}$ These initial interviews were with participants involved in the Energy Evolution participatory process, or Sounding Board and/or working group members with various levels of involvement belonging to different respective organizations. Potential interviewees were contacted from an email list from early in the Energy Evolution process (September 2016) of 92 participants that the researcher categorized by organization. Each interview subject was asked to provide their perspective representing their organization. They were asked to: describe their involvement, relationship to and recruitment in the Energy Evolution participatory process; provide their perspective on the importance of Energy Evolution for their organization and the issue-at-stake; outline their practical participation in the process; and discuss the accountability of the process in addition to its outcomes for decision-making, policy and their own organization (see Appendix $\mathrm{C}$ for sample interview questions for Sounding Board members). After interviews were completed, they were transcribed by the author, and each participant was given a pseudonym based on the type of organization they represented, including: three participants representing energy organizations (or

\footnotetext{
${ }^{1}$ The majority of these interviews occurred before the Final Energy Evolution Report was presented to Ottawa City Council on October 282020.
} 
organizations that provision and/or plan energy services) ${ }^{2}$, one participant representing the federal government ${ }^{3}$, two participants representing industry (including those that either specifically represent an industry or commercial groups), one journalist participant, one participant representing a environmental non-governmental organization (ENGO), two participants representing 'quasi-governmental' organizations (or organizations that are in arms length to the City of Ottawa via ownership and/or funding connections), and two participants representing each university located in Ottawa.

In early winter 2021, two additional interviews were conducted with City of Ottawa staff members (whereas other staff members did not respond to interview requests) considered to be integrally involved in the Energy Evolution process. These interviews were conducted as "expert interviews" to elicit specific information (Halperin \& Heath, 2017), as they had specialized knowledge and expertise relating to the Energy Evolution process). These interviews also allowed the author to verify accounts of the process given by Sounding Board members, and to begin to test their overall analysis of the process. These interviews were similar to the Sounding Board member interviews, but were framed according to outstanding gaps raised by those earlier interviews. Expert Interview subjects were asked to: describe their involvement and role in the Energy Evolution participatory process; outline how Sounding Board members were recruited into the process, how the parameters of the issue were outlined and how the practical participation was conducted; explain how decisions were made and whether input made a

\footnotetext{
${ }^{2}$ Two subjects that represent an energy organization (given the pseudonyms 'Energy subject B' \& 'Energy subject C' were employed by the same firm in different roles at the time of this study.

${ }^{3}$ This participant straddles categorization, as they originally joined Energy Evolution employed by an

ENGO, but their most recent involvement was as an employee of the Government of Canada.
} 
difference in influencing decision-making and policy outcomes; and to discuss the accountability and reflect on the overall process (see Appendix D for sample interview questions for City of Ottawa staff).

Interview data were analyzed using a qualitative thematic coding approach based on the criteria developed from the literature. First, transcripts were reviewed and data was reduced by discarding all but the most interesting and compelling statements concerning particular issues or themes (Halperin \& Heath, 2017) relevant to Energy Evolution. Next, interview responses were assigned to different thematic categories relevant to the theoretical frameworks in this work, as pre-existing constructivist and ecological democracy theory informed the analysis of the data. Similar to Schirmer et al. (2016), this 'theory-driven' coding was conducted based on the criteria found in the theoretical frames. Interviews gave insight and context into the participatory process surrounding Energy Evolution and were analyzed based on the creation of tables summarizing the criteria of constructivist STS (see Table 1 below) and ecological democracy (see Table 2 below). Interview data was then corroborated by triangulating it with multiple sources and methods of data collection, including: primary document analysis of reports related to Energy Evolution, committee/council minutes, budget allocations, Term of Council Priorities related to the Energy Evolution Strategy and secondary sources such as news articles. Triangulation of data increases the reliability of data and yields more complete data and results (Halperin \& Heath, 2017). Triangulation enables the evaluation of the overall participatory process by finding agreement or disagreement between different perspectives and the examination of multiple sources of data through the lens of constructivist STS and ecological democracy. 
Table 1. Main analytical themes of participatory collectives (Adapted from Chilvers \& Longhurst, 2016)

\begin{tabular}{|c|c|c|}
\hline \multicolumn{3}{|l|}{ Orchestration } \\
\hline $\begin{array}{l}\text { Enrollment \& } \\
\text { mediation }\end{array}$ & $\begin{array}{l}\text { Enrolment refers to the way in } \\
\text { which different (human and non-human) } \\
\text { actors are drawn into a particular form of } \\
\text { participatory collective practice and } \\
\text { definition of the issue at stake. } \\
\text { Mediation refers to the way in which a } \\
\text { participatory collective is held } \\
\text { together by different devices, processes, } \\
\text { skills, or 'technologies of participation'. }\end{array}$ & $\begin{array}{l}\text { How are particular human } \\
\text { and non-human actors } \\
\text { enrolled in the participatory } \\
\text { collective and how is the } \\
\text { issue at stake defined? } \\
\text { What are the methods used to } \\
\text { mediate the participatory } \\
\text { collective? }\end{array}$ \\
\hline $\begin{array}{l}\text { Exclusions \& } \\
\text { resistance(s) }\end{array}$ & $\begin{array}{l}\text { While forms of enrollment and mediation } \\
\text { can differ between collectives, a constant } \\
\text { is that all forms of participation are by } \\
\text { definition exclusive, lead to exclusions, } \\
\text { are } \\
\text { always partial, framed in particular ways, } \\
\text { and subject to 'overflows'. } \\
\text { Resistance can be both 'internal' and } \\
\text { 'external' to the collective which attempt } \\
\text { to actively reject, contest, or modulate } \\
\text { moves to stabilize the three dimensions } \\
\text { of: the model of participation, subjects } \\
\text { (participants) and objects (central } \\
\text { issue(s)). }\end{array}$ & $\begin{array}{l}\text { Which human and non- } \\
\text { human actors are included in } \\
\text { the participatory collective? } \\
\text { Which are excluded? } \\
\text { How are forms of resistance } \\
\text { (or lack thereof) manifest in } \\
\text { the participatory collective? }\end{array}$ \\
\hline \multicolumn{3}{|c|}{ Productive Effects } \\
\hline $\begin{array}{l}\text { Model of } \\
\text { participation }\end{array}$ & The how: procedural format/configuration & $\begin{array}{l}\text { How is participation } \\
\text { conducted? }\end{array}$ \\
\hline Public & The who: identity of participants/publics & $\begin{array}{l}\text { Who are the } \\
\text { participants/publics? }\end{array}$ \\
\hline Issue/vision & $\begin{array}{l}\text { The what: The central topic or theme of } \\
\text { participation }\end{array}$ & $\begin{array}{l}\text { What is the central } \\
\text { topic/theme? }\end{array}$ \\
\hline
\end{tabular}

${ }^{4}$ Callon et al.'s (2009) work examining democracy and 'hybrid forums' of experts, non-experts, ordinary citizens, and politicians conceptualizes 'overflows' as an unexpected technical and social problem or "disconcerting event" (p. 28) creating different dimensions (or controversies) of what is at stake in a project. In these forums, overflows can be identified by actors and/or arguments can multiply, causing the project to overflow the "smooth framework outlined by its promoters" (e.g., technical specialists and decision makers) (Callon et al. 2009, p. 15). 
Table 2. List of ecological democracy criteria (Dryzek, 2009; Schirmer, Dare \& Ecran, 2016).

\begin{tabular}{|l|l|l|}
\hline 1. & $\begin{array}{l}\text { Access to deliberative public } \\
\text { space }\end{array}$ & $\begin{array}{r}\text { Is there an area that...? } \\
\text { Does not restrict who can participate? } \\
\text { Has few legal restrictions on what } \\
\text { participants can say? (encouraging a diversity } \\
\text { of viewpoints) } \\
\text { Recognizes that the overall success of } \\
\text { deliberation is based on active participation } \\
\text { in the process itself? }\end{array}$ \\
\hline 2. & Inclusive empowered space & $\begin{array}{l}\text { Is the deliberative process inclusive for all existing } \\
\text { discourses in a space recognizably part of institutions } \\
\text { producing collective decisions? }\end{array}$ \\
\hline 3. & Deliberativeness & $\begin{array}{l}\text { Is there a deliberative quality or nature of dialogue } \\
\text { that includes an exchange of arguments where actors } \\
\text { offer reasons for their proposals? }\end{array}$ \\
\hline 5. & Transmission & $\begin{array}{l}\text { Are there any means by which public deliberative } \\
\text { space can influence inclusive empowered space? }\end{array}$ \\
\hline Consequential decisiveness & $\begin{array}{l}\text { Do the elements above have an impact on decision- } \\
\text { making and/or social outcomes (e.g. public policy)? }\end{array}$ \\
\hline allowing legitimacy for collective outcomes?
\end{tabular}

\subsection{Conclusions: Analyzing Participation in Energy Evolution in Practice}

This work began with a CBR approach, though in the end the community partner only provided the impetus for the project. The research itself was not conducted as CBR. It adopts an in-depth case-study approach to examine what Energy Evolution means in Ottawa and the extent to which its process was participatory and democratic. In doing so it uses fourteen semi-structured interviews with participants and city staff. Responses 
from participants and staff in the process were first aligned with constructivist STS and ecological democracy criteria, then data was synthetized to match with the theoretical criteria and core arguments, which were identified in response to my two theoreticallyinformed research questions, which are: 1) How is participation in this process manifest? and 2) How does the participatory process in Ottawa stand up against the procedural norms of ecological democracy? After this, data was reorganized to tell a narrative of participation in the Energy Evolution process in the constructivist STS and ecological democracy analysis chapters (Chapters 6 and 7). The next chapter provides a detailed background to the case by presenting an overview of Ottawa's Energy Evolution Strategy. 


\section{Chapter 5: The Case Study of Energy Evolution}

Energy Evolution is an ongoing strategy that aims to make fundamental city-wide changes to Ottawa by transitioning to zero GHG emissions by 2050. It is a case of community engagement in energy transition planning. And the selection of this case study began via a partnership with Ecology Ottawa and the Ottawa Eco-Talent Network. In addition to this work's relevance to the ST and environmental decision-making literature (which is discussed in Chapter 2), this project began as a way to understand the creation of the participatory process of Energy Evolution and the extent to which it is ecologically democratic, and to assist community organizations in understanding and better solving environmental problems such as energy transitions in Ottawa (as discussed in Chapter 4).

This chapter provides a background to this case and an overview of Ottawa's Energy Evolution Strategy. First, it provides wider context to the case by providing a primer on the characteristics of the City of Ottawa, its energy-use and the jurisdictional division of energy responsibilities between the three levels of Canadian government (federal, provincial and municipal). It then provides a general chronological timeline of the development of the Strategy from 2014 to 2020, presenting key facets of the Strategy and elements of participation throughout the process. This section begins by providing the pre-context to the development of Energy Evolution. It then outlines Phase 2 of the Strategy beginning in 2017. After this, it summarizes the development of the Final Energy Evolution Report to its approval in October 2020. 


\subsection{The City of Ottawa: Context, Energy Mix \& Jurisdictional Responsibilities}

The city of Ottawa, Ontario is Canada's capital city and the fourth largest municipality in Canada. In 2019, Ottawa's population surpassed one million people, growing from a population of 934,243 people in 2016 (City of Ottawa, 2020c; Statistics Canada, n.d.).

Ottawa's population has doubled over the past fifty years, and it is expected to grow further, as the City's draft New Official Plan published in 2020 estimates that by 2046, it will surpass 1.4 million people representing a growth rate of about 40 per cent from 2018 , according to what they deem a 'medium scenario' estimate (City of Ottawa, 2020c). Much of this growth is caused by immigration, as 25 per cent of the Ottawa population are immigrants, with 165,780 landing between 1980 and 2016 (Ottawa Public Health [OPH], n.d.). Three per cent of residents are recent immigrants, or those who immigrated in the past five years (OPH, n.d.). In 2016, one quarter (26 per cent) of Ottawa residents self-identified as a visible minority and 2.5 per cent of the population identified as Indigenous (OPH, n.d.).

Ottawa's population is relatively well-off, and - on average - its citizens are economically capable of withstanding an energy transition. Three-quarters of residents aged 25 to 64 have a postsecondary certificate, diploma or degree in Ottawa (OPH, n.d.), and residents of Ottawa are generally affluent compared to the rest of Canadians. In 2015, the median total income of Ottawa households was 85,981 dollars and the total income of economic families was 109,083 dollars, which were both above the Canada-wide averages of 70,336 and 88,306 dollars respectively (Statistics Canada, n.d.). However, in $2015,115,180$ residents or 13 per cent of individuals in private households in Ottawa were considered low-income (OPH, n.d.; Statistics Canada, n.d.). And while Ottawa has a 
diverse labour force, it is home to the largest technology park and federal government employment hub in Canada (City of Ottawa, n.d.-d). In 2018, one out of three federal government employees worked in Ottawa-Gatineau and the region comprised 20 per cent of its total employed labour force (Statistics Canada, 2018).

Certain characteristics of Ottawa make the possibility of an energy transition difficult. It is uniquely large geographically, with a land area of 2,790 square kilometres, making it larger than the Canadian cities of Vancouver, Calgary, Edmonton, Toronto and Montréal combined (City of Ottawa, n.d.-d; Statistics Canada, n.d.). This large land area of the city is a result of a 2001 amalgamation that combined the former City of Ottawa and ten other local municipalities (City of Ottawa, 2015a). Nearly 80 per cent of the city (by area) was considered rural in 2015 (City of Ottawa, 2015a). And Ottawa's population density according to the 2016 Canadian Census was 334.8 persons per square kilometre. This is considerably lower than Toronto, which had 4,334.4 persons per square kilometre (Statistics Canada, n.d.). Within Ottawa is a 'Greenbelt', which is a protected green space of 20,000 hectares (of which 14,950 is owned by the National Capital Commission) that wraps around Ottawa, and was created in the 1950s to protect the rural land bordering the Capital from urban sprawl (National Capital Commission, n.d.). In 2017, 66 per cent of Ottawa residents lived within the Greenbelt (with 11 per cent considered downtown and 55 per cent considered inside the Greenbelt, but outside of downtown) and 46 per cent lived outside the greenbelt (with 36 per cent in suburban areas and 10 per cent in rural areas) (OPH, n.d.). In 2017, the largest population growth took place in suburban centres outside the Greenbelt, following a consistent pattern of previous years (OPH, n.d.). This growth outside of the Greenbelt in Ottawa is expected to continue into the future. Given 
this large and divided landmass, residents are highly dependent on the car as a mode of transportation. The 2016 Canadian Census showed that about 62 per cent of Ottawa residents commute as a driver of a car, truck or van, and this has not changed, as the City estimates that this figure was the same in 2019 (City of Ottawa, 2020b; Statistics Canada, n.d.). This is less than the Canada-wide average of 77 per cent, given its low overall population density, but higher than major cities such as Toronto, which had a 54 per cent rate of commuting by car truck or van according to the 2016 Census (Statistics Canada, n.d.). These factors all need to be considered as Ottawa plans a transition to more sustainable energy sources.

The City of Ottawa is governed by an elected City Council which includes a Mayor and 23 Councillors subject to four-year terms who each represent one city ward. Ottawa City Council meets twice a month at City Hall in meetings open to the public and makes democratic decisions that impact the residents of Ottawa. Council members are also appointed to Standing Committees, which make decisions on City policies, programs and service levels (City of Ottawa, 2015a). Energy Evolution is a process that is responsible to the Standing Committee on Environmental Protection, Water and Waste Management (EPWWM), which is one of eleven committees.

There are several ways that public participation by citizens and stakeholders inform Council decisions in Ottawa. Members of the public and/or organizations interested in providing their opinion on an issue can sign up beforehand to make a presentation at these meetings as delegations. And decisions made at these meetings are presented to City Council and voted upon (City of Ottawa, 2015a). The City also has five advisory committees (Accessibility, Arts Culture and Recreation, Environmental 
Stewardship, French Language Services and Planning) that are mostly composed of citizens with specific expertise. These committees hold the purpose of advising Council on specific matters related to their mandate. As the City of Ottawa conducts over one hundred consultations per year, it has a public engagement strategy that was created in 2015 called Public Engagement Strategy: Guidelines and Toolkit, used where public input helps define or influence policy or decision-making outcomes. As will be discussed in the forthcoming ecological democracy chapter (Chapter 7), these guidelines partly set the basis for the public engagement process undertaken by staff concerning Energy Evolution. In 2019, the City also launched an online public engagement tool called Engage Ottawa to promote meaningful participation (City of Ottawa News, 2019).

Outside of these formal institutional mechanisms, Ottawa also has a vibrant collection of environmental and community organizations. One organization that this work partnered with is Ecology Ottawa, an environmental non-government organization (ENGO) that aims to make Ottawa the green capital of Canada, provide residents with information to understand local environmental issues in Ottawa and hold City Council to account for decisions (or non-decisions) related to environmental issues in Ottawa (Ecology Ottawa, n.d.). And movements exist to lobby and influence City Hall in Ottawa. For example, one current movement is called the People's Official Plan, which is a coalition of 17 community and environmental groups focused on bringing greater urgency and ambition on climate and social justice issues to the development of new Ottawa's Official Plan (a policy framework for the physical development of Ottawa to 2045) (A People's Official Plan, n.d.), with only a small fraction of these groups involved in Energy Evolution. 
When it comes to energy use in Ottawa, in 2015 Ottawa residents consumed approximately 114,000 terajoules of energy. This generated 5,200,000 tonnes of GHG emissions at a total cost of three billion dollars, or about 3,200 dollars per resident (City of Ottawa Planning, Infrastructure and Economic Development, 2017). Because of how much residents of Ottawa pay for energy use (and what they produce in GHGs), energy systems are not solely about hardware or technical matters, but are also about moral concerns over equity and justice (Sovacool et al., 2017). Energy availability, access and pricing affect all residents of Ottawa (including those aforementioned low-income residents). Ottawa is heavily reliant on energy imports as 95 per cent of its energy comes from outside the city (City of Ottawa Planning, Infrastructure and Economic Development, 2017). And while Ottawa is geographically situated along the Ottawa River, and there is a presence of hydropower facilities, only 5 per cent of energy consumption is generated in the form of renewable electricity energy from waterpower, solar and biogas generation (City of Ottawa Planning, Infrastructure and Economic Development, 2017).

The five main energy types supplied to Ottawa are: electricity, natural gas, heating oil, propane and vehicle fuels. In 2015, natural gas accounted for 39 per cent of total energy, followed by electricity at 28 per cent and gasoline (retail sales only) at 26 per cent (Environment and Climate Protection Committee [ECPC], 2017). The remaining 8 per cent came from propane ( 3 per cent), heating oil ( 3 per cent) and diesel ( 1 per cent) (ECPC, 2017). Energy consumption between sectors is fairly even in Ottawa. In 2015, the industrial, commercial and institutional sector accounted for 39 per cent, followed by the residential sector at 34 per cent and the transportation sector at 27 per cent of energy 
consumption (ECPC, 2017). The majority of Ottawa's electricity is produced by Ontario Power Generation and transmitted to Ottawa via the Hydro One grid, which owns 97 per cent of Ontario's transmission lines (Ottawa City Council, 2014). Electricity is distributed locally via Hydro Ottawa (which is owned by the City of Ottawa) and by Hydro One in rural areas. Hydro Ottawa also owns Portage Power, which is Ontario's largest municipally-owned green power producer. It owns six hydroelectric stations on the Ottawa River and two landfill gas to energy plants (Ottawa City Council, 2014). The City also generates a small amount of electricity (2,430 kilowatts) at the Robert O. Pickard Environmental Centre. Natural gas originates even further than the electricity supply, as it is piped to Ottawa via TransCanada Pipeline infrastructure and distributed locally by Enbridge Gas Distribution (Canada's largest natural gas distribution utility) (Ottawa City Council, 2014). Home heating oil and propane are mostly hauled to Ottawa and are dependent on road conditions and vehicle fuels are imported and supplied by a variety of distributors across the city (Ottawa City Council, 2014).

Canada's federal system divides governing power under the Constitution Act, 1867 between the federal and provincial governments. Energy jurisdiction is a shared responsibility between these two levels of government. As per the Constitution Act, provinces own their ground resources (except those in Aboriginal and federal lands) and are responsible for electricity systems within their borders (Senate of Canada Standing Committee on Energy, the Environment and Natural Resources, 2013). The federal government is responsible for the management of energy resources on federal lands and Crown owned lands (particularly in the north and offshore areas), and it regulates the international and interprovincial movement of energy goods in addition to being involved 
in matters related to economic development and energy security. In contrast, the provinces and territories are responsible for energy matters related to economic and energy security solely within their borders and can impose royalties and taxes on energy production. Provincial and territorial boards (such as the Ontario Energy Board) regulate energy pricing and most provinces and territories own Crown utility corporations in the electricity sector (Senate of Canada Standing Committee on Energy, the Environment and Natural Resources, 2013). However, in Ontario, Hydro One (the province's largest power utility) was privatized in 2015 and is no longer a Crown corporation.

Municipal governments in Canada are created under provincial law and receive their authorities from provincial governments. This fact has important implications for any discussion about the energy transition towards non-renewable energy sources: Emissions from energy production occur mostly outside of municipal boundaries and their legal jurisdiction (Jaccard et al., 2019). Canadian cities cannot implement strict GHG emissions caps, levy carbon taxes or use their revenues toward subsidy programs for energy efficiency or energy-switching technologies or regulate the sale or choices of energy and technology choices (Jaccard et al., 2019). Municipal governments can work alone via the creation of by-laws to deal with a variety of local matters or work in tandem with other levels of government (federal, provincial) to enact policies that have an impact on GHG emissions. For example, they can: increase urban density and land-use through rezoning; aim to change building codes to increase energy efficiency; influence the expansion and fuel choice of efficient district heating systems; enact road pricing, parking changes and the expansion of pedestrian zones to restrict the access of vehicles; expand infrastructure for public transit, cycling and walking; transition municipal owned 
bus and train fleets to zero-emissions fuels; and encourage the adoption of electric vehicles by expanding recharging stations (Jaccard et al., 2019). Ottawa can reduce private automobile use via plans and projects in their Transportation Master Plan and associated Cycling Plan and Pedestrian Plan (Ottawa City Council, 2014). However, the City does not own most buildings and cannot direct changes in behaviour and consumption (Ottawa City Council, 2014). Building codes are also a provincial matter (under the Ontario Building Code Act) and Ontario's Residential Tendencies Act makes the ability to retrofit difficult (Ottawa City Council, 2014). But the city can enact behavioural change via education, incentives, policy, standards and planning and approval processes (Ottawa City Council, 2014). In addition, municipalities are often dependent on agreements with other levels of government. For example, Ottawa's light rail transit project is projected to reduce GHG emissions by 38,000 tonnes annually by 2031, which is the equivalent of removing 7,300 cars from use (Ottawa City Council, 2014). However, this project has had an ongoing dependency on federal and provincial funding commitments. Due to the jurisdictional limitations and dependencies of municipalities on other levels of government, the involvement and engagement of the wider community, other levels of government, and a wide range of governmental and non-governmental actors in municipal energy planning is critical.

\subsection{Origins of Energy Evolution: Ottawa's Renewable Energy Strategy}

In May 2014, Ottawa City Council approved an update to their Air Quality and Climate Change Management Plan (AQCCMP). The AQCCMP was first completed in 2005, and is a local action plan establishing a framework for how Ottawa aims to mitigate and adapt to climate change over the next decades (City of Ottawa Planning, Infrastructure and 
Economic Development, 2017). The 2005 AQCCMP set the target for Ottawa to reduce corporate GHG emissions by 30 per cent and community emissions by 20 per cent from the City's 1990 levels (City of Ottawa, 2014). However, these targets fell short, as from 2004 to 2012 , GHG emissions only fell by 12 per cent at the community level and 6 per cent at the corporate level (Environment Committee, 2014). The updated 2014 AQCCMP set a new target of a 20 per cent reduction in per capita GHG emissions between 2012 and 2024 (Environment Committee, 2014) and provided a goal of no increase in corporate GHG emissions from 2012 to 2024 (City of Ottawa, 2014). In addition to setting goals and performance measures, the updated plan highlighted a need to work with community partners to attain its goals, explaining that, "collaboration is needed amongst various levels of government, utilities, stakeholders, and the broader community to effect change" (City of Ottawa 2014, p. 7).

On October 27, 2014 Ottawa held a municipal election and incumbent David Chernushenko was re-elected as Councillor of Ottawa's Capital Ward. During the 2014 election, Councillor Chernushenko campaigned on a proposal for Ottawa to create a renewable energy strategy that involves all sectors, with a goal of moving Ottawa to one hundred per cent renewable energy by 2050 (Hoedeman, 2014). On December 9, 2014 Councillor Chernushenko replaced former Councillor Maria McRae as the Chair of the City's Environment Committee ${ }^{5}$ for the 2014-2018 City Council term (Nominating Committee, 2014). For one long-time observer of the City of Ottawa's political institutions, this event was referred to as a key cultural change in the City's attitude

\footnotetext{
${ }^{5}$ Environment Committee and Environment and Climate Protection Committee are former names of the current City's Standing Committee on Environmental Protection, Water and Waste Management (EPWWM).
} 
toward the environment (Environmental Non-Government [ENGO] Subject A interview, 2020). Table 3 below provides a general timeline of key Energy Evolution events explained in this chapter from 2014 (before its inception) to the Final Report's approval on October 282020.

Table 3. General timeline of key Energy Evolution events

\begin{tabular}{|c|l|}
\hline Date & \\
\hline May 2014 & $\begin{array}{l}\text { Ottawa City Council approves an update to their 2005 Air Quality and } \\
\text { Climate Change Management Plan (AQCCMP) }\end{array}$ \\
\hline December 2014 & $\begin{array}{l}\text { David Chernushenko becomes Chair of the City's Environment } \\
\text { Committee }\end{array}$ \\
\hline July 2015 & $\begin{array}{l}\text { The City identifies the development of a renewable energy strategy as a } \\
\text { strategic priority (both in the City's 2015-2018 Strategic Plan, and as a } \\
\text { 2015-2018 Term of Council Priority) and provides a one-sentence basis } \\
\text { to direct staff to begin this strategy }\end{array}$ \\
\hline January 2015 & $\begin{array}{l}\text { The City publishes a public engagement strategy, called: Public } \\
\text { Engagement Strategy: Guidelines and Toolkit }\end{array}$ \\
\hline Energy Evolution: Phase 1 \\
\hline January 2016 & $\begin{array}{l}\text { One city staff member is formally brought on to begin the process and } \\
\text { Phase 1 of what would become Energy Evolution begins }\end{array}$ \\
\hline February 2016 & $\begin{array}{l}\text { City Council approves a GHG reduction target for Ottawa of 80 per } \\
\text { cent by 2050 }\end{array}$ \\
\hline March 2016 & $\begin{array}{l}\text { City staff convenes the first Sounding Board meeting, and early on } \\
\text { participants name the renewable energy strategy Energy Evolution }\end{array}$ \\
\hline October 2016 & $\begin{array}{l}\text { A City-wide reorganization of staff moves the staff member that was } \\
\text { first brought on to the process to another department, which affects } \\
\text { Energy Evolution participation from about 2017-2018 }\end{array}$ \\
\hline June 2018 & $\begin{array}{l}\text { Ottawa City Council approves Phase 1 of Energy Evolution, and directs } \\
\text { staff to begin Phase 2 of Energy Evolution }\end{array}$ \\
\hline December 13 \\
2017
\end{tabular}




\begin{tabular}{|c|l|}
\hline April 2019 & $\begin{array}{l}\text { City Council declares a climate emergency, and directs staff to include } \\
\text { a list of items in the Final Energy Evolution Report }\end{array}$ \\
\hline January 2020 & $\begin{array}{l}\text { City Council approves the Climate Change Master Plan, which includes } \\
100 \text { per cent corporate and community reduction targets (by 2040 and } \\
2050 \text { respectively) and directs staff to bring forward the Final Report in } \\
2020\end{array}$ \\
\hline October 28 2020 & $\begin{array}{l}\text { Energy Evolution Final Report is approved by Ottawa City Council as } \\
\text { an ongoing initiative }\end{array}$ \\
\hline
\end{tabular}

\subsection{Energy Evolution: Phase 1}

In July 2015, the development of a renewable energy strategy was identified as a priority in Ottawa's 2015-2018 Strategic Plan (EPWWM, 2019). And on July 8, 2015 City Council approved the development of a renewable energy strategy project as one action in their AQCCMP. The development of a renewable energy strategy was also approved as a $2015-2018$ Term of Council priority, and the City provided $\$ 100,000$ of base Operating funding for 2014 and 2015 (ECPC, 2017). With this approval, Ottawa City Council provided direction to staff to, "complete a baseline analysis of energy supply and demand within the City of Ottawa and assess options, in collaboration with community partners, for all partners to advance energy conservation, energy efficiency and renewable energy generation within their respective areas of control/influence" (EPWWM 2019, p. 12). Following this, the City seconded a single staff member from another city department, who formally began the work in January 2016 (City Staff B interview, 2021). Shortly after this, City staff created a brought together a group of participants to assist staff to, "define a vision, approach and process for developing the pathway options and other opportunities for recommendation to Council for the City of Ottawa's renewable energy strategy", and to act as what they called a 'Sounding Board' for the project (ECPC 2017, p. 11). This group was compiled via what staff refer to as a 
‘stakeholder mapping exercise', which involved contacting individuals or organizations primarily in Ottawa who had influence or expertise in the energy domain (City Staff B interview, 2021).

In February 2016, City Council promoted what they deemed continued collaboration with key stakeholders and community partners to reduce community-wide GHG emissions produced within the geographic boundary of Ottawa and approved a new long-term GHG reduction target of 80 per cent (below their 2012 levels) by 2050 (ECPC, 2017). Following this in March 2016, city staff convened the first Sounding Board meeting (City Staff B interview, 2021). In early meetings, Sounding Board participants renamed the City's renewable energy strategy as, 'Energy Evolution: Ottawa's Community Energy Transition Strategy' (or 'Energy Evolution' for short). The Sounding Board also informed the creation of eight initial working groups whose purpose is to discuss in-depth aspects of Energy Evolution, which initially included: a vision, communications and engagement, new buildings, existing buildings, transportation, energy supply and distribution, funding, and governance working group (ECPC, 2017). The vision working group would establish a guiding vision for Energy Evolution as, "Ottawa is a thriving city powered by clean, renewable energy", which was endorsed by the Sounding Board (ECPC 2017, p. 9). According to the City of Ottawa, Energy Evolution aims to achieve this vision by transforming Ottawa into a thriving city powered by clean, renewable energy, as well as reduce the city's current dependence on fossil fuels and enhance sustainability via three goals: reducing energy use through conservation and efficiency; increasing the supply of renewable energy via local and regional production; and prioritizing the procurement of clean, renewable energy (City of 
Ottawa, 2020b). Sounding Board participants helped establish the goals of the Strategy, including: helping meet or exceed locally established energy reduction targets; developing local renewable energy generation opportunities; improving energy security; providing greater opportunities for residents to own or invest in local energy systems and businesses; reducing environmental impact; complementing long-term municipal land use, transportation and infrastructure master plans; advancing economic development objectives; and bringing groups together to facilitate information sharing and the development of joint solutions (City of Ottawa Planning, Infrastructure and Economic Development, 2017).

In October 2016 there was a major reorganization of city staff, and the sole staff who was tasked with the Council direction to develop a renewable energy strategy and who initiated the stakeholder mapping was put into another department and removed from the file. Nevertheless, Phase 1 of Energy Evolution was informed by Sounding Board participants made up of over 100 individuals representing 50 organizations (see Appendix A). This group includes individuals from local utilities, the federal government, the development industry, institutions, academia, the non-profit sector and the private sector (ECPC, 2017). And consultation towards Phase 1 included three Sounding Board meetings and sixteen working group meetings (ECPC, 2017). Ottawa City Council received and approved Phase 1 of the Strategy on December 13, 2017. It focuses primarily on energy supply and distribution in Ottawa by providing a baseline inventory and analysis of Ottawa's energy consumption, provided by the firm Leidos Canada Inc. (which was contracted by City staff for this purpose) (ECPC, 2017). And it provides nine pathway studies, describing how a specific energy technology or initiative 
could develop over time in Ottawa. These pathway studies were also provided by the firm Leidos Canada Inc. in Phase 1. And these studies were primarily related to renewable energy, including: including: large-scale solar power, commercial rooftop solar power, residential solar power, water power, wind power, heat pumps (air and ground source), biogas, district energy and the electrification of transportation (cars and light trucks) (City of Ottawa Planning, Infrastructure and Economic Development, 2017; Leidos Canada Inc., 2017). In addition to this, Phase 1 includes 'catalyst projects' as a result of Council's 2016 approval of one-time funding of $\$ 300,000$ toward green initiatives led by Ottawa-based organizations related to Energy Evolution. For these projects, Ecology Ottawa was contracted to conduct an online application, compile the applications and review the first-round of proposals (ECPC, 2017). These community-projects aim to, “increase energy literacy, pilot emerging technologies, and/or enable innovative approaches" (City of Ottawa Planning, Infrastructure and Economic Development 2017, p. 28). Approved catalyst projects in 2017 included: energy saving equipment and energy displays in Ottawa Community Housing buildings; the creation of solar powered 'innovation pods'; the installation of Solar Photovoltaic arrays to heat water at the City's Plant Bath Recreation Centre; the creation of a business energy and emissions profile to display business community emissions online; days that allow residents to test drive electric vehicles; energy audits for five non-profit buildings to begin retrofits; and the piloting of a device at City Hall by Hydro Ottawa that determines when to use an electric boiler rather than a natural gas boiler (City of Ottawa Planning, Infrastructure and Economic Development, 2017). Phase 1 also includes 33 short-term initiatives to be undertaken by the City and its community partners to 2020 that forward Energy 
Evolution's goals. These for example, include: undertaking analyses of technologies that support Energy Evolution; engaging in information sharing and collaboration with partners; conducing pilot projects in technologies and green initiatives; establishing funding opportunities; exploring options within the City's jurisdiction and municipal codes; and advocating provincial and federal levels of government for incentives related to Energy Evolution (City of Ottawa Planning, Infrastructure and Economic Development, 2017).

\subsection{Energy Evolution: Phase 2}

Following the reception of Phase 1, in December 2017 City Council directed staff to initiate the recommendations in the report and complete Phase 2 of the Energy Evolution Strategy. Phase 2 of Energy Evolution focuses heavily on the development of energy and financial modelling toward achieving GHG reduction goals. However, the aforementioned staff reorganization at the City caused a change of management in Energy Evolution with a different approach that did not value as much public consultation. And due to a lack of capacity and resources, staff contracted consultants on board to fulfill much of the work (City Staff B interview, 2021). This meant that primarily from 2017 to 2018, there was a lull in participatory input from the Sounding Board and working groups. Nevertheless, Phase 2 builds on the pathway studies and baseline energy analysis created in Phase 1. It completes fourteen total pathway studies, which focus on: renewable energy, buildings (new and existing), transportation, waste and wastewater, and energy storage and demand management (City of Ottawa, 2019). These were contracted to the firm Sustainability Solutions Group (SSG), who looked at thermal and electricity energy systems in Ottawa, including their benefits, drivers and 
barriers to update and opportunities to reduce GHG emissions via these technologies (Sustainability Solutions Group, 2019). And these pathway studies were used to inform the development of a "custom-built" emissions reduction model for Ottawa called 'CityInSight' that is central to Energy Evolution (City of Ottawa 2020b, p. 37). This model was primarily developed by contracted consultants (SSG and whatIf? Technologies Inc.) with the Sounding Board and working groups giving feedback on these products during this Phase (City of Ottawa, 2020b; City Staff B interview, 2021).

For the City, Energy Evolution modelling in Phase 2 of the Strategy outlines the necessary actions for Ottawa to reduce emissions from 2012 (the baseline year) by 80 to 100 per cent by 2050 (the target year) in five key sectors: land use and growth management, buildings (new and existing), transportation, waste and renewable natural gas (RNG), and electricity use (City of Ottawa, 2019). Three different GHG emissions scenarios were carried throughout Phase 2, including: a business as planned scenario (BAP scenario), an 80 per cent GHG emissions reductions scenario and a 100 per cent emissions reductions scenario. Although the baseline year of Ottawa's GHG emission reduction targets is 2012, 2016 was chosen by staff and consultants as the baseline of the modelling exercise (as seen in Figures 2, 3 and 5) to align to the 2016 Canadian Census (City of Ottawa, 2019). These three scenarios help the City better understand what it would take to achieve 80 to 100 per cent GHG emissions reduction targets in exploring possible low carbon futures for Ottawa and "how the community could change through a set of given actions" (City of Ottawa 2019, p. 5). For a comparison of the three scenarios together from the 2012 baseline target year to 2050 , refer to Table 4 below. 
Table 4. Summary of City of Ottawa GHG emissions projections for BAP, $80 \%$ scenario and 100\% scenario 2012-2050 (Adapted from City of Ottawa 2019, p. 8)

\begin{tabular}{|l|c|c|c|}
\hline Scenario & \multicolumn{3}{|c|}{ Carbon emissions (metric tons of carbon dioxide equivalent) } \\
\hline BAP & $\mathbf{2 0 1 2}$ (annual) & $\mathbf{2 0 5 0}$ (annual) & Change \\
\hline $80 \%$ & 6.9 & 5.4 & -1.5 \\
\hline $100 \%$ & 6.9 & 1.2 & -5.7 \\
\hline
\end{tabular}

For the City, the BAP scenario illustrates projected energy use and GHG emissions if there are no further strategies implemented to address energy and emissions beyond those currently anticipated until 2050. For the City of Ottawa, this model projects that there will be a decrease in community-wide GHG emissions of "1.5 megatonnes of carbon dioxide equivalent" or 22 per cent compared to 2012 to 2050 despite projected population growth in the city (City of Ottawa 2019, p. 6). The 80 per cent scenario examines the scope and scale of change required if the City is to achieve the current-long term target to reduce community GHG emissions by 80 per cent below 2012 levels by 2050 and is consistent with the 2016 Paris target of limiting global temperature increase to $2^{\circ} \mathrm{C}$. This target would require the reduction of 5.7 megatonnes of carbon dioxide equivalent compared to the 2012 year in Ottawa via improved efficiency of existing buildings, higher performance standards for new buildings, fuel switching to electricity heating and vehicles, increases in local renewable energy generation and energy storage, enhanced transit and active transportation, increased organic waste diversion, and energy generated from organic waste streams (City of Ottawa, 2019) (see Figure 2 below for emissions reductions by sector in this scenario from a model year of 2016).

The final and most ambitious scenario presented in Energy Evolution is the 100 per cent scenario, which aims to reduce 2012 emissions levels fully (phasing out all fossil fuels) by 2050 , representing a reduction of 6.8 megatonnes of carbon dioxide equivalent 
(City of Ottawa, 2019). For the City, this would require the full electrification of heating and transportation systems, waste heat and RNG to be added and sufficient renewable energy (solar and wind) generation required to meet demand (City of Ottawa, 2019). This scenario relies on the grid to balance local electricity production and consumption with grid resources for storage and supply (as the timing of renewable energy production does not align with demand) and also relies on the province phasing out fossil fuels used to generate electricity, heating and transportation systems to be nearly fully electrified, waste heat and RNG to be added, as well as sufficient renewable energy (solar and wind) generation required to meet demand (City of Ottawa, 2019) (see Figure 3 below for emissions reductions by sector in this scenario from a model year of 2016).
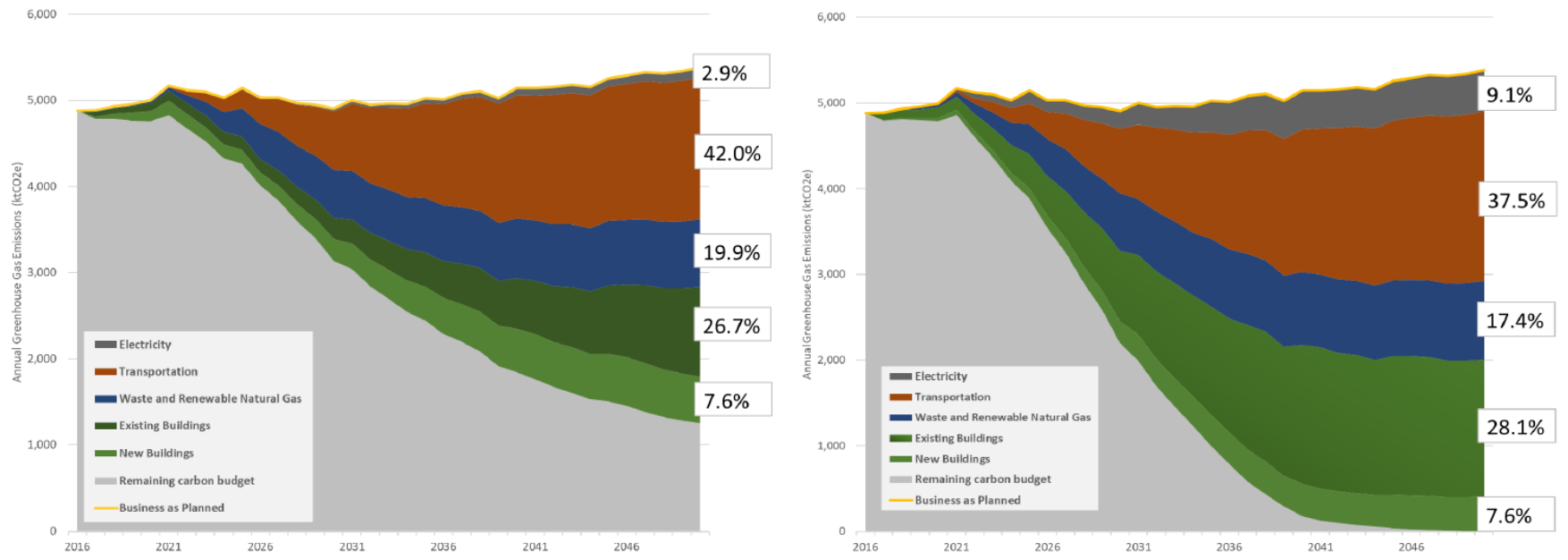

Figures 2 \& 3. Figure 2: "Projected community-wide GHG emissions by sector in the $80 \%$ scenario" (left), Figure 3: "Projected community-wide GHG emissions by sector in the $100 \%$ scenario" (right). Reprinted from "Project status update on Energy Evolution: Ottawa's community energy transition strategy" 2019, City of Ottawa, p. 9-10. Copyright 2020 by City of Ottawa.

In June 2018, City Council approved a motion to set a short-term corporate target to reduce GHG emissions by 20 per cent below 2012 baseline levels by 2024 . And to support community action in Phase 2, the 2018 City budget included a one-time fund of $\$ 500,000$ called the Community Energy Innovation Fund for local, community-based 
projects that increase energy literacy, encourage behavioural changes, pilot emerging technologies, and/or enable innovative approaches to energy conservation and efficiency or renewable energy generation (City of Ottawa, 2019). In January 2019, the staff member who initiated the Energy Evolution process who was subject to the staff reorganization in the City returned to Energy Evolution as a lead of a new climate change and resiliency team and reconvened the Sounding Board and working groups in summer 2019 (City Staff B interview, 2021). In March 2019, City Council approved a motion from staff to undertake annual GHG emission inventory reporting and approved that any surplus from the Hydro Ottawa Dividend received in the 2018-2022 Term of Council be directed toward energy efficiency, conservation or renewable energy programs within Ottawa (EPWWM, 2020b). Hydro Ottawa is a private energy delivery company owned by the City of Ottawa, that pays an annual dividend to the City. And in 2018, the City invested $\$ 633,000$ of the approximately $\$ 22$ million Dividend to support Energy Evolution projects (City of Ottawa, 2019).

From 2016 to 2019, participation in Energy Evolution was comprised of over 30 meetings with more than 180 key stakeholders representing approximately 90 organizations in Ottawa (City of Ottawa, 2019). This grew from an initial list of 25 stakeholders that participated in an initial scoping session at the beginning of the process to determine how to interpret Council direction to staff to complete a renewable energy strategy. Throughout the process, Energy Evolution grew, as staff asked and encouraged Sounding Board members to "identify other stakeholders and invite them to the process" (ECPC 2017, p. 29). Staff cite inputs from stakeholders and consultants as critical in 
guiding and informing Phase 1 and 2 pathways, modelling and proposed Energy

Evolution projects (City of Ottawa, 2019).

\subsection{Energy Evolution Final Report}

On April 24, 2019, Ottawa City Council declared a climate emergency and directed city staff to include the following in the Final Energy Evolution report: a status update of Energy Evolution Phase 1 actions, new concrete actions and resource implications (staff and financial) to achieve GHG reduction targets, as well as the use of an equity and inclusion lens in the polarization of actions and funding and savings options for the City when implementing emission reductions (Ottawa City Council, 2019). The City's approach to equity and inclusion is published in their 2018 Equity and Inclusion Lens Handbook, which directs staff and management ensure that policy planning is inclusive of full resident diversity. And in 2020, staff provided assurance to consult with equity seeking groups in the development of Energy Evolution projects where applicable (EPWWM, 2020b). In addition, Council directed staff to review the AQCCMP and analyze how the 80 per cent target compares to the Intergovernmental Panel on Climate Change's (IPCC) target of limiting global temperature increase to $1.5^{\circ} \mathrm{C}$ (EPWWM, 2019).

On January 29 2020, Ottawa City Council unanimously approved the Climate Change Master Plan, which included the approval of GHG emissions reduction of 100 per cent below 2012 levels by 2040 for corporate targets and 100 per cent below 2012 levels by 2050 for community targets (Ottawa City Council, 2020a). This brought the City in line with the IPCC's recommendation to limit global warming increases to $1.5^{\circ} \mathrm{C}$. 
As Figure 4 shows, Energy Evolution is simply one priority of eight that are approved in the City's Climate Change Master Plan.

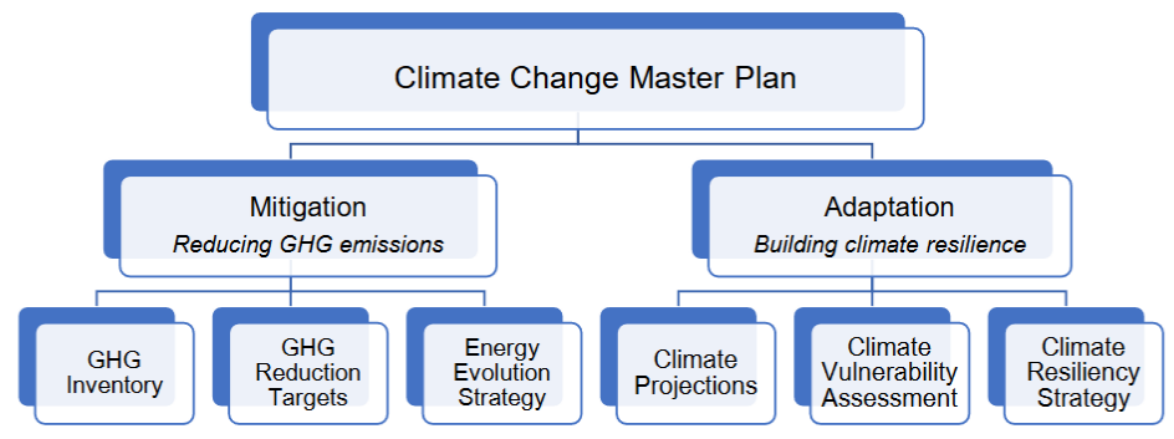

Figure 4. "Ottawa's climate change framework". Reprinted from "Climate Change Master Plan" 2020a, City of Ottawa, p. 6. Copyright 2020 by City of Ottawa.

In addition, at this time City Council directed staff to bring forward the Final Energy Evolution Report in 2020 and include: a final energy and emissions model, a financial and affordability analysis of the model, descriptions of proposed Energy Evolution projects, equity and inclusion considerations and resourcing needs (Ottawa City Council, 2020a).

On October 92020 City of Ottawa staff held a technical briefing on the Energy Evolution Final Report for Councillors and members of the Environmental Stewardship Advisory Committee. Following this, staff delivered the Final Energy Evolution report to the EPWWM on October 20 2020. The Final Report boldly removes the aforementioned 80 per cent scenario carried throughout Phase 2 and focuses solely on the 100 per cent scenario as with the January 2020 approval of 100 per cent 2040 corporate and 2050 community targets in the Climate Change Master Plan, staff no longer felt the need to carry the 80 per cent scenario, and functionally dropped it from Energy Evolution (City staff A \& B interviews, 2021). The Final Report explains that in order to reach the 100 
per cent scenario, there is a need to phase out all fossil fuels, electrify or transition to zero emission heating and transportation systems, add waste heat utilization and RNG production and renewable electricity (mostly wind and solar) generation and electricity storage will be required to meet demand and offset emissions on the provincial grid (City of Ottawa, 2020b). The Report outlines that buildings and transportation sectors are projected to account for roughly 75 per cent of the cumulative emission reductions until 2050 in Ottawa, while the remaining 25 per cent comes from waste, RNG and electricity sectors (City of Ottawa, 2020b). The Final Report outlines that in the five sectors shown in Figure 5 (electricity, transportation, waste and RNG, existing buildings and new buildings) 39 actions have been identified to achieve the 100 per cent scenario with five main actions that account for 80 per cent of projected cumulative GHG emissions reductions required, including: the electrification of personal vehicles, retrofitting residential buildings, diverting organics and creating RNG, retrofitting commercial buildings, and the transition to zero emission commercial fleets (City of Ottawa, 2020b).

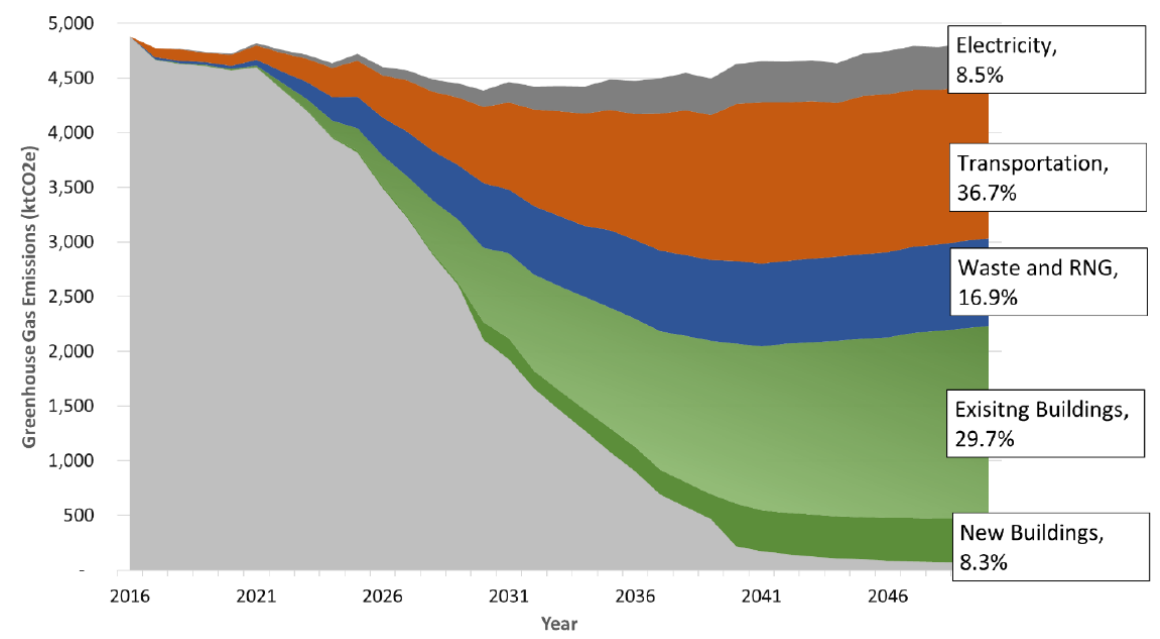

Figure 5. "Total projected community-wide GHG emission reductions required to achieve $100 \%$ scenario incremental to BAP scenario by sector, 2016-2050 (percentages shown at 2050 are non-cumulative)". Reprinted from "Energy Evolution: Ottawa's community energy transition strategy" 2020a, City of Ottawa, p.13. Copyright 2020 by City of Ottawa. 
The Final Energy Evolution Report outlines 20 projects from 2020-2025 to be undertaken towards achieving the 100 per cent scenario. These include land growth management projects (by integrating energy and climate mitigation policies into the City's new Official Plan and supporting master plans); projects in the buildings sector (including retrofit programs, a heating strategy and updating the municipal green building policy and development standard); projects in the transportation sector (such as a personal vehicle electrification strategy, a zero emissions commercial vehicles strategy, a municipal green fleet plan update, a zero emissions transit project and encouraging a shift to sustainable transportation modes); projects in waste and RNG (including an organics resource recovery strategy and an RNG strategy); projects in the electricity sector (providing an electricity resource strategy); and what Energy Evolution calls 'enabling projects' (including a climate ambassadors network, outreach program and funding) (City of Ottawa, 2020b). But these projects are contingent on ongoing Committee, Council and budget approval (City of Ottawa, 2020b). The financial analysis in the Report was completed by SSG who developed a "cost catalogue" based on research with internal and external experts (City of Ottawa 2020b, p. 72) and was also developed industry representatives according to staff rather than Sounding Board participants (City Staff B interview, 2021). It indicates that in order to reach the 100 per cent scenario, communitywide investment from 2020 to 2050 will need to amount to $\$ 57.4$ billion with a community-wide net return of $\$ 87.7$ billion (City of Ottawa, 2020b). And it outlines that, "compared to the BAP, annual incremental municipal investments of approximately $\$ 621$ million per year present value would be required for the next decade (2020-2030) to achieve GHG reductions in line with the model and the targets" (City of Ottawa 2020b, p. 
79). But for the City, the financial information presented in Energy Evolution "represents high level estimates that are currently uncommitted and unfunded capital and operational needs" and, "does not commit the municipality or any partners to any financial decision or provide direction on how to address funding gaps" (City of Ottawa 2020b, p. 18). Last, the report indicates reporting of annual status updates and rerunning the energy and emissions model every five years (City of Ottawa, 2020b). In August 2020, the City held two public information sessions on Energy Evolution (Engage Ottawa, n.d.). And on October 28 2020, City Council unanimously approved and carried the Final Energy Evolution Report (Ottawa City Council, 2020b). With this approval, it will move from the study and planning phase to implementation from 2021 to 2025, and remains an ongoing initiative in Ottawa.

\subsection{Conclusions: Examining a case study of Ottawa's Energy Evolution process}

Energy Evolution is a case of engagement in transitions planning, as the Final Report cites community partners as critical in guiding and informing the development of the Strategy, including a total of more than 200 key stakeholders representing approximately 90 organizations (see Appendix B) with 9 technical working groups and over 45 meetings from 2016 to 2020 (City of Ottawa, 2020b; City of Ottawa 2020b). The Report additionally cites technical experts from the municipality, senior levels of government, utilities developers and three consultants (Leidos, Sustainability Solutions Group, and whatIf? Technologies Inc) as key in developing the pathway studies, modelling and financial analysis in the Strategy (City of Ottawa, 2020b). Energy Evolution is a Strategy that was created by the City of Ottawa as participatory, and included actors that would contribute to its creation and implementation. And the Final Energy Evolution Report 
notes that ongoing engagement with these "community partners is crucial to the successful implementation of Energy Evolution" (City of Ottawa 2020b, p. 69). It is also a Strategy that is important to ENGOs such as Ecology Ottawa in their goal of achieving a green and sustainable city. And Energy Evolution addresses that, "expanding education and outreach with the broader public" is crucial to achieving its goals (City of Ottawa 2020b, p. 69). It is a Strategy that aims to enact community-wide GHG reduction targets that aims to affect the citizens of Ottawa, who will see the first-hand effects of an energy transition.

This study is premised on the idea that analysts need to better understand the creation and design of participatory processes like Energy Evolution, examining the level democratic engagement, the extent to which participatory processes are inclusive or exclusive, exploring which actors are present (or not present) in these processes, how these processes engage in the politics and power relations and whether they push or constrict transitions. In the next two chapters, this work explores these themes using the frames of constructivist STS and ecological democracy. 


\section{Chapter 6: Analysis Part I - Participation 'in the making' in Ottawa's Energy Evolution Strategy}

This chapter engages with constructivist STS theory to respond to my first research subquestion: How is participation in Ottawa's Energy Evolution process manifest? Drawing on the evidence provided by interviewees and relevant documents, this chapter argues that participation in Energy Evolution was a creative process, started by political actors (City Council members) and then shaped by City staff. Energy Evolution was purposefully created and only partially framed as participatory, showing a need for actors to be more aware of contexts they are participating in. This chapter is divided into two main sections based on Chilvers and Longhurst's (2016) analytical themes, as introduced in Chapter 4 (see Table 1). It first examines the productive dimensions and effects of Ottawa's participatory collective. This theme reviews the fundamentals of the participatory process. It includes the model and conduct of participation, the type of participants and public(s) created in the process and the definition of the issue-at-stake. On this first theme, I argue Energy Evolution's model was invited, professionally facilitated, and purposefully planned. It involved the construction of informed stakeholders who had an attachment to the object of participation while simultaneously producing an imaginary of an uninformed public. It also provided an issue-at-stake that is highly focused on future GHG reductions. In effect, this was a technocratic and managerialist vision of the transition to sustainable energy systems.

The second theme deals with how the collective of participation emerged and was orchestrated, including forms of enrolment and mediation used and the exclusions and resistance(s) present in the participatory process. I show that enrolment in this process 
was centralized and institutional. Mediation took place through participatory designs and technologies, the design of the Sounding Board group and issue framing by consultant and industry actors. In addition, there were broad exclusions of the general public and non-human actors in addition to geographic exclusions. Internal resistance was directed toward facets of the Strategy and participation, whereas external resistance stemmed from negative sentiments toward wider environmental processes in Ottawa.

\subsection{Productive Effects}

Chilvers and Longhurst (2016) argue that a researcher must examine three main aspects of the productive effects of any participatory process. For Energy Evolution, this first means studying the material conduct of participation in the process, or its "model of participation". Second, it means examining the identity of the participants and public(s) produced in the Energy Evolution process. Finally, it means examining the central topic and theme, and how the "issue-at-stake" was defined through the Energy Evolution process. This section examines these three productive effects.

\subsubsection{Model of participation}

Energy Evolution's model of participation was invited, professionally facilitated and purposefully planned. Large Sounding Board meetings, smaller topic-specific and technical working groups, as well as opportunities for participants to provide feedback and input, were the main forms of participation.

Participants in Energy Evolution were invited to the process as members of the Sounding Board, and then subsequently participated through working group meetings (City Staff B interview, 2021). Sounding Board meetings were typically large summary sessions that looked at the overall Strategy. For example, one participant recalled a 
Sounding Board meeting with "over one hundred people in a room of City

Hall...facilitated by an individual who at various times was the lead on the project"

(Quasi-Governmental Organization Subject B interview, 2020).

Early Sounding Board meetings contained visionary and wide discussion related

to the Strategy, while later meetings involved more "information sharing," with participants providing direction on specific matters to staff (City Staff A interview, 2021). City staff would send material in advance of these large Sounding Board meetings, provide a presentation, give an update and identify questions (City Staff B interview, 2021). After these large Sounding Board meetings, participants would break out into smaller group sessions. One participant described what a typical day of participation looked like, explaining:

Well, typically you were invited to a meeting. You had an agenda that you worked through. You were asked for input. We often broke into smaller groups and had discussions and we fed that back to the larger group. There would be discussion and there would be a collection of the ideas that eventually, I think, fed into [the] Evolution Strategy. (Industry Subject B interview, 2020)

In these small group discussions, staff explained "we had facilitators at each table who were taking notes and then reporting back on the key questions that had been sent in advance, organized by table" (City Staff B interview, 2021). Another participant painted a wider picture of the development of the participatory process:

Most of it started off with visioning sessions, trying to get priorities, trying to work out what that goal could be. So, a lot of it was roundtable discussions with different stakeholder groups and so forth. They would put us all together and we would talk about what was important, what we were doing, what others were doing, what we thought would work [and] what we definitely thought should not be done. And slowly that morphed into more pointed groups, breaking down into saying how we would deal with existing builds versus new builds, [or] transportation specifically. So, it got more and more pointed, and now it has gotten to the point where they are giving us their plan and we are giving comments on the whole thing so it has been an iterative process the whole way through. (University Subject A interview, 2020) 
The eight working groups established at the first Sounding Board meeting occurred between Sounding Board meetings. They functioned in a similar fashion, but were much smaller in size, technically focused, and structured around participants' "expertise" or specific "role in their work" (City Staff A interview, 2021). These groups did not remain constant throughout the process, but fluctuated. A city staff member explained that during the staff reorganization, the working groups "probably shrunk to five" and then "grew to fourteen or fifteen" toward the Final Report (City Staff B interview, 2021). Early in Energy Evolution, a staff member explained that "what was pretty standard was to get some of the members at those pathway discussions [to] get someone to do a presentation", based on if staff was "starting to learn that some people had key information about the field of interest", with "even four presentations in a morning in a technical meeting" (City Staff A interview, 2021).

Later in the process, in Phase 2, the participatory process was more consultantdriven. Staff explained that "pathways would go out from the consultants to the working groups in advance" giving them a chance to review before a meeting, where "the consultants would do a presentation, answer questions [and] have some guiding questions so they could move on to the next stage" (City Staff B interview, 2021).

Despite these process differences between Phase 1 and 2, in each phase participants acted as a Sounding Board (both in-person and via email), hence the board's name. They reviewed materials, shared information, and asked clarifying questions to provide feedback to staff (City Staff B interview, 2021; Energy Subject A interview, 2020). 


\subsubsection{Participants/publics}

The second subset of productive effects of any participatory process involves the production of specific types of participants and publics. In Energy Evolution "participation" involved the construction of educated or informed stakeholders who had a particular (often economic) attachment to the object of participation. Chilvers and Longhurst (2016) write that collectives of participation also produce publics through constructing particular identities of the actors involved. In this case, Energy Evolution produced an imaginary of a wider public of actors who were not involved, uninformed, passive non-experts.

The Final Energy Evolution Report refers to "community partners including more than 200 stakeholders" representing approximately 90 organizations in Ottawa as "critical in guiding and informing the development of the strategy and action and investment plan" (City of Ottawa 2020b, p. 69). And Energy Evolution documents throughout the process used the term "stakeholders" and "community partners" or "members" interchangeably. A Phase 2 update on Energy Evolution presented to the Environment and Climate Protection Committee (2018) summarized the Sounding Board as a group of "community partners" made up of "representatives from local energy utilities, the federal government, the development industry, schools and academic institutions, non-profit organizations and the private sector" (p. 24). An email list from early in the Energy Evolution process (September 2016) of 92 Sounding Board members that was used in this study to categorize participants supported this breakdown (see Table 5 below). 
Table 5. Early Energy Evolution Sounding Board Members (2016) by organization type

\begin{tabular}{|l|c|}
\hline \multicolumn{1}{|c|}{ Type of organization } & $\begin{array}{c}\text { Number of } \\
\text { participants }\end{array}$ \\
\hline City of Ottawa staff or affiliation with the City of Ottawa & 18 \\
\hline Energy providers and/or government services & 13 \\
\hline Federal Government of Canada & 8 \\
\hline Industry representatives & 4 \\
\hline Non-government or non-profit organization & 20 \\
\hline Private firms & 22 \\
\hline University or school affiliated & 7 \\
\hline
\end{tabular}

The sample in this study also qualitatively reflected this variety of participants in their professional roles. Seven of the participants in this study had specialized energy expertise in their roles (for private firms, universities, industry organizations and the Government of Canada) whereas there were three participants with more 'generalist' environmental roles (including one involved with an ENGO, one journalist and one industry representative). Two participants had less technical expertise, but worked in engagement and planning (with one involved with a utilities provider and one with an advocacy group). And one city staff member who participated in this study originally began as a Sounding Board member, but went on to become full-time staff in Energy Evolution.

Many participants in this study had specific vested interests or a stake in Energy Evolution. For example, one related "an interest in helping guide and mould what happens in the City", especially concerning issues on which their organization had lobbied the City. They also had an interest in potential outcomes of the Strategy, explaining:

...for us we are also interested in seeing what the City's plan is going to be to entice (selfishly) the University. What are they going to do to help us put up more solar panels, or to help us to build to a greener standard? Are there going to be financial 
incentives? Are there going to be design trade-offs? (University Subject A interview, 2020)

Another participant explained alignment with the City, an interest in potential projects, and in funding for their organization's aims (University Subject B interview, 2020). Yet another participant explained that more business would be done for their various commercial groups if Energy Evolution became "serious" (Industry Subject A interview, 2020) and one explained the promotion of policies that provided incentives to their industry for reducing GHG emissions (Industry Subject B interview, 2020). Furthering this theme of organizational self-interest, one participant's organization engaged directly by providing funding to help the development of the Strategy. This move allowed the City to hire consultants in Phase 2 (Quasi-Governmental Subject B interview, 2020). In another case, two interviewees in this study received funding from Energy Evolution related to the catalyst projects in Phase 1 . And while other interviewees did not have a specific economic interest in Energy Evolution, they had a "stake" due to their operational work. For example, two participants worked for an energy company that closely works with the City. Another participant engages in utility planning for municipalities. One works with an energy technology that could have uptake in Ottawa. And the last participant was originally interested in documenting Energy Evolution and simply engages with climate and energy in their organization's day-to-day work.

As referred to by the City of Ottawa, the Sounding Board is a "stakeholder group" (ECPC 2017, p. 5). Interviewees agreed that participants in Energy Evolution were composed of experts who had a stake in the process, characterizing the group as "an evolving group of private and public sector organizations [and] representatives of 
community groups that have a stake or an interest in building a better city in ways that touch on the Energy Evolution Strategy and that either represents different communities or have specific technical expertise" (Quasi-Governmental Subject B interview, 2020).

Interesting points were made in interviews about the differences between these "stakeholders" and the broader public. For example, one participant was clear on the Sounding Board's role and questioned public involvement:

The Sounding Board part itself is like no, the City has ideas what do you think? And then we give our reactions and expert opinions. That part itself I don't know how open that needs to be to the public, because sometimes it tends to be a bunch of jargon. Does your average citizen want to know that sort of thing? Do they want to know the minutia of the back and forth? (University Subject A interview, 2020)

Another participant presented the public as not knowledgeable enough to engage with this discussion, explaining that they "don't really know enough to get engaged" (Energy Subject C interview, 2020). One asked "who would know about it unless you were engaged in it anyway?", explaining that the public is not uncaring, but "do not care about getting involved" as it is "someone else's job" (University Subject B interview, 2020).

And one participation explained their participation as the following:

I was always in the group... who had an interest of some kind and those were always sessions run during the day so it wasn't joe [from the] public, it was [interviewee name] from organization X representing organization X's point of view, not my personal opinion". (Government Subject interview, 2020)

Only one participant considered themselves to be a citizen-participant (despite representing their organization) in the process, while two others considered their role as residents of Ottawa in relation to the Strategy.

City staff agreed with a characterization of participants as interested and invested stakeholders, sharing a similar idea of the public, explaining: 
I cannot imagine going to the public at large and saying "okay, what do you guys think about power to gas versus hydrogen? What do you think about renewable natural gas versus natural gas? What do you think about how we should prioritize our land for wind versus solar?" I don't think we would get quality input that would inform a plan. I think we would get emotional responses that are based on very limited information. Or, we would get some very blank stares and 101 questions like, what is power to gas? And how do we make hydrogen? (City Staff B interview, 2021)

To sum up, Energy Evolution was a participatory process that reflects a stakeholder strand of environmental decision-making focusing on "interactions among representatives of the organised interests that are already enmeshed in the nexus of environmental problems", rather than "noble citizens" (Meadowcroft 2004, p. 2). As a result, the wider public was deemed to be innocent citizens, or a passive "pure public", meaning they are assumed to have limited knowledge of the issue in question (Chilvers \& Longhurst 2016, p. 592)

\subsubsection{Issue/vision}

The third subset of productive effects of any participatory process involves the production of a central topic or theme and a definition of the issue-at-stake. The section argues that the vision of Energy Evolution fits with a type of low carbon energy transition that Chilvers and Longhurst (2016) describe as "technocratic" and "managerialist," which ignores the potential political and social implications in the Strategy and assumes a fairly straightforward degree of governance over the energy system. The issue produced by the Energy Evolution process was the result of the City of Ottawa's commitment to achieving a 100 per cent reduction in their own GHG emissions by 2040 and by 2050 for the whole city. This issue was initially created and shaped by political actors, based on the premise that deep GHG reductions will require fundamental changes to society (City 
of Ottawa, 2020b). Sounding Board participants then contributed to refining the vision of the city's Strategy. Participants renamed the Strategy to Energy Evolution and provided a goal of a city powered by clean renewable energy, as well as including conservation and conceptualizing the Strategy as a multi-year program. The issue was then moved forward by Ottawa's City Council and aligned with international science through adjusting the Strategy's goals. The process openly outlined that achieving GHG reduction targets required specific technological choices to be made, via the use of pathway studies and sectoral modelling.

The vision of Energy Evolution began as an open-ended strategic initiative by the City of Ottawa in July 2015 to develop a renewable energy strategy. This initiative was located in the City of Ottawa's 2015-2018 Strategic Plan of providing sustainable environmental services that "balance protection of our natural resources and support the planned growth of the city" (City of Ottawa 2015a, p. 34). The original vision was originally guided by Council, where the chair of the Environment Committee in 2015 Councillor David Chernushenko "simply identified a one sentence line in an otherwise robust city strategic plan and said "I want to develop a renewable energy strategy" (City Staff B interview, 2021). With this, a staff member noted that they were brought on as a sole member to an initiative with questions that had never been asked before at the City, and that they had no budget or other targeted resources. Staff began by consulting with David Chernushenko, explaining "it would become apparent that he would have a very technical understanding of what a renewable strategy would be", that "would not necessarily be corporate wide", or only for internal City matters (e.g., municipally owned buildings and City-owned transportation fleets), but city-wide as a whole (City Staff B 
interview, 2021). The visioning of the Strategy first began with discussions with David Chernushenko. It was then taken over by a Council Sponsors Group of three Councillors, established in February 2016 (ECPC, 2017).

The vision of the process expanded after the first Sounding Board meeting in March 2016, when the Sounding Board was presented questions from Councillors by city staff, where the vision and goals of the Strategy, including conservation and efficiency became part of the agenda. A staff member described that this meeting expanded the scope of the project:

And at that point, that is when it was clear that there was a broader desire and recognition that we can't just focus on renewable energy like solar, wind renewable natural gas. We have to focus on conservation and efficiency, otherwise we have no hope in being able to achieve what Councillor Chernushenko had envisioned initially which was a city which was powered by a hundred per cent renewable energy by 2050. (City Staff B interview, 2021)

In initial meetings, Sounding Board members contributed to the framing of the Strategy.

One member recalled that at "the first Sounding Board meeting we ever had was the idea that we're going to be the greenest city in North America", but "the Board kind of tempered that back down, like no no no that sounds like a thing you say because you just want say it but you're not putting honest effort into it, here's the direction we think it should go in" (University Subject A interview, 2020). City staff explained that the Sounding Board assisted with the original visioning of the issue, including naming the project, setting the scope and developing guiding principles and objectives (City Staff B interview, 2021). The Board would be credited with the initial Energy Evolution vision, established as: "Ottawa is a thriving city powered by clean, renewable energy", through promoting a multi-year actionable renewable energy strategy that would transition from a 
dependence on fossil fuels by: reducing energy use through conservation and efficiency, increasing the supply of renewable energy through local and regional production and prioritizing the procurement of clean and renewable energy (City of Ottawa Planning, Infrastructure and Economic Development 2017, p. 27).

According to a city staff member, the 80 per cent reduction target approved by Council in February 2016 was what staff had when the process was started and it "guided the Energy Evolution work for the first few years", primarily in Phase 1 of the Strategy (City Staff B interview, 2021). That target was carried along by staff throughout the Energy Evolution process, because going further above 80 per cent would require "Council buy-in" (City Staff B interview, 2021). As a staff member explained, as there was an increased trend of declaring climate emergencies, the release of the IPCC 1.5 degree Report (Intergovernmental Panel on Climate Change [IPCC], 2018) and "an avalanche of international reports", city staff "couldn't ignore the face that we didn't know how our baseline targets compared" to the IPCC's 1.5 degree Celsius target (City Staff B interview, 2021). As part of Ottawa's 2019 declaration of a climate emergency, staff were tasked with comparing their 80 per cent reduction target to the $1.5^{\circ} \mathrm{C}$ IPCC recommendation, with it becoming clear that Energy Evolution would need to move to a one hundred per cent reduction in GHG emissions by 2050 (City Staff B interview, 2021).

One city staffer explained that when Energy Evolution went toward Council, tangible targets and immediate actions were needed because staff "knew that some Councillors wouldn't go for just a motion on a target with nothing behind it" (City Staff B interview, 2021). To present political actors a palpable renewable energy strategy, city 
staff favoured a pathway approach from the onset of the process in figuring out how to use less energy with combining "all the recommendations into each study area into an overall report that says everything we have to do" (City Staff B interview, 2021). In January 2020 with Council's approval of the Climate Change Master Plan, GHG emissions reduction targets were brought to 100 per cent for the community by 2050 and 100 per cent from city operations by 2040 (Ottawa City Council, 2020a). This put the City "in lock step with the recommendations of the Intergovernmental Panel on Climate Change" (City of Ottawa 2020b, p. 10). And as staff explained, once participants were brought through the process and shown "what that process was to get us to a hundred, we didn't need to bring the 80 per cent along [any further] because Council had an approved target of getting to a hundred percent", and "stakeholders understood the implications of what that meant" (City Staff B interview, 2021).

The Final Energy Evolution Report outlines its vision as a framework for how Ottawa will achieve GHG emission reduction targets by managing energy consumption, promoting the use of renewable energy and advancing local economic development opportunities in Ottawa (City of Ottawa, 2020b). It states that "at the core of Energy Evolution is a is a comprehensive, custom-built energy, emissions and finance model" that incorporates growth, land use, buildings, transportation, and waste data with energy conservation, efficiency, and renewable energy pathway studies" in presenting the two scenarios of BAP and a one hundred per cent by 2050 scenario (City of Ottawa 2020b, p. 11-12). Participants in this study outlined a similar definition of the issue of Energy Evolution. Several explained the general goal of Energy Evolution as a "strategy" or "blueprint", which brings stakeholders together and for example "defines and categorizes 
the city's goals and targets and measurable outcomes for how they're going to achieve their environmental goals and GHG reduction targets" (Energy Subject A interview, 2020). Many participants explained the reduction of GHG emissions, lowering the city's carbon footprint and transitioning to other forms of energy production and consumption, for example one participant explaining Energy Evolution as an "approach to how we generate use and store energy locally in way that helps the city meet its goals which is around transitioning to a renewable energy system that helps us meet the international targets around stabilizing the climate" (Quasi-Governmental Subject B interview, 2020). Notably, one participant took issue with a lack of focus on end-use or the consumption of energy in the city, explaining "they were talking about technology" (Industry Subject A interview, 2020). The Final Energy Evolution Report frames the issue at stake as technological, as it prefaces that "the technological solutions, skills and knowledge exist to transition away from fossil fuels to clean, renewable energy sources" (City of Ottawa 2020b, p. 24).

In sum, Energy Evolution began as an open-ended and flexible process created by political actors, and they gave direction to staff who used participants to refine the Strategy. As one city staffer explained, the issue at stake was guided by a "long Council history" throughout the whole process that "moved the needle and science that pushed the needle" (City Staff B interview, 2021). The issue of GHG reductions gained wider global support throughout the process, where international science also assisted in forwarding the issue-at-stake. And for the Strategy to be acceptable to political actors, it maintains a technocratic and managerialist nature where it openly outlines that achieving GHG reduction targets requires a technological switch to new energy sources and efficiencies, 
via sectoral modelling and pathway studies that describe how "a specific energy technology or improvement in energy use may be developed over time in Ottawa" (City of Ottawa 2020b, p. 39) rather than focusing on a reduction of consumption.

The first theme of productive effects has shown how Energy Evolution constructed a particular model of participation, production of participants/publics and a definition of the issue-at-stake. The model of participation was invited, professionally facilitated and purposefully planned. Energy Evolution reflects a stakeholder strand of environment decision-making (Meadowcroft, 2004) as participants were educated and informed stakeholders who had a particular (often economic) attachment to the object of participation. In turn, these participants produced an imaginary of an uninvolved public as uninformed, passive non-experts. The issue-at-stake was how the City could achieve GHG reductions via a technocratic and managerialist low carbon energy transition that focuses on technologies that could change the energy system.

\subsection{Orchestration}

A researcher needs to consider three distinct aspects to understand the orchestration of a participatory process (Chilvers and Longhurst, 2016). First, one must examine how actors (human and nonhuman) are enrolled in the participatory collective and what this means for the process. Whereas the model of participation dealt with in section 6.1 .1 deals with the procedural format or configuration of Energy Evolution as professionally facilitated and purposefully planned, enrolment refers to the way that different actors are drawn into the participatory process. Second, one must consider the technologies used to mediate the participatory collective. Third, one must consider how the process excluded human and non-human actors, and that the enrolment and mediation of participants are subject to 
forms of internal and external resistance (Chilvers \& Longhurst, 2016). In the case of Energy Evolution, in this section I argue that enrolment in this process was centralized and institutional, with participants mediated by the use of standardized participatory designs and technologies, the design of the Sounding Board and issue framing by consultant and industry actors. I show that there were broad exclusions of the general public and other actors, as well as geographic exclusions. Next, I demonstrate how internal resistance was directed towards the parameters of the Strategy, technologies toward reducing GHGs, the use of consultants and the costing of reduction measures. The limited external resistance found towards the process stemmed from negative sentiments toward wider environmental processes in Ottawa in general. This section first deals with enrolment and mediation together. It then addresses questions of exclusions and resistance.

\subsubsection{Enrolment \& mediation}

City staff were resourceful in their creation of the Sounding Board and working groups. One participant in this study appropriately characterized participants in Energy Evolution as "already very engaged in the public in civic processes and has pre-existing relationships with the City on other or familiar with the municipal planning engagement process" (Quasi-Governmental Subject B interview, 2020). Enrolment in Energy Evolution was centralized and institutional. It was initially controlled by City of Ottawa staff via their 'stakeholder mapping exercise', deeming those to be fit with experience, expertise or have a stake as geographically or technically relevant energy-related actors from local energy utilities, the federal government, development industry, schools and academic institutions, non-profit organizations and the private sector. But Energy 
Evolution also grew via a semi-organic process, with actors who were enrolled in turn enrolling other actors they deemed relevant into the participatory collective.

The enrolment of actors in Energy Evolution began after Council's direction to staff to develop a renewable energy strategy, and a sole city staffer tasked with this work before it became Energy Evolution explained, that they did not have a technical background, and could only address the City's goal of creating a renewable energy in their words if they "have a robust group of other people who know what they're talking about" (City Staff B interview, 2021). This became realized when this initial staff member explained that they "just reached out and I started by mapping out the stakeholders who we thought would be critical players in all of the areas which we typically generate renewable energy" in what they referred to as a 'stakeholder mapping exercise' (City Staff B interview, 2021). Initial enrolment of Sounding Board members was established by this staff member, using the City's GHG inventories to crossreference "the key stakeholders who had power or influence over and ideally direct control over emissions." This meant finding participants in the utilities and those that produce the largest amount of emissions (City Staff B interview, 2021). Further, given that the City's inventory showed that "90 per cent" of emissions came "from buildings and transportation", staff broke sectors into categories (including: new buildings, existing buildings, personal vehicles, commercial fleets and transit) and asked "what organizations and/or individuals do we know?" to get involved (City Staff B interview, 2021). As a result, staff reached out, for example, to the development industry for new buildings, contacted Hydro Ottawa for utilities, Enbridge Gas because of future business opportunities in RNG and looked toward ENGOs for networking for a future 
communications and engagement campaign for the community (City Staff B interview, 2021). With the constraints staff faced, they for example, asked an ENGO director: "who are some movers and shakers who could get on the Sounding Board that are not going to be stuck in the bureaucratic traps that I am going to be stuck in?" (City Staff B interview, 2021). When it came to the working groups and pathways, staff explained that their process of enrolment was based on "technical ability" related to the nature of the work, as well as: business interests, knowledge of planning, legislation and regulation, and historical perspectives of the technologies being considered in the process (City Staff A interview, 2021).

Energy Evolution began with an initial list of 25 participants (ECPC, 2017), and each invitation of a participant also included "word of mouth" request for other key influential members, asking: "who do you think should also be at the table?" (City Staff B interview, 2021). Staff explained that the group would get "bigger by osmosis", via an "unscripted" method of "talking to people and getting referred to other people and then inviting people to be involved a little more" (City Staff A interview, 2021). The initial group of 25 would grow to more than 200 individuals representing 90 organizations contributing to the Strategy (City of Ottawa, 2020b), showing a semi-organic process of enrollment.

The majority of participants (ten out of twelve) in this study were enrolled in Energy Evolution based on a prior relationship and/or experience with the City of Ottawa and most were contacted by email based on this connection. Some participants specifically mentioned close relationship with the City of Ottawa. One explained that they were a recipient of early Energy Evolution grant funding and laughed at the question 
of enrolment, noting that they personally worked with the managers involved with Energy Evolution on projects for decades (Quasi-Governmental Organization Subject A interview, 2020). Another said "when they're looking for the voice of the industry, they'll often come to us" (Industry Subject B interview, 2020). Two other participants noted "existing relationships with the City" (Energy Subject C interview, 2020), and a longstanding relationship with Hydro Ottawa (Energy Subject B interview, 2020). Another explained that they were a contact of the City and the City was a previous beneficiary of grants and low-interest loans that their organization provides (QuasiGovernmental Organization Subject B interview, 2020).

The two remaining participants in this study self-selected their participation in Energy Evolution. However, in each case this was done via existing connections. The first participant became enrolled via a connection to Ecology Ottawa, an organization that received funding at the beginning of Energy Evolution. This participant went on to document a workshop at City Hall that tried to prompt action on Energy Evolution. After that event, they volunteered to join the Sounding Board (Journalist Subject interview, 2020). The second participant had established experience as a member of City committees and explained they "knew the team players [involved in Energy Evolution] extremely well" (Industry Subject A interview, 2020). They became interested from the start of the process, explaining that "I insisted I be involved when they were contemplating setting this up", and "wasn't invited", but rather said “'I'm on"” (Industry Subject A interview, 2020).

With over 200 participants involved in Energy Evolution by the end of the process, clearly not all members were enrolled based on prior relationships. As a city 
staff member noted "it would be too ambitious to say there was an existing relationship with all of those members, but we certainly as part of the stakeholder mapping exercise reached out to folks inside of the city and outside of the city" (City Staff B interview, 2021). However, when discussing the need for a Sounding Board, they explained:

Did those people have prior relationships with the City? Certainly, we would've drawn on existing relationships where we had them either because the councillor at the time knew them, the council sponsors group which was established to support it knew those people, or because senior management... because we reached out to them as well as part of that first list. We drew on those relationships. In some cases, there were consultants who have done work for the city in the past where we approached them..." (City Staff B interview, 2021)

This collective, constructed by staff, was mediated via three forms of participation. The first was the use of standardized participatory designs used to gather input from participants via participatory activities and technologies. The second form of participation was the design of the Sounding Board itself, as a group intended for ideas, suggestions and feedback, which mediated how they provided input. The final form was the mediation of the group via consultant and industry representative modelling, where the issue of deep GHG reductions and projected costs framed how the collective participated and provided feedback.

First, standardized participatory designs were used to gather input from participants via participatory activities. Participants outlined the use of these at in-person meetings, for example, one noted "we would write some ideas up on the board and put your sticker beside it", as well as referring to the techniques at several in-person events as: "dotmocracy" (University Subject A interview, 2020). Another participant noted the use of a consensus-driven methods in larger Sounding Board meetings:

So, in the in-person meetings that I participated in 2016, I remember that the lead at the time used kind of a coloured card system to kind of gauge the temperature in the 
room and establish whether there was enough consensus to move on in certain points. So, if you were fully on board it was green, if you had some reservations it was yellow, if there was absolutely something you put out a red card and that was the way they would engage where everyone was at. (Quasi-Governmental Organization Subject B interview, 2020)

Notably, this consensus-building tool was only used early in the Energy Evolution process, during Phase 1. As a staffer who conducted this form of participation noted "in the early days, I used a lot of that card system as a consensus-building tool so that we could more through things more quickly", as this was used to figure out the "scope, the approach, the name [and] the guiding principles that we were going to come back to over and over", because the staff member "felt strongly at the beginning of the process, we needed to have a high degree of buy-in" from participants (City Staff B interview, 2021). Such consensus-making participatory practices were thus used to create cohesion within the participatory collective.

Technology was used to mediate participation. One participant outlined that "... in the last draft that was presented to us we been using technologies in the process to ask questions and to upvote or downvote people's thoughts and ideas and how they should be responded to or whether they should be responded to" (University Subject A interview, 2020). Surveys were another key technology used between meetings. These are a corporate standard for the City of Ottawa. A staffer explained "we would send out surveys to get for instance input on names", where:

A working group would meet, they would generate a very long list of names, they would settle on their top, let's call it ten, and then we would send that out to people for them to provide input in a survey mechanism. (City Staff B interview, 2021) 
These surveys were used to generate agreement on larger level, as not many surveys were conducted at the smaller "working group level, because they tended to get just get resolved in meetings" according to city staff (City Staff B interview, 2021).

Second, the design of the Sounding Board itself as a group used for ideas, suggestions and feedback mediated how participants provided input. One participant summarized the methods of participation as "very open, democratic [and] consultative methods", but disliked the lack of involvement and responses from city staff, noting they would only say "we are here to listen" (Industry Subject A interview, 2020). This sentiment encapsulates the mediation of the Sounding Board, which was purposefully designed to provide "opinions and thoughts, ideas and suggestions" (Government Subject interview, 2020) by reviewing and commenting on draft versions of reports and/or recommendations (Quasi-Governmental Organization Subject A interview, 2020). A key example of this is During Phase 2 of the process in January 2019, when there were a series of pathways outlining low, moderate and aggressive scenarios to reach the targets of 80 per cent and 100 per cent GHG reductions. These pathways were originally developed via discussions with the Sounding Board.

The third form of mediation was the use of consultants and industry representatives for modelling, where the issue of deep GHG reductions and projected costs these reductions both framed how participants provided feedback. The introduction of consultants in 2017-18 provided a significant change to the mediation of participants. Professional consulting organizations were enrolled to develop the energy and emissions model and industry representatives were used to develop the finance model used in the Strategy, which participants responded to (City of Ottawa, 2020b). In this period, 
consultants were enrolled in the process due to limited internal city capacity. And one consultant, Sustainability Solutions Groups (SSG), was directed by staff to build a model almost wholly from pathways that participants helped develop (City Staff A interview, 2021). When Energy Evolution shifted to reflect the IPCC and moved its target to 100 per cent, the modelling needed to be adjusted. Staff noted that "there was no time to redo the pathways", and "there were a couple of things added", such as a little bit of "waste heat" "hydrogen", and "some more renewable energy" (City Staff A interview, 2021). After this, the Sounding board was reconvened to give feedback this change (City of Ottawa, 2020b). One participant recalled online meetings during summer 2020, explaining "it has been questions and feedback towards the projection that they have come up with and then if we have had any specific issues or concerns with what it was" and "then we were feeding into it at that point" with the City "using this Board as sort of a Sounding Board to say "have we missed anything?" (University Subject B interview, 2020). The issue of deep GHG reductions not only framed and provided the basis for the participatory process, but it also mediated participants in framing how they would participate. While GHG reductions framed participation throughout the process, consultant firms and industry representatives in Phase 2 set the parameters of participation and mediated participants in the orchestration of the participatory space. This meant that during Phase 2, consultant and industry actors mediated the participatory process.

In sum, enrolment in Energy Evolution was centrally controlled by City of Ottawa staff, who deemed those to be fit with experience, expertise or have a stake as a geographically or technically relevant energy-related actor as initial participants. Staff resourcefully drew on actors based on existing or prior relationships. These participants 
grew via a semi-organic process, where enrolled actors brought on other actors that they deemed relevant into the participatory collective. The collective was mediated via three forms of participation, including: the use of standardized participatory designs and technologies, the design of the Sounding Board as a feedback mechanism and issue framing by consultant and industry actors.

\subsubsection{Exclusions \& resistance(s)}

Section 6.1 outlines that the construction of participants as invested and interested stakeholders with a particular attachment to the object of participation both excluded the general public and other actors (e.g., non-humans), but also created a vision of excluded actors as uninformed, passive and non-expert. In addition to these broad forms of exclusion in the overall process, the technical working groups were invited and smallscale, thereby producing geographic exclusions. And in Energy Evolution, internal resistance from participants included resistance towards the parameters and conduct of the participatory process, differing perspectives on the role of various technologies in reducing GHG emissions, skepticism of the involvement of consultants in the process, and resistance towards the costing of reduction measures in the Strategy. External resistance from participants included negative sentiments toward wider processes in Ottawa related to the environment.

As an example of one geographic exclusion created by Energy Evolution was a participant that was not invited to Ottawa and wished for conference call ability at the beginning of the process, explaining they did not travel for meetings and create a carbon footprint (Energy Subject C interview, 2020). While the majority of the Sounding Board was composed of individuals and organizations deemed to be representative of the local 
community, some outside actors were invited. One participant explained that they provided input to "the lead at the time, who was asking about contacts in other cities and resources related to the strategy development” (Quasi-Governmental Organization Subject B interview, 2020). Working groups contained some representatives from the Canadian cities of Toronto and Montréal (City Staff A interview, 2021). Staff were resourceful in expanding a knowledge network, but participation in the initial Energy Evolution process was focused on in-person sessions, with geographic exclusions based on those willing or able to travel to participate.

Internal resistance emerged in various ways. First, one participant displayed internal resistance to an overfocus on discussing electricity and technologies and a lack of a discussion of end-use, conservation and efficiency (Industry Subject A interview, 2020). This participant also felt like the process did not pay enough attention to high levels of energy exports and imports of energy in the city (Industry Subject A interview, 2020). And they took issue with the inclusion of RNG in the Strategy, arguing "you are still not getting anybody off gas" as they questioned the composition of the product (i.e., the amount of natural gas versus biomethane present) and the emissions it produces (Industry Subject A interview, 2020). Further, they displayed resistance to how staff conducted participation, explaining that they provided "actionable" recommendations, but staff explained "we're here to listen" and they disliked this open-ended approach (Industry Subject A interview, 2020).

Other participants also expressed skepticism with the involvement of consultants. One participant explained that a lot of the Strategy "seemed to have been developed from the consultants that they had", noting that the latter stages of the process seemed like 
"more of an information session" (University Subject B interview, 2020). A second participant presented resistance to the consultant's costing of their own preferred GHG reduction measure in the Strategy. They explained that the consultants "grossly mischaracterized" their specific solution, stating that the "cost per kiloton of reduction" is "completely out of whack", which "creates a situation where it would really draw the wrong conclusion about the value of our solution", and "that the work we've done is far too expensive" (Government Subject interview, 2020). This participant explained that they disagree with the information that has gone to Council and disagreed with the findings of the consultant as a stakeholder and member of their organization. While this interviewee noted this "minor disagreement at the end of a very long process", they also referred to 95 per cent of the Strategy as "fantastic". They described the inaccurate costing of their reduction measure as a "major irritant", noting that they "have not actually been able to get [City staff or consultants] to change the model" (Government subject A, personal communication, 2020).

Internal resistance in this case appears to have two key meanings. First, constructivist STS suggests that internal resistance from participating actors can stem from mediation, where professional facilitators discipline participants to conform to a certain type of participation. In Energy Evolution, some participants resisted the topics focused on and the conduct of participation. Second, resistance demonstrates dissatisfaction on the part of some participants who felt like their voices were not heard, suggesting that the Sounding Board as feedback mechanism did not always work as intended. I consider what this may mean for the success of Energy Evolution as a participatory Strategy for energy transitions below. 
Two participants showed "external resistance" to the Energy Evolution participatory process as a whole, which deals with forms of contestation to the whole participatory collective or external characteristics relevant to the process and can illuminate larger issues than internal resistance. In fact, they had negative sentiments toward wider processes in Ottawa related to the environment. The first participant quit their role on the Energy Evolution Sounding Board in summer 2019, believing "Ottawa is leading the charge for being non-environmental" (Industry Subject A interview, 2020). This participant was dissatisfied with the institutional structures in City Hall, explaining that advisory committees could not listen to public recommendations and lacked power. These are long-standing institutional issues with these committees, which "have a long history of sucking up interested citizens with expertise, ignoring them and making them mad, and then spitting them out again" (Reevely 2017, para. 3). Nevertheless, they noted the lack of feedback mechanisms in these committees, and that committee reports are not recorded. They provided the example of a report presented to the Planning Committee from a consultant that outlined that energy efficient homes could be accomplished by providing code for them in the City's official plan, and that this report had been rejected at the Committee level. As a result of these other experiences, this informant was also critical of initiatives adjacent to Energy Evolution, such as Ottawa's New Official Plan for 2021 (which replaces the City's 2003 Official Plan). They explained all the City had to do was provide one paragraph that forced developers to build better than code, but that the City had now lost that opportunity for years, as the new plan seeks to guide the development of Ottawa until 2046 (City of Ottawa News, 2020b; Industry Subject A interview, 2020). They also expressed dissatisfaction with the City's declaration of a 
climate emergency, explaining that there was little substance in the declaration, and that this aligned with overall inaction by the City (Industry Subject A interview, 2020).

The second participant that displayed external resistance explained that they have "been intermittently involved" and have "been mostly an inactivate member of the Sounding Board" (Journalist Subject interview, 2020). They explained dissatisfaction with the slow movement of climate initiatives in Ottawa, for example, with a delay in Energy Evolution, explaining:

In the time the City of Ottawa has been talking about this and maybe occasionally funding Energy Evolution to be doing what it needs to do and sometimes not... over that time from 2015 to 2020, the gap between atmospheric carbon and where we need to get to has increased 27 per cent. (Journalist Subject interview, 2020)

This participant described their involvement with a movement lobbying against the City's decision to expand the urban boundary in 2020 that was rejected, and outlined dissatisfaction with the City's progress toward climate change and energy efficiency, stating: "all of us struggled like mad to get rhetorical commitments and it takes forever" with "little or no budget commitments behind it", and an overfocus on "building new roads and maximizing congestion and sprawl" (Journalist Subject interview, 2020). In both cases of external resistance toward Energy Evolution, participants' negative perceptions were informed by adjacent involvement and negative sentiment toward the City of Ottawa's progress toward climate initiatives and wider political processes situated in Ottawa.

The Energy Evolution process excluded the general public and other actors such as non-humans, in addition to producing geographic exclusions. Internal resistance toward the process manifested toward the parameters and conduct of the participatory 
process, perspectives on technologies that would reduce GHG emissions, skepticism of the involvement of consultants and resistance toward costing measures. This resistance suggests that in some cases, participants negated the mediation of the process and felt their feedback was not heard or included in the process. External resistance was found in participants who held a broader critique of the City of Ottawa's institutions and adjacent inaction on climate initiatives.

\subsection{Conclusions: The Manifestation of Participation in Ottawa's Energy Evolution Strategy}

This chapter presented a descriptive analysis of the Energy Evolution participatory process using a constructivist STS frame based on the work of Chilvers and Longhurst (2016). It first analyzed the productive effects of the participatory collective. The model and conduct of participation in the Energy Evolution process was purposefully planned, professionally facilitated and invited. This represents a stakeholder strand of environmental decision-making as it is composed of invested and interested participants. This process, in turn, was built on a construct of an uninterested and unknowledgeable public that was never explicitly invited to participate. The central issue at stake was how to achieve deep GHG cuts, which are modelled by sector and pathway, and will require careful planning and technological management to be successful.

This chapter also analyzed the orchestration of participation. Enrolment of actors into the Energy Evolution process was centralized and institutional, controlled by city staff via 'stakeholder mapping'. It involved a semi-organic process of participants enrolling actors they were connected to. Participants were mediated through planned participatory designs/activities, the nature and use of the Sounding Board as a collective 
that provided input and feedback and the issue framing of GHG reductions, as well as the use of consultant modelling. The latter also mediated how participants were involved in the process.

This chapter also considered the nature of exclusions and resistance within the Energy Evolution process. Excluded were the general public and non-human actors. There were also geographic exclusions resulting from how the technical working groups operated. Internal resistance manifested toward the overall parameters and conduct of the process, perspectives on technologies, resistance to consultants and costing measures in the Strategy. External resistance was found among actors who negated the process based on their perspectives toward inaction on climate initiatives and a distrust of political processes in Ottawa.

The application of constructivist STS to Energy Evolution shows a co-production of the three dimensions of participation (Chilvers \& Longhurst, 2016) including: the model of participation, subjects and objects (see Figure 1). In Energy Evolution, the construction of the object/issue as technological, the subjects as expert stakeholders and the procedural format or configuration of participation as institutional and purposeful not only shaped participation and defined a greater participatory collective, but were consistently complementary to one another, each influencing one aspect of the collective and influencing another back. Table 6 below provides a summary of the findings in this chapter in relation to each main constructivist STS analytical theme. 
Table 6. A summary of Ottawa's Energy Evolution participatory collective in relation to the main constructivist STS analytical themes (adapted from Chilvers \& Longhurst, 2016)

\begin{tabular}{|c|c|c|}
\hline Theme & Theme subsets & Ottawa's Energy Evolution Strategy \\
\hline \multirow[t]{3}{*}{$\begin{array}{l}\text { Productive } \\
\text { Effects }\end{array}$} & $\begin{array}{l}\text { Model of } \\
\text { participation }\end{array}$ & Planned, invited, professionally facilitated \\
\hline & Participants \& public & $\begin{array}{l}\text { Participatory collective as a 'Sounding Board' } \\
\text { composed of technical experts and community } \\
\text { members as invested/interested stakeholders } \\
\text { Construct of the public as uninformed, passive } \\
\text { non-experts }\end{array}$ \\
\hline & Issue/vision & $\begin{array}{l}\text { Originally open-ended goal to develop a } \\
\text { renewable energy strategy with a one-sentence } \\
\text { directive to staff } \\
\text { Refined by participants to a multi-year program } \\
\text { to transition off fossil fuels } \\
\text { Deep GHG cuts: } \\
\text { City-wide (community) GHG reductions of } \\
100 \% \text { by } 2050 \text { (originally } 80 \% \text { before alignment } \\
\text { with IPCC) } \\
\text { Corporate (city) GHG reductions of } 100 \% \text { by } \\
2040 \\
\text { Technocratic, managerialist vision of energy } \\
\text { transitions }\end{array}$ \\
\hline \multirow[t]{2}{*}{ Orchestration } & $\begin{array}{l}\text { Enrolment \& } \\
\text { mediation }\end{array}$ & $\begin{array}{l}\text { Enrolment: Centralized \& institutional (via } \\
\text { 'stakeholder mapping'), semi-organic enrolment } \\
\text { of others } \\
\text { Mediation: Standardized participatory } \\
\text { technologies and designs, framing of the } \\
\text { Sounding Board collective \& parameters of } \\
\text { GHG reductions and consultant modelling }\end{array}$ \\
\hline & $\begin{array}{l}\text { Exclusions \& } \\
\text { resistance(s) }\end{array}$ & $\begin{array}{l}\text { - General public, non-human actors \& } \\
\text { geographic-dependent exclusions } \\
\text { - Internal resistance: parameters surrounding the } \\
\text { process, technologies toward reducing GHG } \\
\text { emissions, skepticism of the consultants } \\
\text { involved, costing of reduction measures } \\
\text { - External resistance: adjacent climate } \\
\text { initiatives, political processes and institutional } \\
\text { structures at the City of Ottawa }\end{array}$ \\
\hline
\end{tabular}

Energy Evolution is a process that was institutionally orchestrated. The issue was created and framed by political actors to create a renewable energy strategy in Ottawa. It was then delegated to city staff, who were constrained and used 'stakeholder mapping' to 
reach out to networks that had influence over the energy domain in Ottawa. As Energy Evolution progressed it "overflowed" (Chilvers \& Longhurst, 2016) its original onesentence purpose created by political actors. This involved expanding the number of participants, growing the issue-at-stake and becoming more complex. As a city staffer explained, the scope "has grown substantially". Energy Evolution is "much more detailed and technical" and "much more complex than what was initially envisioned" (City Staff B interview, 2021). It grew to a Strategy that aims to make Ottawa a city fully powered by clean, renewable energy and emit zero GHG emissions by 2050 . The Final Strategy contains a high level of detail, and what began with an initial list of 25 would grow to over 200 participants. This growing participation matters and could make a difference in achieving the goals of a sustainable energy transition in the city, as "actors play pivotal roles in sustainability transitions" where they can apply their resources, capabilities, beliefs, strategies, interests and agencies to promote change (Bjerkan et al. 2021, p. 2). In Energy Evolution, staff also invested in participatory activities and technologies, which provided a central role in mediating and organizing the participatory collective, as well as stabilizing participation and the issue-at-stake. Staff disciplined participants in a forum that focuses on a technocratic and managerialist view of energy transitions through GHG reductions via technologies. This disciplined approach was designed to increase buy-in from stakeholders and political actors in Ottawa's City Council.

Consultants also mediated participation, via their development of pathways and sectoral modelling (in addition to industry representatives who created financial modelling). These actors sped up a constrained process and provided substantive content 
to the Strategy, but also constrained and controlled participation. In addition, the development of modelling by consultants along with other traits of the participatory process created some resistance among participants, which suggests that wider dissatisfaction both arose from the mediation and disciplining of participants to a type of participation that is based on open suggestions and feedback. I also found some dissatisfaction from participants who felt their voice was not heard, suggesting flaws in the feedback mechanisms at times in the process.

Last, as a consequence of orchestration, this institutional process pacified the vision of a wider public and shut down opportunities for them to participate. Energy Evolution carried an ongoing tension throughout the process between inclusion and exclusion. On the one hand, it claimed to be an inclusive 'community strategy'. On the other hand, it focused heavily on expert and/or invested stakeholders, excluding most other actors. During participation, staff disciplined participants into a standardized and purposeful forum that focused on GHG reductions via technologies. This partial framing of deep GHG cuts via technological pathways excluded other potential issue definitions and visions for the future, such as a more equitable low carbon energy transition that also requires fundamental socio-political changes. As a contrasting and more inclusive approach, consider Lyytimäki et al.'s (2019) examination of "The Commitment to Sustainable Development 2050", a national-level initiative in Finland. They find a sustainability narrative that emphasises a holistic and long-term management approach with an aim of widespread inclusion of various actors (the public sector, companies, civil society actors, organisations and citizens) participating on voluntary basis. 
The partialities in the Energy Evolution case show the need for greater information given to participants in forums, as they should be aware of the construction and institutional context in which they are participating. But also, this particular construction and mediation of participation produced an identity of the actors involved as expert and informed, while producing an imaginary of a wider public as uninformed and passive, creating a distance between the forum and the potential concerns of the public. This rejection of the general public such as energy users and environmentally concerned citizens who have a stake in energy transitions opens an avenue for an ecological democracy analysis in the next chapter. 


\section{Chapter 7: Analysis Part II - Participation in Ottawa's Energy Evolution Strategy in Contrast to Ecological Democracy}

Whereas the previous chapter engaged with constructivist STS theory to describe the creation of participation in Ottawa's Energy Evolution process, this chapter draws on ecological democracy theory to respond to my second research sub-question: How does the participatory process in Ottawa stand up against the procedural norms of ecological democracy? This chapter argues that, Energy Evolution did not meet many of the criteria of ecological democracy, and was only partly participatory. At times, Energy Evolution was a deliberative process for its participants. However, significant deliberation was accompanied with low access and inclusiveness. Further, low accountability and transparency made the space insular and protected. In addition, high levels of transmission or influence in the beginning of the process were hampered by the enrolment of consultants (due to institutional constraints). Both internal and external constraints threaten the consequentiality of the process. All together, this analysis shows that researchers, transition advocates and political leaders/policy makers serious about participation need to challenge institutional power relations to allow the possibility of more effective sustainability transitions.

The analysis presented in this chapters uses six pre-set normative criteria, combining Dryzek (2009) and Schirmer et al. (2016), as previously outlined in the methodology chapter (see Table 2). These criteria are: access to deliberative public space, inclusive empowered space, deliberativeness, transmission, transparency and accountability and consequential decisiveness. It evaluates the Energy Evolution process against these criteria in three major sections. The first section evaluates the participatory 
space in the Energy Evolution process. This refers to any physical or non-physical (e.g., online) situation where participants were given an opportunity to contribute to the development of the Strategy. This section covers the first three criteria, which are: access to deliberative public space, inclusive empowered space and deliberativeness in examining the level of access, inclusivity and deliberation of the participatory space itself. The second section evaluates the level of influence and accountability of the process. It covers the next two criteria of transmission and transparency and accountability by examining whether participants in the Energy Evolution process influenced empowered space and whether this process was accountable to public space in Ottawa. The final section examines the consequentiality of the overall process. It considers whether and how the overall participatory process impacted the wider decisions and social outcomes from the Energy Evolution Strategy.

In response to these criteria, this chapter finds that both access and inclusiveness were relatively limited, and there was a lessening amount of deliberativeness from Phase 1 to Phase 2. It finds that the transmission or influence from participants was significant in Phase 1 of the process, but lessened in Phase 2 and transparency and accountability was low throughout the process, as it was primarily institutional. Last, it finds that while participants contributed to the legitimacy of the strategy, their influence was not the only factor that moved the Strategy forward in Ottawa and there are serious institutional, jurisdictional, budgetary and political constraints to Energy Evolution. This chapter concludes with a summary of the analysis and the implications this case-study poses for the study of participatory processes using the normative theoretical lens of ecological democracy. 


\subsection{Participatory Space in Ottawa's Energy Evolution process}

This section examines the inner participatory space of the Ottawa Energy Evolution process by looking at three criteria of: access to deliberative public space, inclusive empowered space and deliberativeness. I argue that access to the space was limited, as it was controlled in an exclusive-invitation based process by staff where growth was primarily accomplished via actors enrolling one another. Second, while it is located in a decision-making institution, Energy Evolution did not meet ecological democracy's highbar of inclusivity, as it is a future-oriented process that only considers a 'domino-effect' on other discourses and groups. Last, while there was a presence of authentic deliberation and meta-consensus in Phase 1, Phase 2 saw a significant lessening of this deliberativeness, due to a lack of resources, a lull in participation and a control of the space by consultants.

The first criterion of access to deliberative public space includes three key subaspects, the first of which is a participatory space with few restrictions on who can participate. On this criterion, I find that the participatory space of Energy Evolution was primarily exclusive to knowledgeable stakeholders, via an invitation-based and connective process. At the beginning of Energy Evolution, access was determined institutionally by city staff. One staff member referred to the initial 'stakeholder mapping exercise', as a "call out" to actors who staff deemed had power or influence over the energy domain (City Staff B interview, 2021). Several barriers to entry existed that restricted the Energy Evolution participatory space. This call out was not public, or advertised, but solely invitation-based, meaning a small amount of information about the process was available and there was no formal process to gain access or nominate actors 
to the participatory space. Staff felt that the meetings were open to anyone in the community who wanted to be involved in the process. However, those interested needed to show initiative to gain entry. For example, staff explained the case of "a community member who got forwarded an invite by a Councillor", who "never attended anything before, but a Councillor thought they might be interested because they were asking questions" (City Staff B interview, 2021). The two interviewees in this study who gained access to the participatory space outside of the stakeholder mapping process did so via connections to other actors and privileged channels, showing that they needed to be aware of the existence of the process, or be an actor 'in the know', to gain access. And whereas the total number of participants expanded greatly from Phase 1 to Phase 2, access became somewhat more restricted, as city staff resourcefully relied on already enrolled participants to use their connections to grant others access to the participatory space. Notwithstanding the barriers to entry, it is notable that access to participation was not fully restrictive. There was no cap on the number of participants in the Sounding Board, and no actors or groups were outwardly denied participation. Instead, the participants grew in a semi-organic process which staff deemed useful to contributing to the overall Strategy (City staff A \& B interviews, 2021).

This focus on technical actors was highlighted both by staff and interviews as the right approach to build the Energy Evolution Strategy. But ecological democracy is a frame that aims to include (so much as is possible) the perspectives of all entities affected by decisions in the decision-making process (Eckersley, 2004; Schirmer et al., 2016). The exclusionary approach of Energy Evolution means there is a tension between ecological 
democracy's push for inclusion and the technical nature of the discussion that occurred in this participatory forum. I return to this tension below.

The second sub aspect of access to deliberative public is a space that has few legal restrictions on what participants can say, thereby encouraging a diversity of viewpoints (Dryzek, 2009). In Energy Evolution meetings, there was no indication of any legal or strict guidelines of the input of participants. Rather, participants pointed to a cordial and open environment, with for example "a very rich exchange of ideas" (Government Subject interview, 2020). There were no legal restrictions on what participants could say and the participatory space was generally open for input from Sounding Board members. One interviewee, for example, noted the presence of a "wacko" participant that promoted unconventional ideas at certain meetings (Industry Subject A interview, 2020).

The last sub aspect under access to deliberative public space is one that recognizes that the overall success of deliberation is dependent on whether people can take an active part in the deliberation process. The Energy Evolution space was created by city staff with formal Council direction. Staff acknowledged that the Strategy's success was dependent on active participation in the process (City Staff B interview, 2021). The participatory space was first created by Council's one-sentence direction to collaborate with "community partners" in developing a renewable energy strategy (City of Ottawa Planning, Infrastructure and Economic Development, 2017).

When considering access to this deliberative public space, it is notable that Energy Evolution was created in a context of new City policy that promotes public consultation. One year before Energy Evolution's first meetings, the City published its 
Public Engagement Strategy: Guidelines and Toolkit to standardize and guide city staff in conducting public engagement activities (Bridgman \& Gakhal, 2019; City of Ottawa, n.d.-b). This Strategy urges public consultation when there is Council direction to consult the public and when it is considered that the public's input will influence the final outcome of City initiatives (City of Ottawa, 2015b). Energy Evolution was directed by Council and staff considered input important to the creation of the Strategy, showing that it was partly a result of the City's push to engage in public consultation.

Notwithstanding many opportunities for access by participants, administrative changes at the city led to reduced access to the process over time for participants. Staff were originally constrained and limited, and resourcefully created a space for knowledgeable participants to take a continuing and active part in the process to contribute to the Strategy, but in what they referred to as the 'middle of the process', there was a limited access to the space and "the least amount of public consultation in 2017 to 2018" due to the staff reorganization (City Staff B interview, 2021). Because of a change in management, the hiring of consultants, a lack of leadership and what staff referred to as a "team in disarray", three working groups were abandoned and participants were simply providing feedback sporadically rather than actively participating in the process (City Staff B interview, 2021).

The second criterion this section examines is inclusive empowered space, which measures whether the participatory process is inclusive of all existing discourses (Schirmer et al., 2016) in a space that is recognizably part of an institution producing collective decisions (Dryzek, 2009). This high threshold on inclusivity in participatory environments outlines that such processes ought to include all existing discourses 
(Dryzek, 2009; Schirmer et al., 2016) as practices, interests, or "a shared way of comprehending the world embedded in language" (Dryzek 2010, p. 31). Participation must include the perspective of several entities (physically present or not) that are affected by decisions, such as all affected others, citizens and noncitizens, the living and not-yet-born, the human and nonhuman (Eckersley, 2004; Schirmer et al., 2016). Energy Evolution was located in a recognizable participatory space and embedded in empowered decision-making institutions in Ottawa City Hall as a process formally run by staff that are responsible to the EPWWM as a decision-making committee, which itself feeds into the larger decision-making body of City Council. It was a process that was future-oriented and technically focused on GHG reductions, while acknowledging that it could potentially have a ripple effect on residents and groups within the city. It is important to note that Energy Evolution did include a wide range of stakeholders, from energy providers in the goal of including actors that represent the most emissions in Ottawa, to ENGOs (that educate and inform the public) in the goal of a future communications and public engagement for the community. However, it did not meet the high bar of ecological democracy's requirement or intent to include all existing (or "all affected" (Eckersley, 2020)) discourses in its decision-making, of for example, the general public, non-human beings, and future generations. This choice allowed the forum to maintain a technical and focused nature, resulting in an intricate and actionable Strategy.

Energy Evolution focuses on a goal of a "better future" for the City of Ottawa "and beyond" (City of Ottawa 2020b, p. 10) through emissions reductions and modelling. One way it considers other discourses is through possibility of an energy transition that 
could cause "co-benefits," or a domino effect on citizens and groups in the city that could include "local economic development and job creation, improved public health, equity and inclusion, energy security and resiliency, and mitigating future risk" (City of Ottawa 2020 b, p. 26). Instead of considering other discourses in the participatory space, the consideration of energy futures "wasn't so much the social”, but highly technical, focusing on GHG reductions (Industry Subject B interview, 2020). As one participant explained:

We haven't sat down and gone through it and gone through gender-lens to say how do these decisions affect women more than men? Or we haven't gone through with a racial-lens and said, how could this affect underprivileged communities more than it might affect other communities? (University Subject A interview, 2020).

Notwithstanding this admission, Phase 1 of Energy Evolution did briefly consider lowincome residents based on "small discussions" and "light conversations" (University Subject A interview, 2020), as Ottawa Community Housing (an organization owned by the City) was given $\$ 70,000$ to engage with its tenants and install energy savings equipment pilot green energy technologies and programs that benefits their tenants (City of Ottawa Planning, Infrastructure and Economic Development, 2017). However, this was the extent of direct consideration of the needs of low-income groups who could be affected by an energy transition in Ottawa.

Several interviewees thought that the consideration of other groups and discourses could come after the participatory process via avenues other than the Sounding Board and working groups. The Final Report takes this perspective, as it promises to consider vulnerable populations in Ottawa who have "fewer resources to take the recommended carbon reduction actions" and "experience high energy cost burdens" in the development 
of future projects, programs and policies (City of Ottawa 2020b, p. 79). The Final Report does not mention the City's Equity and Inclusion Lens Handbook (2018), which assists City staff and management to ensure that planning and program development and delivery activities are inclusive of the full diversity of residents. But it does acknowledge the Canadian Urban Sustainability Practitioners' Energy Poverty and Equity Explorer tool in addressing equity and inclusion concerns (City of Ottawa, 2020b).

Beyond the distinct perspectives of low-income Ottawa residents, another discourse (or set of discourses) left out of the process were the voices of the general public, as staff aimed to collect the advice of actors with power or influence over the energy domain. However, staff did recognize a need for a communication and education campaign for the public from the beginning, as for the City, Energy Evolution is a community-oriented Strategy (City Staff B interview, 2021). Two interviewees considered the inclusion of the broader public with one expressing the need to have "regular homeowners" who say "but if my energy bill goes up, I don't know if I'm going to be able to do this, or I'm not going to get value for this proposition that you're putting out" (University Subject A interview, 2020). And the second explained an effort in Phase 2 of the Energy Evolution process in 2019 to reach out to city staff and offer support for broader community engagement as a part of an organization they were involved with, to try to build "stronger awareness amongst the general public", explaining:

I feel that while the Sounding Board, while very knowledgeable and representative of the different movers and shakers in the community, that the work didn't necessarily get out to the average resident of Ottawa on what the plan was, its objectives [and] what it meant to the average person. (Quasi-governmental subject B interview, 2020) 
Nevertheless, this participant's attempt to garner public awareness fell short not because of the City, but due to the capacity of their own organization (Quasi-governmental Subject B interview, 2020).

Proponents of ecological democracy argue that to alleviate ecological degradation, there ought to be procedures that provide a form of voice for all those affected by environmental risk to participate in the decision-making processes that implicate them (Eckersley 2004; Plumwood 2005). This form of inclusion does not mean an opening of the floodgates for basic institutional structures of participation, such as public consultation, but more idealistic and active forms of inclusion in public deliberation. While Energy Evolution excluded groups to keep an insular, focused and technical process, the public's perception was framed as an information gap or deficit with both staff and participants holding the perspective they had little to meaningfully contribute to the Strategy and that simply providing information to the public and enabling technological changes might eventually lead them to switch from negative behaviours to sustainable practices. However, there is growing awareness amongst policy-makers and in the ST literature that the public rarely responds this way, and that ignoring the public could lead to a more costly and time-consuming energy transition (Lennon et al., 2019). As energy is ubiquitous and affects the whole community, a more inclusive space might have allowed participants to adopt a moral point of view rather than a self-interested one, encouraging ecological responsibility and justice on behalf of a broader community at risk (specifically for traditionally excluded and under-represented groups) (Eckersley, 2004). Further, it might have allowed those affected by changes in energy production and consumption have access to decision making. Including 
representatives of low-income communities as decision-makers in this process, for example, could also lessen the exposure of these more "remote" or "distant" actors to potential risks (Plumwood, 2005). One interesting method of achieving reflective deliberation is a consensus conference between experts and citizens, and experience with including citizens has shown that they have favoured stronger action to reduce GHGs than their own governments (Dryzek, 2013). In the Energy Evolution case, more public engagement might have garnered public support that could push forward the Strategy's transition goals.

The third criterion that involves the participatory space is deliberativeness, meaning a deliberative quality or nature of dialogue is present that includes an exchange of arguments where actors offer reasons for their proposals (Schirmer et al., 2016). Ecological democracy provides a valuable path for addressing environmental issues which contain "incommensurable values and perceived impossibility of achieving consensus" (Schirmer et al. 2016, p. 290) via the process of deliberation. Deliberation involves "reaching judgements and reflecting upon preferences in the context of dialogue that is informed, respectful, and competent" and communication should be "noncoercive, strive to connect any particular claims to more general concerns, and to reach others who do not share the conceptual framework of the speaker" (Dryzek 2013, p. 236).

In Phase 1, there was a high level of deliberativeness and the presence of metaconsensus in the participatory process, which was enabled by staff, who created an open space for deliberation. There was a deliberative nature or quality of dialogue, where actors provided an exchange of arguments and offer reasons for their proposals, as "input was put out there, debated, discussed [and] put forward", and "if there is a contentious 
topic, everybody got an opportunity to give their view on the topic and where made sense offered their solution" (Industry Subject B interview, 2020). Further, these solutions were "cumulative", where suggestions resulted from the collaboration of participants and no one person got credit for a suggestion (Government Subject interview, 2020). The space was also open and respectful, as the group was, "very convivial", and there were not "any all out launches or attacks on each other or anything like that" (University Subject A interview, 2020). One participant, explained the participatory forum as the following:

It's your standard group dynamics. And the city staff handled it extremely well, oh my goodness they were the smilingest group of people I've ever seen. They were very, very nice. And so were most of the participants. I don't think I ever remember somebody losing it, you know from either side or any technology (Industry Subject A interview, 2020).

The participatory space's level of deliberativeness was influenced by how staff mediated and approached the process. One representative of renewable energy explained "the worst thing you want is for people to fight, because that polarizes... You want everybody to stay friends. I totally understand [the staff's] methodology that they want to keep us friends because that way, I can talk to the gas guys", as they explained they will however "never agree with the gas guys" (Industry Subject A interview, 2020).

This high degree of consensual deliberation was possible, in part, because participants shared a goal of reducing GHG emissions. As a result of this shared goal, in meetings the overall "targets were never a topic of hot debate", but rather "what we need to do to get the targets" was contentious (City Staff A interview, 2021). One interviewee explained the difficulty of "preaching to the choir" when compiling a room full aligned people, as Energy Evolution was a process of people who are part of large organizations that are on board with the overall goal of the Strategy, but had dissent only in the minutia 
of attaining those goals, through for example, building retrofits via heat-pumps versus a district energy system or geothermal system (Quasi-Governmental Subject A interview, 2020). Staff explained that "grievances" were present in discussions but took the position that participants should "get them on the table and have a discussion" (City Staff A interview, 2021). With these differing goals, participants were not free from initial judgement on their perspectives and roles.

Having diverse voices in the room made a difference. One city staff member who was originally a Sounding Board member, initially questioned the presence of a gas representative in the participatory space, asking "what's the enemy doing here?”, but explained that hearing this representative speak changed their initial opinion (City Staff A interview, 2021). And one participant from an energy company explained that other participants had "predisposed opinions" and initially looked at them like they "had two heads", but they continued to explain that once they spoke about the different roles and energy services their company is involved in, other participants became more open to their perspective (Energy subject B \& C interview, 2020).

Reaching consensus amongst these different participants was "never a stated objective" and not sought after by staff (City Staff B interview, 2021). And participants explained that their participation never involved consensus as "there was never a vote" (Industry Subject A interview, 2020) and people did not "confirm or block consensus in any way" (University Subject A interview, 2020). This aligns with the goals of deliberative democratic theory. While traditional consensus was once thought of as "the gold standard of political legitimacy" (Dryzek 2010, p. 86), the purpose of deliberation for ecological democracy is to produce meta-consensus rather than consensus. Meta- 
consensus refers to "reaching agreement about the nature of the issue at hand, not necessarily on the actual outcome" (Niemeyer \& Dryzek 2007, p. 500, as cited in Schirmer et al., 2016). And it means recognizing the "validity or legitimacy of others" values and viewpoints on the issue at stake" (Schirmer et al., p. 290), which allows to structure continued dispute (Dryzek, 2010). There are three kinds of meta-consensus, including: normative, which involves agreement on recognition of the legitimacy of a value; epistemic, which is an agreement on the credibility of disputed beliefs and on their relevance to the norms that define the issue at hand; and preference, which consists of agreement on the nature of disputed choices across alternatives (Dryzek, 2010).

In Phase 1, Energy Evolution participants wholeheartedly agreed on a shared goal of GHG reductions, agreeing on the nature of the issue at hand. There was a growing level of normative and epistemic level of meta-consensus in the legitimacy of values and credibility of beliefs toward GHG reduction measures throughout the process. And while there were differences in participants' preferences of technologies to reach the goals of GHG reduction scenarios, there was general preferential meta-consensus towards the nature of disputed technological choices toward reducing GHGs. While meta-consensus was present and can be applied as a standard of particular participatory forums, it should "not be sought and celebrated uncritically" (Dryzek 2010, p. 15). Instead, there is a need to "pay careful attention to the deliberative qualities of the processes" that produce metaconsensus (Dryzek 2010, p. 15). In the case of Energy Evolution, the presence of metaconsensus was fostered by staff in creating an open participatory forum.

However, when Phase 2 moved to focus on modelling and was dominated by consultants, there was a "fallow period" of participation (City Staff B interview, 2021) 
which diminished deliberativeness. As one participant explained, the "views of stakeholders were well represented to the point when they switched over to the modelling exercise", where meetings involved participants, "presenting our opinions and thoughts on the model" that was developed by the consultants (Government Subject interview, 2020). But, in the "last year in a half" participants were reconvened, to assist in contributing to the Strategy. And the end of Phase 2 toward the Final Report saw a beginning of the return to the deliberative approach that staff employed in Phase 1 of the process. Nevertheless, as a whole, staff purposefully enrolled similar and technical stakeholders to the process, which created a trade-off between access and inclusiveness versus deliberativeness by forming an alike group with an expert focus on the issue. Mediating the group in an open and accepting way led to an increase in participants viewing each other as legitimate and accepting each other's perspectives, which raised the level of meta-consensus and broadening the process to be more accessible and inclusive could have threatened this level of focused deliberativeness and metaconsensus.

This section has shown that Energy Evolution is a space with key cleavages. It is a space purposefully exclusive to technical actors, but on that did not have any legal restrictions. It was created by a City push for increased participation, but administrative changes at the City that reorganized staff reduced access significantly. Further, while it is located in an institutional decision-making body and it includes a diversity of organizations, it did not fully include other potentially affected or at-risk groups. Staff and expert participants alike mostly took the position that these groups would become part of Energy Evolution's program roll out at a later date. This exclusion allowed the 
formation of an "alike" group of participants who perceived a value to deliberation, allowing the formation of meta-consensus in Phase 1, though this meta-consensus ultimately diminished in Phase 2 with the enrolment of consultants.

\subsection{Influence \& Accountability in the Energy Evolution Participatory Process}

Whereas the previous section examined the participatory space of Energy Evolution, this section looks at the procedural effects of the process. First, it considers the level of transmission in the process by looking at whether there are means by which the deliberative participatory space influenced the empowered space - with the latter referring to a forum for collective decision making (Dryzek, 2009). More simply, it examines the extent to which the participants in Energy Evolution, and the process they were part of, had an effect on the Strategy. Building on points already introduced in Chapter 6 on Energy Evolution as a participatory process, I argue that Phase 1 of the Strategy included significant influence from participants, who provided visionary guidance and parameters to the plan as well as contributing to the design of their own participation. However, this influence lessened in Phase 2 primarily due to institutional constraints, which led to less influence by participants compared to consultants and industry representatives. This section then examines the level of outward accountability and transparency of the participatory process, examining whether the empowered Energy Evolution space in the City of Ottawa is accountable to the public. I argue that while the Strategy was institutionally accountable and transparent, both were limited overall throughout the process.

Phase 1 focuses heavily on Energy Evolution as a Strategy that is communityoriented (City of Ottawa Planning, Infrastructure and Economic Development, 2017). 
According to one participant, it "reflected the views of the community in a very fair way" (Government Subject interview, 2020). In this Phase, as discussed in Chapter 6, section 6.1.3, participants helped set the vision and parameters of the Strategy, where they renamed the renewable energy strategy to 'Energy Evolution', developed a vision for the Strategy of Ottawa as a "city powered by clean renewable energy", and determined that Energy Evolution ought to be a "multi-year program with short- (2020), medium- (2031) and long-term (2050) deliverables" (City of Ottawa Planning, Infrastructure and Economic Development 2017, p. 27). Participants also conceptualized the Sounding Board as "being a place where all ideas came back to" and provided input on how to divide working groups, which gave direction on how their own participation would be designed (City Staff B interview, 2021). One staff summarized the contribution of participants in this stage as:

My recollection is they very early on helped to wordsmith... well it was more than wordsmithing. They helped to give language around what we're trying to do and were even involved with things like, 'what's our Energy Evolution symbol going to be?' And the fact that we were going to have a governance structure involving the community. Those were kind of the big early things. (City Staff A interview, 2021)

This early stage was referred to by city staff as the "consensus stage." It was used to generate a high degree of internal buy-in from participants (City Staff B interview, 2021). After this, the Sounding Board and working groups examined baseline energy-use in Ottawa, including the costing of energy and the pathway studies (City Staff B interview, 2021). Input from participants was used to build a draft pathway document of conservative, medium and aggressive scenarios for GHG reductions, where staff decided pathways based on what they heard in the discussion, explaining: 
We would often edit the section on actions to take to advance the pathway based on what we would hear in the discussion. Because things would come up and from the discussion some you'd stroke off because everybody would say 'no, no, no, that's not really an issue', some would but more would appear. And then that led to how ultimately the model was built. (City Staff A interview, 2021)

At this point in the process, input from participants was "critical" for staff toward showing "what kind of pathway we could take to get our target of 100 per cent of reductions by 2050" (City Staff B interview, 2021).

However, from 2017 to 2018 when there was a reorganization of staff in the city and a lull in participation due to a change in management with a different approach to Energy Evolution and a lack of budget and resources, the influence of participants on the Strategy became much lower than in Phase 1. In Phase 2, staff began to take the pathways informed by Sounding Board members and working groups to develop GHG reductions modelling toward the Final Strategy (City of Ottawa, 2020b). To do this, a hired consultant (SSG) worked on integrating these pathways into GHG modelling (City Staff B interview, 2021). A city staff member explained the process behind using the pathways to build a GHG reductions model, where consultants had to "tweak the pathways" and consider what was aggressive to build the 80 per cent reduction scenario (City Staff A interview, 2021). Further, during the shift to the one hundred per cent scenario, there was a lack of time to "redo the pathways", but staff and consultants had to create measures themselves that "go beyond aggressive and create a couple more ways for us to get to a hundred per cent" (City Staff A interview, 2021). The model's transition to one hundred per cent was decided by staff and consultants rather than participants, where staff for example "looked at what we thought the appropriate split would be between wind and solar", finding that it is "roughly 3 times more wind than solar" (City Staff A interview, 
2021). But with a community tapped into more solar than wind, staff explained participants were "very surprised", and this was an example of when references were sent to justify a decision to the group (City Staff A interview, 2021). One interviewee took major issue with this modelling, arguing that "the model does not reflect a consensus", but rather "the model is the opinions of a hired consultant who did research, but had provided their opinion" (Government Subject interview, 2020).

...when the modelling came along that seemed to be more done in a vacuum. So, the points of input weren't as broad and open as the first study. And I think that the consulting team that did the second study had some sort of ideological parameters that they working with that I think you could see in the work. (Government Subject interview, 2020)

After this modelling, staff were directed to complete a financial analysis of the Strategy, and explained that for this, "the participation went less to working groups at a whole, but more to targeted industry representatives" (City Staff B interview, 2021). For example, revenue that could be generated via RNG was look at both public and private natural gas developers; estimates of retrofits for the community were done via building industry organizations; and two industry organizations related to renewable energy looked at potential revenue that could be generated via renewables (City Staff B interview, 2021). City staff also took peer-reviewed literature on finances and applied them to Ottawa (City Staff B interview, 2021). One area that participants contributed to in Phase 2 was the proposed 20 projects in the Final Strategy, but staff explained that this only comprised "a couple [of] meetings" in 2020 (City Staff B interview, 2021).

Overall, Phase 2 of Energy Evolution as a whole saw a low level of transmission by participants, as GHG reductions modelling were built by staff and consultants and financial estimates were gathered by industry representatives. Most interviewees were 
simply unaware that this shift occurred, whereas some were accepting, for example, explaining "it's very difficult for you to write that plan in a committee situation" because "eventually someone, somewhere is going to sit down... you know the consultants and parties within the city and say okay these are the scenarios" (University Subject B interview, 2020). However, others were against a move to consultants and industry representatives. This shift towards consultants shows that in the latter stage of the process, participants had significantly less influence on the Strategy.

The second criterion this section examines is transparency and accountability. The empowered participatory space's accountability to transparent public space in Energy Evolution was highly limited, as it was only accountable and transparent to public space via standard political and institutional mechanisms in the City of Ottawa. Energy Evolution was processed through institutional structures within the City of Ottawa, as it was first presented to the EPWWM followed City Council at various stages. Staff were beholden to these institutional structures as resolutions and timelines to make reports came from the EPWWM and Council. And for staff, it was "accountable to the public through their Councillors" (City Staff A interview, 2021). For example, some interviewees took the position that "if people have problems, they could have gone to Council meetings and made requests, they could have written to the Environment Committee, and they could have had their say at those sorts of levels" (University Subject A interview, 2020).

In addition to these institutional mechanisms, for some participants, accountability stemmed from the publication and public visibility of Energy Evolution documents which began during Phase 1 in 2017, one year after the process began. As of 
that point, people could read documents via the City's Council and Committee Meetings Portal. It is notable that while there was a list of Sounding Board participants by organization first released with the publication of Phase 1 (see Appendix A), there was "never a list of Energy Evolution people released to the public" that divided individuals by technology or interests" (Industry Subject A, personal communication 2020). In addition, Sounding Board meetings and working groups were conducted in private, with no minutes or transcriptions of what was said at meetings. One participant explained that "I think it's possible to find information about it, but unless you were actually engaged as a Sounding Board and related groups, I'm not sure that the average person would be aware of the goals and the process to develop the plan" leading them to "feel like there has been limited public engagement" (Quasi-Governmental Subject B interview, 2020). Nevertheless, both staff and participants explained that they thought this public engagement would come after the publication of the Final Energy Evolution Strategy in 2020, with staff explaining a problem with communicating a complex Strategy to the public and explaining that they “don't feel like we've been at a place where we can be publicly accountable to the public at large" (City Staff B interview, 2021).

Notwithstanding this point about the public at large, staff did think they were accountable to participants that were involved, explaining "I think we should have been accountable to the people who have engaged in process and I think throughout the project we have been more or less accountable..." (City Staff B interview, 2021). However, there was also a lack of transparency to participants. First, participants were unclear on how their input was used and how decisions were made in the process. One participant explained that staff were "very open about input" and "transparent about how they use 
our information, but could not recall the tools used for decision-making (Government Subject interview, 2020). Another participant explained they were unsure of "how we got processed and analyzed behind the scenes", explaining:

It was a good endeavour. I think it's like any other process, I wish I could see the step-by-step of every decision and I wish I could see the business model breakdown of why one thing got accepted and the one didn't so I could understand the difference between an economic decision and a political decision. But that's a lot of work, that's hard and sometimes that's things that best not always see the light of day. (University Subject A interview, 2020)

Another participant explained that "there were no real decisions" made in the participatory forum (Industry Subject A interview, 2020). Second, participants were confused about the steps of the Strategy and aspects related to transparency and accountability. Some, for example, explained that they "don't actually know what steps were taken to reach out to the public" (Government Subject interview, 2020). Others were "not sure if that part of the process has come yet" (University Subject A interview, 2020), maintaining that public engagement is a forthcoming objective, though they were confused about the timeline of the process.

Right before Energy Evolution's Final Report went to City Council in October 2020, public consultation did begin. In summer 2020, Energy Evolution was given an Engage Ottawa webpage. In August 2020, the City held two public information sessions on Energy Evolution (Engage Ottawa, n.d.). Further, staff provided examples of "a newsletter with almost 5,000 subscribers that we are sending tips and tricks and updates to" (City Staff B interview, 2021). However, one participant pushed back on this, arguing "I think if it's actual genuine consultation and engagement then I think it's too late just to release a strategy and say, "well what do you think of this?"” as, they explained "by then 
everything has been decided" (University Subject B interview, 2020). But this participant also considered the longevity of Energy Evolution as a 2050 Strategy, with potential ongoing consultation (University Subject B interview, 2020). Staff are "identifying where we are going to need input from the public" as an ongoing process and took the position that the Final Strategy is accountable to the City's institutional and political bodies due to the presence of annual reporting via status updates and rerunning the energy and emissions model every five years (City of Ottawa, 2020b). Supporting this point, staff also explained that these are, ultimately "hollow" commitments, due their recency (City Staff B interview, 2021).

On one hand in Energy Evolution, there was limited accountability and transparency to the public, but also to participants involved in the process. On the other, participants and staff suggested that formal institutional democratic processes of government and consultation would begin, which would alleviate concerns of a lack of public engagement in the process up to 2020. For Dryzek (2013), this move is representative of a discourse of "democratic pragmatism," which involves "interactive problem solving within the basic institutional structure of liberal capitalist democracy", through for example, public consultation (e.g., environmental impact assessments) (p. 99). In contrast to democratic pragmatism, ecological democracy holds that a legitimate governance structure depends on the right, opportunity and capacity of those subject to a decision to participate in the deliberation about that decision (Dryzek, 2013) and take an active role in doing so. In the Energy Evolution process, this level of inclusion was not established, and means that there was a low level of transparency and accountability according to ecological democracy theory. This lack of transparency and accountability 
resulted in an insular and focused process, which simultaneously meant there was a severe lack of public awareness of Energy Evolution. A more idealistic form of engagement that actively brings in, for example, a "green public" (Eckersley, 2004) that is informed and ecologically sensitive, could have generated greater pressure for action on Energy Evolution as a transition initiative. It is worth noting that such forms of engagement would have their own practical challenges, and could likely not have been achieved with the budget and staffing associated with Energy Evolution.

The generation of accountability is "key for the generation of broad deliberative legitimacy for collective outcomes” (Dryzek 2009, p. 1386). And for Dryzek (2009), institutions such as "a legislature, a corporatist council, sectoral committees in a corporatist system, a cabinet, a constitutional court, or an empowered stakeholder dialogue... might also act as accountability mechanisms" (Dryzek 2009, p. 1385). Energy Evolution's accountability and legitimacy were created by the existence of the process and the traditional institutional mechanisms that is situated in, where the possibility for the public to gather information and/or scrutinize the Strategy is via City resources and institutions. But this institutional approach is severely limited in the eyes of ecological democracy. Further, while public scrutiny of the deliberative process provides an effective tool for legitimization (Schirmer et al., 2016), throughout the process there was a low level of accountability and transparency, which led to a lack of overall scrutiny. Further, while staff felt they were accountable to the participants involved, there was little transparency towards them in how decisions were made and information regarding the timeline or progress of the Strategy, with participants unsure of when public engagement would occur. Nevertheless, this low openness and transparency of Energy 
Evolution's participatory environment (as demonstrated by the restriction of participants, lack of public information on who was participating and lack of reporting on the content of the negotiations), this was still a participatory process that achieved more than it might have if it had entirely been executed by staff and consultants. Energy Evolution's participatory space was simply an insular environment that included a small base of participants and a very technical level of deliberation.

\subsection{The Consequentiality of the Energy Evolution Participatory Process}

According to ecological democratic theory, the elements above ought to lead to a level of consequential decisiveness, or an impact on decision-making and/or social outcomes. This section examines the extent to which participants had an effect on public policy outcomes and considers the extent to which participation and the production of Energy Evolution created an impact on the wider social and political environment in Ottawa. It argues that while participants lent legitimacy and support to the Strategy, their influence was not the only factor that moved the Strategy forward in Ottawa and there are serious constraints (institutional, jurisdictional, budgetary and political). The evidence shows that this is a typical case of the need for sustainability advocates, researchers and political leaders/policy makers to engage with multiple facets of power relations in transitions to ensure greater consequentiality for a process like this. And those who initiate and maintain transitions (e.g., political leaders and staff) ought to aim to empower actors to have more influence on sustainability processes.

First, whereas participants lent legitimacy and detail to the Strategy, they did not solely impact the consequentiality of Energy Evolution's approval on October 28, 2020 by City Council. Participants had differing perspectives on how their input was used and 
the range of their influence on the Final Strategy. For some, their views, ideas and suggestions were reflected in the Final Strategy, while for others, they had only provided a small amount of influence and were not convinced they had made any significant impact. Nevertheless, as a whole, participants provided concreteness and bolstered support for the plan. One participant explained "I think our participation showed great support and gave them the confidence to be able to put forward specific proposals" (Quasi-Governmental Subject A interview, 2020). Staff explained that Energy Evolution provides "a solid integrated plan as opposed to notional things", which were preferred by Councillors "so they could put their support behind it" (City Staff A interview, 2021). Staff were surprised as Councillors who they thought lacked interest became "fans" of the Strategy (City Staff A interview, 2021). During City Council's October 28 vote, one skeptical Councillor asked for proof of the support of organizations for Energy Evolution, taking the position that this was needed before an ask for billions of dollars (Ottawa City Council, 2020b). But, at the EPWWM meeting before this on October 20 2020, 24 individuals representing various organizations expressed verbal and written support for the Final Energy Evolution Strategy (see Appendix E). Energy Evolution reflects a "stakeholder strand of participation", which assumes that the informational basis of decision-making improves due to the varied perspectives of organized groups. In this strand, stakeholders add legitimacy leading to better decisions that are more likely to be implemented (Meadowcroft, 2004). The Sounding Board and working groups provided this legitimacy and buy-in to help push Energy Evolution forward as staff could "point to a robust level of engagement" in the Strategy, showing that they "not develop this in a vacuum" (City Staff B interview, 2021). 
But while participants added a level of concreteness and legitimacy to the Strategy, their participation was not the sole cause of the Strategy's approval. One city staff member expressed the sentiment that they were "not convinced that [participants] were as critical as the science or the media", which were "more important in advancing Council than public pressure". While the Sounding Board and working groups "were critical in informing and shaping the documents and providing the credibility that this had not been developed in isolation", global scientists and IPCC reports, public protest, and media influence were "more important in moving and influencing Council's thinking than the Sounding Board and the working groups" (City Staff B interview, 2021). This data suggests that participation does not have a simple directional influence on consequentiality.

Consequentiality is not only contingent on participants, as there are also several serious internal and external limitations to the potential consequentiality of Energy Evolution, including: institutional, jurisdictional, budgetary and political constraints. First, staff faced serious institutional constraints during the Energy Evolution process. In some cases, these were from City's institutional and bureaucratic processes, which limited the feasibility of recommendations by participants (Industry Subject A, interview, 2020). Staff explained that they cannot make the "procurement bylaws and administrative requirements go away", but questioned whether "they still serving us in the context of a climate emergency" or whether there is "enough information to make decisions without all of that administrative red tape?" (City Staff B interview, 2021). Further, while the Final Strategy outlines it was developed with six City departments (City of Ottawa, 2020b), staff explained they "only had direct control over our process and our project", 
and while they would "share the feedback with other departments, but it was up to them to decide how to use it" (City Staff B interview, 2021).

More importantly, institutional constraints led to a delay in the tabling of the Final Strategy as staff admitted the reorganization of staff during Phase 2 "was slowing things down" (City Staff A interview, 2021). This reduction in staff was not abnormal for the City, as it has reduced staff in "other key environmental initiatives over the years" (Ecology Ottawa 2019b, p. 6). And Energy Evolution is a process that faced perpetual staffing and resourcing constraints. In 2015 it began with a lack of resources and budget and was led by only one staff member. In 2018, the draft budget added no new full time staff positions to Energy Evolution (Ecology Ottawa, 2017). In 2019, the Energy Evolution team only grew to two people (City Staff B, personal communication 2021). By 2021, the team grew to seven employees with "environmental program and project managers that each have their own areas" they are responsible for, in addition to "a planner who can manage all of the land-use considerations, and "a communications outreach coordinator" (City Staff B, personal communication 2021). Nevertheless, even with an increased number of roles, staff admitted "we still do not have that much capacity", comparing the team to major Canadian cities such as Toronto and Vancouver who have "both had more than 90 staff members who are working on this file" (City Staff B, personal communication 2021). The allocation of additional staff to Energy Evolution could have significantly impacted the consequentiality of the process.

Energy Evolution is still constrained by a capacity issue and reliant on the input of community members and stakeholders. A well-connected participant raised the perspective that "at one point, it was proposed that Energy Evolution would not be solely 
under the City of Ottawa. [Instead], the City would be a partner and the stakeholders would have more control, but this never went through due to logistical reasons" (ENGO Subject interview, 2020). Staff explained that this "was put out there from the beginning" and have "always felt that governance for Energy Evolution should not necessarily be grounded at the City" (City Staff A \& B interviews, 2021). Because Energy Evolution is intended to be a community-wide project with a risk that "the City does not have control and no one entity has control", staff outlined a need for "community partners to step up in real ways" and explained a commitment to a governance structure that includes participants as part of the City's Climate Change Master Plan as "it will be critical for us to have the technical expertise and experience of those stakeholders in shaping the programs themselves" (City Staff B interview, 2021). And the Final Strategy outlines that, the City's ability to meet GHG reductions targets is "contingent upon senior levels of government, stakeholders and partners to commit to action within their specific jurisdictions (i.e., utilities, housing, development industry, etc.)" (City of Ottawa 2020b, p. 32). The Final Strategy explains that "everybody has a role to play" (City Staff B interview, 2021). The greater inclusion of actors in more influential roles could also lead to greater consequentiality for Energy Evolution.

Second, Energy Evolution is bound by significant jurisdictional constraints. As a municipality, the City's jurisdiction over GHG reductions is severely limited. The Final Energy Evolution Strategy does not ignore this, as it recognizes "there are limitations to the extent of power that can be exerted by local government", such as from financial resources, jurisdictional barriers and conflicts with regulatory requirements from other levels of government" (City of Ottawa 2020b, p. 32). And each sector used toward 
reducing GHG emissions in the Strategy (land use and growth management, new and existing buildings, transportation, waste and renewable natural gas and electricity) is prefaced with jurisdictional limitations (City of Ottawa, 2020b). As city staff explained "only five per cent of the emissions are under direct city-control", and "maybe we can influence half and about the other half are pretty hard for us to steer the ship on" (City Staff A interview, 2021). And regarding internal emissions, staff explained that "we do not have good electric garbage trucks and snowplows yet" as "the market has not quite matured enough to respond to this" (City Staff B interview, 2021). Participants explained that the City's ability to manage emissions is limited, where they do not "have the ability to walk up to private businesses and force them to be carbon neutral" (University Subject A interview, 2020) and cannot give rebates for solar panel installation such as the federal and provincial governments (Industry Subject A interview, 2020). One city staff member explained for example, that " 20 per cent of the emissions that we are going to need to make are only from personal electric vehicle purchases", but the City has "no control over the personal purchasing decisions that people make when they are buying a new car" (City Staff B interview, 2021). Rather, as the lowest level of the government, one participant explained that "the City is a cheerleader", and must lobby other levels of government (Industry Subject A interview, 2020). Staff explained that the Strategy openly addresses jurisdictional constraints, but managing these constraints could have an impact on the consequentiality of the process.

Third, budget allocation towards Energy Evolution is a constraint that touches both the inner institutional capability and consequentiality of the wider implementation of the Strategy, relating to how the City can leverage funds from various places such as 
other levels of government. Energy Evolution's budget has been the most contentious topic amongst both participants and Councillors, with one Councillor at the Final Strategy's vote questioning the realistic nature of committing to Energy Evolution, by challenging the ask of 57.4 billion dollars and framing it as almost equivalent to 14 City budgets, explaining that the public needs to know if it is possible (Ottawa City Council, 2020b). For staff, the release of financials was "internally contentious" as Ottawa was the first municipality in Canada to release these funding estimates, and it represents money the City does not have (City Staff B interview, 2021). The Final Strategy lists a variety of sources of potential funding toward success in emission reductions, such as, future year funding commitments by the City, revenue streams, private capital sources, funding from senior levels of government (provincial and federal), and the City's ability to debt finance projects (City of Ottawa, 2020b). Nevertheless, the Strategy also outlines that it is "unknown at this time what level of financial support and timing of investment is to be expected by other levels of government" (City of Ottawa 2020b, p. 92-93). Further, a significant constraint of Canadian federalism is that Canadian municipalities such as Ottawa are explicitly prohibited from running deficits in their operating budgets by provincial legislation (Policy Options, 2007).

Future financial challenges associated with implementing this energy transition strategy are reflective of the financial challenges that this initiative faced from the get-go. Energy Evolution was funded $\$ 500,000$ in 2018 . Then, in 2019, funding was reduced to $\$ 150,000$. The Draft 2020 Budget allocated $\$ 70,000$ while simultaneously providing \$66.2 million for road growth projects in the City (Ecology Ottawa, 2019a). The 2021 City of Ottawa budget allocates three million dollars in Energy Evolution initiatives 
toward enhancing and retrofitting facilities reducing energy use costs and greenhouse gas emissions (with $\$ 2.6$ million coming from the Hydro Ottawa dividend rather than directly by the City), but it simultaneously allocates $\$ 57$ million to continue to fund road growth projects (City of Ottawa, n.d.-c; City of Ottawa News, 2020a). In summer 2020, two million of this funding for the City's toward Energy Evolution was proposed to be clawed back due to financial shortfalls from the COVID-19 pandemic, but activism and public pressure from Ottawa-based non-governmental organizations contributed to its restoration (For Our Kids, 2020). There are serious risks to implementation if there is a lack of funding toward Energy Evolution, and the evidence shows that inadequate funding has been the norm to date.

Last, the City's political institutions pose a severe constraint to Energy Evolution, with Councillors and politicians needing to get behind Energy Evolution to ensure its success. In Energy Evolution's vote, Councillor Hubley expressed confusion with the vote and opposition to the vote as a potential funding commitment (Ottawa City Council, 2020b). And Councillors have a history of not knowing precisely what they are voting for, due to an institutional structure that delegates staff to deal with the details of projects (Chianello, 2021). But as actors in positions of power, they are a barrier to environmental initiatives, as Ottawa's City Council has historically not seen as an environmentally progressive body, and there has been a lack of environmental leadership from political actors (Barnes, 2018). And in Energy Evolution, the City's political and managerial leadership was a barrier to the Strategy, as a lack of funding hindered the Strategy's consequentiality and kept it insular, which lowered its overall awareness amongst the general public. 
Research suggests that "if a municipality does not have an established track record on implementing effective environmental policy and is not supported in this by its electorate", then "it is unlikely that its politicians will be ready to move forward with the aggressive policies necessary" (Jaccard et al. 2019, p. 9). Ottawa's City Council is composed of "different wards with different councillors and different political leanings" as a "very divisive council in which an urban core typically votes as a unit, and a suburban and rural core are often not with them" (City Staff B interview, 2021). And staff are faced with the possibility of a changing Term of Council and priorities with the four-year municipal cycle and an election in 2022, which could limit Energy Evolution as an ongoing Strategy to 2050 (City Staff B interview, 2021).

As a future-oriented Strategy, the consequentiality of this process is far from settled. It begins with a goal to implement 20 projects from $2020-2025$ that contribute to the one hundred percent scenario. However, my ecological democracy analysis shows that participation does not have a simple directional influence on the consequences of a process. Rather, consequentiality is highly complex and multidirectional, and is affected by many internal and external factors. This case begs an engagement with multiple facets of power relations in transitions. And in this case, sustainability advocates, researchers and political leaders/policy makers addressing these constraints (institutional, jurisdictional, budgetary and political) could ensure greater consequentiality for a process like this. And those who initiate and maintain transition processes ought to empower actors that could alleviate these concerns, thereby increasing the chance of a successful sustainable energy transition. 


\subsection{Conclusions: Energy Evolution \& Ecological Democracy}

Energy Evolution was never intended as participatory process that explicitly set out to follow the pre-determined ideals of ecological democracy. It came after the publication of official policy by the City to engage in public consultation, showing that in principle, consultation is important to the City. Further, it was guided by political direction to develop "in collaboration with community partners" (City of Ottawa Planning, Infrastructure and Economic Development 2017, p. 4). As a result of this formal direction and institutional limitations in resources and budget, staff designed a participatory space that allowed for a contribution by individuals and organizations toward an energy transition plan in Ottawa. All of these factors mean Energy Evolution is still fit for an analysis in accordance with ecological democracy theory.

This Chapter analyzed Energy Evolution according to six pre-set criteria of ecological democracy using Dryzek (2009) and Schirmer et al. (2016). It first explored the participatory space in the Energy Evolution process. Access to deliberative space was relatively limited, as it was institutionally controlled by staff in an exclusive-invitation process and its growth was primarily accomplished via actors enrolling one another. However, there was no cap on the number of participants and no groups or individuals outwardly denied, and no legal restrictions on what participants could say. Energy Evolution created and fostered a participatory space where participants actively participated in the process during Phase 1, but Phase 2 saw access diminish. Second, it examined inclusivity in the process and found that while participation was located within a recognizable decision-making institution and included a variety of organizations, Energy Evolution was highly technically focused, exclusive and future-oriented, and only 
considers a 'domino-effect' on other discourses/groups. In turn, it does not meet the high bar of ecological democracy's requirement of including all existing discourses in its considerations. Third, it examined deliberativeness, finding a high level of authentic deliberation and argument in Phase 1 with the presence of meta-consensus, but a lessening of this deliberativeness in Phase 2 due to a lack of resources, a lull in participation and a control of participation by consultants. Fourth it examined transmission, finding a high-level of influence by participants toward the vision, parameters of the Strategy and the contents of energy analysis and pathway studies in Phase 1. But, Phase 2 saw a severe reduction of this transmission as staff, consultants and industry representatives contributed to the modelling and the financial analysis rather than participants. Fifth, the transparency and accountability of the Strategy was found primarily via formal institutional mechanisms, but there was little public information available and little transparency toward participants, who were unaware of procedural aspects surrounding the Strategy's timeline. Last, it examined consequentiality, finding that while participants contributed to the legitimacy of the Strategy, their influence was not the only factor that moved the Strategy forward in Ottawa. And Energy Evolution faces serious constraints that show it is a case that displays the need for sustainability advocates, researchers and political leaders/policy makers to engage with power in transitions. Further, the political leaders who initiate and maintain these processes ought to empower the participating actors to have more influence. Table 7 below provides a summary of these findings in relation to each ecological democracy criterion.

A system with a high deliberative capacity features authentic deliberation in public space, empowered space, transmission and accountability and ought to be 
inclusive and decisive (Dryzek, 2009). Nevertheless, "real world political systems will fall short to greater or lesser degrees, and they may conceivably miss one or more elements entirely" (p. 1387). And the ecological democracy criteria used to describe and evaluate real-world deliberative systems constitute a "starting point" (Dryzek 2009, p. 1387). Similar to Schirmer et al. (2016), this analysis of Energy Evolution in accordance with the theory of ecology democracy shows that trade-offs were necessary between criteria, and not all of them could be satisfied equally and simultaneously.

The analysis of Energy Evolution showed that the criteria of ecological democracy are interdependent and overlapping. They are also constantly changing through participatory processes and not static, contributing to a need to evaluate the intricacies of participatory processes over time. For example, higher deliberativeness in Energy Evolution (particularly in Phase 1) was a result of lower access to inclusiveness in the participatory space and low accountability and transparency, which led to an insular environment and a higher technical level of discussion. Meta-consensus was also achieved in the process not only from the reduction of some criteria in favour of others (such as sacrificing inclusiveness), but by the purposeful design of the participatory space by staff, who invited highly (technically) specialized participants with similar goals and fostered an open environment that increased participants' acceptance of the validity of others' viewpoints. At this stage in Energy Evolution, including more perspectives (such as the public) would have likely slowed down the process and reduced the Strategy's competency and actionability. But using ecological democracy shows that fostering greater public engagement could have increased awareness and helped push Energy Evolution's transition goals, via an informed and ecologically aware public. 
The analysis of consequential decisiveness in this case shows that the influence of participatory processes do not exist in a vacuum and there is need to pay specific attention both to the internal and external factors that could influence outcomes. Energy Evolution is a case that requires researchers and transition advocates alike to consider the role of power relations in transitions. This particular process remains seriously hampered by a number of constraints. It is institutionally constrained by a severe lack of staff and budget allocation. It is constrained by a lack of jurisdiction over energy by Canadian municipalities. And it is constrained by unwilling political actors. These constraints beg for a more active involvement of stakeholders and publics in helping address these constraints to forward energy transition goals, as discussed in the conclusions to this thesis. 
Table 7. Summary of the Energy Evolution participatory process against the norms of ecological democracy (adapted from Schirmer et al., 2016)

\begin{tabular}{|c|c|c|c|c|c|c|c|}
\hline \multirow{2}{*}{$\begin{array}{l}\text { Energy } \\
\text { Evolution } \\
\text { Phase }\end{array}$} & & \multicolumn{6}{|c|}{ Assessment against deliberative criteria } \\
\hline & & Access & Inclusiveness & Deliberativeness & Transmission & $\begin{array}{c}\text { Transparency \& } \\
\text { Accountability }\end{array}$ & Consequentiality \\
\hline \multirow{2}{*}{$\begin{array}{l}\text { Phase 1 } \\
2016-2017\end{array}$} & Level & Low to medium & Low to medium & High & High & Low & Low to medium \\
\hline & Description & $\begin{array}{l}\text { - Access was } \\
\text { controlled privately } \\
\text { by city staff in } \\
\text { mapping and } \\
\text { inviting relevant } \\
\text { stakeholders to the } \\
\text { Sounding Board } \\
\text { - Some members } \\
\text { gained access } \\
\text { outside this } \\
\text { invitation process, } \\
\text { but this was via } \\
\text { showing interest } \\
\text { and access was } \\
\text { granted by either } \\
\text { making or forming } \\
\text { connections (e.g., } \\
\text { via actors, } \\
\text { Councillors, or } \\
\text { committees) } \\
\text { - No legal } \\
\text { restriction on what } \\
\text { participants could } \\
\text { say }\end{array}$ & $\begin{array}{l}\text { - EE was located in } \\
\text { a recognized } \\
\text { institutional space } \\
\text { making decisions } \\
\text { - It did include } \\
\text { stakeholders (e.g., } \\
\text { ENGOs) that } \\
\text { inform and educate } \\
\text { the public } \\
\text { - But it did not } \\
\text { meet the high-bar } \\
\text { set by ecological } \\
\text { democracy of } \\
\text { including all } \\
\text { existing discourses } \\
\text { - EE is future- } \\
\text { oriented Strategy, } \\
\text { considering } \\
\text { technical GHG } \\
\text { reductions and } \\
\text { only considers } \\
\text { potential domino } \\
\text { effects on } \\
\text { residents/groups }\end{array}$ & $\begin{array}{l}\text { - Technical } \\
\text { stakeholders } \\
\text { exchanged } \\
\text { arguments in a } \\
\text { respectful } \\
\text { participatory space } \\
\text { - The level of } \\
\text { deliberation was } \\
\text { influenced by the } \\
\text { enrollment and } \\
\text { mediation of } \\
\text { participants } \\
\text { - Meta-consensus } \\
\text { (normative, } \\
\text { epistemic, } \\
\text { preference) present } \\
\text { in this Phase }\end{array}$ & $\begin{array}{l}\text { - Phase } 1 \text { focused } \\
\text { on a community- } \\
\text { oriented strategy } \\
\text { - Participants } \\
\text { focused on high- } \\
\text { level ideas and } \\
\text { aided in framing } \\
\text { and setting the } \\
\text { parameters of the } \\
\text { Strategy, including } \\
\text { assisting in some } \\
\text { of the participatory } \\
\text { design } \\
\text { - Participants also } \\
\text { assisted in } \\
\text { examining baseline } \\
\text { energy and } \\
\text { pathway studies, } \\
\text { critical to modeling } \\
\text { GHG reductions }\end{array}$ & $\begin{array}{l}\text { - EE was } \\
\text { accountable via the } \\
\text { political/institution } \\
\text { al mechanisms } \\
\text { within the City of } \\
\text { Ottawa } \\
\text { - Documents were } \\
\text { posted publicly } \\
\text { throughout the } \\
\text { process and a list } \\
\text { of organizations } \\
\text { involved was first } \\
\text { made public upon } \\
\text { the release Phase } 1 \\
\text { - But invitations } \\
\text { were exclusive, the } \\
\text { content of the } \\
\text { meetings was never } \\
\text { released and little } \\
\text { content was overtly } \\
\text { advertised to the } \\
\text { public }\end{array}$ & $\begin{array}{l}\text { - See transmission, } \\
\text { participants had } \\
\text { influence largely } \\
\text { on the planning of } \\
\text { the Strategy, e.g., } \\
\text { feasibility, } \\
\text { connectivity \& } \\
\text { funding } \\
\text { - Phase } 1 \text { saw } \\
\$ 300,000 \text { of pilot } \\
\text { funding, but only a } \\
\text { hypothetical } \\
\text { commitment to use } \\
\text { Hydro Ottawa's } \\
\text { dividend (which is } \\
\text { not direct City } \\
\text { funding) }\end{array}$ \\
\hline
\end{tabular}




\begin{tabular}{|c|c|c|c|c|c|c|c|}
\hline \multirow{2}{*}{$\begin{array}{l}\text { Energy } \\
\text { Evolution } \\
\text { Phase }\end{array}$} & & \multicolumn{6}{|c|}{ Assessment against deliberative criteria } \\
\hline & & Access & Inclusiveness & Deliberativeness & Transmission & $\begin{array}{c}\text { Transparency \& } \\
\text { Accountability }\end{array}$ & Consequentiality \\
\hline \multirow{2}{*}{$\begin{array}{l}\text { Phase } \\
\text { 2/Final } \\
\text { Strategy } \\
2017-2020\end{array}$} & Level & Low to medium & Low to medium & Low & Low & Low to medium & Low \& unknown \\
\hline & Description & $\begin{array}{l}\text { - The growth of } \\
\text { the Sounding } \\
\text { Board from Phase } \\
1 \text { to } 2 \text { is primarily } \\
\text { attributed to intra- } \\
\text { actors using their } \\
\text { connections to } \\
\text { admit other actors } \\
\text { into the } \\
\text { participatory space } \\
\text { rather than a } \\
\text { formal process } \\
\text { - There was no set } \\
\text { legal cap and no } \\
\text { outright denying } \\
\text { access of } \\
\text { participants } \\
\text { - Members mostly } \\
\text { took a continued } \\
\text { part in the process } \\
\text { throughout the } \\
\text { stages of Energy } \\
\text { Evolution, with a } \\
\text { lull in the middle } \\
\text { of the process in } \\
2017-2018 \text { that } \\
\text { limited access }\end{array}$ & - Same as above & $\begin{array}{l}\text { - A lull in } \\
\text { participation saw a } \\
\text { lessening of } \\
\text { deliberativeness } \\
\text { - Due to changes in } \\
\text { management and } \\
\text { limited staff } \\
\text { resources, the } \\
\text { Sounding Board } \\
\text { acted as a } \\
\text { mechanism to } \\
\text { simply provide } \\
\text { feedback and } \\
\text { thoughts on } \\
\text { consultant models } \\
\text { rather than } \\
\text { authentically } \\
\text { deliberate } \\
\text { - Toward the end } \\
\text { of this stage, there } \\
\text { was however a } \\
\text { reversion back to } \\
\text { the previous mode } \\
\text { of participation }\end{array}$ & $\begin{array}{l}\text { - While } \\
\text { participants } \\
\text { contributed to the } \\
\text { proposed projects } \\
\text { in the Strategy, city } \\
\text { staff and } \\
\text { consultants used } \\
\text { Sounding Board } \\
\text { and working group } \\
\text { input on the } \\
\text { pathways to build } \\
\text { GHG reduction } \\
\text { modelling integral } \\
\text { to the Final } \\
\text { Strategy } \\
\text { - Industry } \\
\text { representatives } \\
\text { rather than } \\
\text { participants } \\
\text { provided input into } \\
\text { financial modelling } \\
\text { found in the Final } \\
\text { Strategy }\end{array}$ & $\begin{array}{l}\text { - Phase } 2 \text { was } \\
\text { similar to Phase } 1 \text {, } \\
\text { with the same } \\
\text { accountability via } \\
\text { political/institution } \\
\text { al mechanisms } \\
\text { - However, toward } \\
\text { the end of the } \\
\text { Strategy, Energy } \\
\text { Evolution provided } \\
\text { a webpage, gave } \\
\text { public information } \\
\text { sessions, and } \\
\text { planned to have } \\
\text { public input in the } \\
\text { future } \\
\text { - The final Strategy } \\
\text { has accountability } \\
\text { mechanisms (via } \\
\text { annual reporting } \\
\text { and rerunning the } \\
\text { energy \& } \\
\text { emissions model) }\end{array}$ & $\begin{array}{l}\text { - Participants } \\
\text { differed in their } \\
\text { perspective of } \\
\text { contributions to the } \\
\text { Strategy, but added } \\
\text { legitimacy in a } \\
\text { context of other } \\
\text { external influences } \\
\text { - While Energy } \\
\text { Evolution is able to } \\
\text { garner some } \\
\text { funding, it is under } \\
\text { resourced and } \\
\text { highly constrained, } \\
\text { with a tight budget } \\
\text { and largely } \\
\text { hypothetical } \\
\text { sources of funding } \\
\text { - It faces serious } \\
\text { institutional, } \\
\text { jurisdictional, } \\
\text { budgetary and } \\
\text { political constraints } \\
\text { - Implementation is } \\
\text { ongoing via } 20 \\
\text { concrete projects }\end{array}$ \\
\hline
\end{tabular}




\section{Chapter 8: Conclusion - Energy Evolution \& Participation in Sustainability Transitions}

The potentially severe consequences of climate change mean that transforming energy systems from fossil fuels to renewable energies constitutes a significant challenge for governments worldwide (Petersen, 2018). This problem is complex, as the transformation of energy-use requires fundamental transformations of society to more sustainable modes of production and consumption. Addressing these complex challenges relies on innovations in socio-technical systems, but also the governing (Smedby \& Quitzau, 2016) and planning of these systems. One response to the problem of energy sustainability has been a growing involvement of municipal governments and other urban actors in efforts to reduce GHG emissions and increasingly adopt adaptation measures (Bulkeley, 2010), as the implementation of national energy and/or energy-related policies requires local action (Petersen, 2018). Because of this, studies of the urban governance of climate change have proliferated as cities across the world place the issue on the forefront of their agendas (Bulkeley, 2010). Municipalities are positioned as significant contributors to sustainable energy transitions (Roelich et al., 2018). And they are increasingly pushing to adopt strategies and plans at regional and local scales towards new sustainable energy systems (Balest et al., 2019).

This thesis contributes to body of work that examines how municipalities are reacting to the consequences of climate change and approaching sustainable energy transitions, by providing an in-depth case-study of the participatory process of one city among many that has begun to consider a sustainable energy transition. The focus here is on Ottawa, the second largest city in Ontario, and the capital city of Canada. Ottawa's 
renewable energy strategy, Energy Evolution, aims to have the city reach net-zero GHG emissions by 2050 by making a sustained transition away from fossil fuels. This thesis analyzed democratic engagement in Energy Evolution via the use of two distinct theories, which together, provide a holistic view of participation in ST. The first theory, constructivist STS, examines participation as it stands, or is 'in the making'. The second theory of ecological democracy provides an ideal or normative framework for evaluating a decision-making process against pre-set criteria of what constitutes fulsome, deliberative participation.

Section 8.1 of this chapter reviews the evidence presented in this thesis to make three arguments about the Energy Evolution process. Drawing on Constructivist STS theory, Section 8.1.1 argues that the process of Energy Evolution was purposely created and only partially framed as participatory. Drawing on ecological democracy theory, Section 8.1.2 argues that the process was only partly participatory in the way that is envisions by ecological democracy theorists. Last, section 8.1.3 sums up my key findings from an analysis using these two theoretical frames. It argues that while participation forwarded an energy transition conversation in the city, other factors will make or break the Energy Evolution process. In section 8.2, this chapter then considers the strengths and limitations of the theoretical frames brought to this analysis. It first examines constructivist STS, then ecological democracy. It argues that the use of these two theories in tandem enable a holistic account of both the creation and outcomes of participatory processes. Section 8.3 draws on the two previous sections to map out possible next steps in this research. This section argues that this study affirms the need for reflexive 
governance processes that are inclusive and empowered, and explores how this could be examined in future research.

\section{Section 8.1 Lessons for Transitions from Ottawa's Energy Evolution Process}

This section provides an overall assessment of Energy Evolution as a participatory process aiming to successfully implement a sustainable energy transition, focusing on how participation was manifest in the process. It is divided into three subsections. The first focuses on an assessment of the participatory process, the second on questions of inclusion and exclusion, and the third considers the relationship between this process and the larger challenge of energy transitions.

\subsubsection{Energy Evolution's participatory process}

The use of constructivist STS provides a descriptive frame that shows that Energy Evolution was purposely created and only partially framed as participatory from 2016 to 2020. Constructivist STS examines the characteristics of the Energy Evolution via its productive effects (participatory model, identities of the participants and publics, and issue at stake) and the orchestration of participation (the enrolment and mediation of actors and exclusions and resistances present in the process). This analysis shows that Energy Evolution was purposefully created, stakeholder focused, invited professionally facilitated and maintained a technocratic and managerialist focus on energy transitions.

The use of STS theory allows a view of the creation of the participatory process of Energy Evolution. It particularly highlights that it was a creative process started by political actors (City Councillors), involving open-ended questions that had not been asked before in Ottawa. It was then delegated to city staff, who were limited in resources and centrally and institutionally invited participants with a particular attachment to 
energy and technologies to shape the Strategy. Further, they mediated participants (along with consultants) into a forum that focuses on future GHG reductions via technologies, exhibiting a technocratic and managerialist view of energy transitions. This disciplined approach was designed to increase buy-in from stakeholders and political actors in Ottawa's City Council. I conclude that this approach was a good start and useful to initiate a sustainable energy transition in the city, as actors provided key support and applied their skills (Bjerkan et al., 2021) to promote change in the attitude of the City. But at the same time, this purposeful approach to participation produced an imaginary of an uninformed public, who were almost wholly excluded from the forum. This lack of a systematic approach to inclusive participation (caused by both political actors and constraints given to staff) created an insular forum and limited the possibilities of other perspectives that might have garnered wider support for the Strategy. And this limited approach to participation points to the suitability of the more evaluative lens of ecological democracy to examine the implications and consequences of participation in this case.

\subsubsection{Deliberation, inclusions \& exclusions}

The use of ecological democracy provides a normative frame that shows that Energy Evolution was only partly participatory from 2016 to 2020 in the way envisioned by ecological democracy theorists. It allows the exploration of multiple areas of the process, including the participatory space itself via analyzing levels of access, inclusivity and the deliberativeness present in the space Energy Evolution space; looking at the level of transmission or influence that participants in the space had on the phases of Energy Evolution and documents produced; examining the level of wider public accountability 
and the transparency of the process; and looking at the overall consequentiality of the process in the wider decisions and social outcomes Energy Evolution created.

Energy Evolution did not meet many of the specific criteria set out by ecological democracy theorists, but it did display specific characteristics of deliberation at times in the process. For example, Phase 1 of Energy Evolution was deliberative (with the achievement of meta-consensus) and transmissive. But this came at the cost of lowering access and inclusiveness to foster an insular space with alike participants. And in Phase 2, this deliberativeness and transmission diminished due to institutional constraints and the enrolment of consultants and industry representatives in the process. Both transparency and accountability were institutionally based and thus low throughout the process. Last, participants were consequential in adding legitimacy to the Strategy, but their influence was not the only factor that moved the Strategy forward in Ottawa and the potential consequentiality could be seriously hampered by existing institutional, jurisdictional, budgetary and political constraints.

The use of ecological democracy as a normative ideal brings awareness to the potentialities of participation in Energy Evolution. Notwithstanding a limited match of the frame to the technical nature of this forum, there was a serious tension between the inclusion and exclusion of participants and what staff deemed as a legitimate stakeholder to participate in this forum. At this stage from 2016 to 2020 in the creation of the Strategy, participation was limited and perhaps for good reason, as wide inclusion might have slowed down the process and reduced the technicality and actionability of the Strategy which was palatable to participants and Councillors. And while the use of consultants added substantiveness and attractiveness, or polish to the Strategy, they 
diminished participation and the influence of participants. Ecological democracy does not advocate for simply opening the floodgates for traditional public input, but begs us to envision an ideal where those affected have a say in environmental decisions for the good of the total community, and are informed and ecologically aware. In the case of Energy Evolution, increasing participation might add further legitimacy and public awareness, and pushed more momentum for a sustainable energy transition in Ottawa.

\subsubsection{Participatory process, energy transitions and sustainability}

Whereas the City of Ottawa had GHG reduction targets in the past, Energy Evolution is a bold initiative of a type never before undertaken in the City. Stakeholder participation provided legitimacy and increased the chance of the adoption of the Strategy, and it moved a serious energy transition conversation forward in the City. At the same time, global scientists (e.g., IPCC reports), public protest and media influence along the way also influenced the adoption of the Strategy, showing that participation alone did not move this conversation forward. This observation suggests transitions are a multi-casual process, as participants in forums are not isolated in a vacuum.

While Ottawa City Council approved a bold energy transition goal, there are serious constraints to the Strategy's implementation. These constraints range from institutional everyday life, such as a lack of staff, internal budget and management culture at the City, which show that transitions are made and managed by people. But there are also wider constraints. It is hampered by a lack of jurisdiction over energy by Canadian municipalities. It is held back and bound to historically unprogressive and unwilling political actors. These constraints show a need for more active involvements of stakeholders and publics in forwarding transition goals. Further, they show that the 
complex problem of energy-use in society means that a change to more sustainability is influenced by a multiplicity of factors. All of this begs for a continued engagement in power relations in ST. Energy Evolution is a Strategy that will be defined by its ability to navigate these co-dependent constraints and factors in its future.

\subsection{Reflections on Theoretical Framing}

This section briefly considers the value, including both strengths and limitations of the theoretical lenses of constructivist STS and ecological democracy brought to this study. It

first considers constructivist STS, arguing that both its strengths and limitations are found in its descriptive nature, showing the importance of partialities in participatory processes. Next, it argues that while ecological democracy's pre-set criteria are sometimes unfitting and overly ideal, it remains a useful tool in examining the intricacies of participation as well as internal and external factors that remind us that sustainability transitions are social, political and economic phenomena. In sum, it argues that the usefulness of these two theories in tandem and displays a need for a holistic account of both the creation and outcomes of participatory processes.

\subsubsection{On constructivist STS theory}

Constructivist STS holds that elements of participation do not come into being spontaneously, but are made via the performance of collective participatory practices (Chilvers \& Longhurst, 2016). It provides an understanding of participation as it is, or "in the making" (Chilvers \& Longhurst, 2016). Its strength is that it allows a look at how participation is created, how it is made and maintained by people and how it can be partial and exclusive, like in the Energy Evolution case. This partial framing shows a need for greater participatory, as well as institutional context given to participants in 
forums. It also outlines the complexity of the three dimensions of participation (model, subjects and objects) as in this case a technocratic issue, expert stakeholders and procedural format of participation as institutional and purposeful shaped participation and defined the participatory collective, but were also complementary to one another throughout the process. While it allows a non-evaluative approach of what participation is, but it also misses other characteristics of participation, such as the inclusion and cohesion of participants, as well as the outcomes and limitations to participation. Its weakness is that it only describes participation, but does not outline what it ought to be.

\subsubsection{On ecological democracy theory}

Ecological democracy provides a useful normative frame for evaluating participation. However, its use of pre-set characteristics compared to the openness of constructivist STS means that it might not always align neatly with a case. One significant shortcoming with this frame is that just as Energy Evolution envisioned a passive uninformed and monolithic public, ecological democracy envisions an ecologically informed public that uses ideal reason and deliberation, but does not account for publics as a conflictual set of diverse actors in and of themselves, with differing values and beliefs. In Energy Evolution, following this frame's normative prescription strictly might have hampered participation, slowed the progress and reduced the technical competence of the forum.

Nevertheless, while ecological democracy is also overly ideal in some respects, is remains a useful frame. Using ecological democracy to examine Energy Evolution shows that there is a need to evaluate the intricacies of participatory processes, as the normative criteria were interdependent and overlapping and not static throughout the process. For example, in this case, it was deliberative (and meta-consensual) in favour of lowering 
access and inclusiveness in addition to low accountability and transparency which made the space insular and protected. But with institutional constraints and the enrolment of consultants, these criteria and the influence of participants significantly lessened.

In addition, exploring the potential consequences of Energy Evolution enables a careful examination of both internal and external factors in this case, bringing to the fore the issue of power relations in transitions. It particularly highlighted a current narrow approach to energy policy which is characterized by problems of, "electrons, fuel, and carbon, the technologies that provide them, and the cost of those technologies", rather than an energy system that is, "deeply enmeshed in broad patterns of social, economic, and political life and organization" (Miller et al. 2015, p. 29). It showed that while the Energy Evolution Strategy takes a highly technocratic approach to transitions, changes to energy systems are not simply characterized by just planning changes in technological aspects of the energy system, but ought to be accompanied by social, economic and political shifts (Miller, 2015). Looking at this case through the lens of ecological democracy theory reminds us that sustainability transitions are social, political and economic phenomena and not just technological ones.

\subsubsection{Bringing theory into dialogue around a case}

This subsection explains what was learned in this case by bringing these two theoretical traditions into dialogue around a single case. Neither constructivist STS nor ecological democracy sufficiently examines the case of Energy Evolution alone. While each theory differs in their approach to analyzing participation, using them in contrast with each other allowed a productive tension. The use of these two theories highlights a co-influence, where for example, the construction of participation, and the purposeful enrolment and 
mediation of actors by staff had an effect on the level of deliberativeness, but also limited levels of access and inclusiveness in Energy Evolution. This shows solely looking at the construction of the participatory process via constructivist STS without examining the normative aspects of ecological democracy would miss important dimensions of the process. And it displays a need for a holistic account of both the creation and the outcomes of participatory processes.

\subsection{Next Steps: The Case for more Reflexive Governance}

The Energy Evolution case highlights the participatory and institutional constraints of energy transition processes. The application of these two theoretical frames to this case highlights a need for reflexive governance, which has been elaborated in both in the ST and environmental deliberative democracy literature (Feindt \& Weiland, 2018). Reflexive governance involves the capacity of social-ecological systems to reconfigure themselves in response to reflection on their performance (Dryzek \& Pickering, 2017). Reflexive governance was adopted as a concept for scholars with an interest in environmental policy and sustainability as it addresses a concern about the viability of institutions in the face of various environmental problems (Feindt \& Weiland, 2018). Chilvers and Longhurst (2016) suggest the need for "actors involved to be reflexively aware of the partialities and exclusions of these collectives with respect to framing effects and "overflows", constructions of publics, and the models of participation enacted" (p. 603). And they additionally argue for a, "need to build the reflexive capacities of actors, institutions, and distributed systems in sustainability transitions to attend to the uncertainties, indeterminacies, and politics of participation and the public" (Chilvers \& Longhurst 2016, p. 603). And Dryzek and Pickering (2017) argue that, "deliberation 
should play a central role in the search for reflexivity" (p. 359). Energy Evolution presents a key example of one emphasis of reflexivity which is the, "need to monitor the impacts of institutions on ecosystems and vice versa, and to rethink and reshape core values and practices accordingly" (Dryzek \& Pickering 2017, p. 353).

Energy Evolution is a case that exemplifies that a sustainability transition requires a different form of governance, as the long-term nature of sustainability problems such as energy sustainability requires "governance arrangements that take into account the interconnectedness and complexity of a broad range of issues" (Feindt \& Weiland 2018, p. 664). Analyzing Energy Evolution through the lens of constructivist STS in this work shows the need for greater information given to participants, as they should be aware of the construction and partiality of participation in addition to the institutional context they are participating in. Looking at this case through the lens of ecological democracy suggests that due to the significant constraints and the limits to implementation faced by Energy Evolution, structural and institutional change is needed to empower Ottawa's decision-making space, with an involvement and further influence of multiple actors from different backgrounds and levels (e.g. the public sector, companies, civil society actors, organizations and citizens) (Lyytimäki et al., 2019) and a strengthening of the green public sphere (Eckersley, 2004) to move forward the energy transitions goals set out by Ottawa's Energy Evolution Strategy.

This thesis has undertaken a multifaceted and detailed approach to analyzing participation in environmental decision-making and sustainability transitions, and suggests a need for future studies to also take this approach to look at the characteristics and effectiveness of participatory processes, as well as which approaches might be able to 
push sustainability transitions. It has shown that while a sustainability transition conversation was forwarded in Ottawa, there are several serious constraints (institutional, jurisdictional, budgetary and political) that need to be surmounted going forward to ensure the effectiveness of an energy transition in the city. Going forward, these multiple facets of power relations ought to be explored to find how the goals of a strategy like Energy Evolution can be achieved, as well as how there can be a greater involvement of several actors who can have more awareness and influence to push energy transition goals. Researchers, sustainability advocates and political leader/policy makers serious about transitions should look at how actors can be empowered and how institutions can hold formats that enable sustainability transitions. 


\section{Appendices}

Appendix A: List of community stakeholders involved in Sounding Board discussions and technical workshops in "Ottawa's Community Energy Transition Strategy: Phase 1" (City of Ottawa Planning, Infrastructure and Economic Development 2017, p. 1-2)

\begin{tabular}{|c|c|}
\hline \multicolumn{2}{|c|}{ Sounding Board Members } \\
\hline Arborus Consulting & Aspen Solar Management \\
\hline Building Owners and Managers Association & Bullfrog Power \\
\hline Canada Green Building Council & Canadian Association for Renewable Energies \\
\hline $\begin{array}{l}\text { Canada Science and Technology Museum } \\
\text { Corporation }\end{array}$ & Carbon Impact Consultants \\
\hline Carleton University & $\begin{array}{c}\text { City of Ottawa (various departments and } \\
\text { branches) }\end{array}$ \\
\hline Chamber of Commerce & Clean Air Partnership \\
\hline Clean Energy Canada & Domicile Development Inc. \\
\hline Eastern Ontario Landlords Organization & Ecology Ottawa \\
\hline Enbridge Gas Distribution Inc. & Energy Ottawa \\
\hline EnviroCentre & Federation of Canadian Municipalities \\
\hline FVB Energy Inc. & Greater Ottawa Home Builders Association \\
\hline Green Communities Canada & Healthy Transportation Coalition \\
\hline Hydro One & Hydro Ottawa \\
\hline Independent Electricity System Operator & Invest Ottawa \\
\hline J. Michael Wiggin Consulting & Leidos Canada \\
\hline Lumos Energy & Minto \\
\hline National Capital Commission & Ottawa Carleton District School Board \\
\hline Ottawa Centre EcoDistrict & Ottawa Community Housing \\
\hline Ottawa Gatineau Hotel Association & Ottawa Renewable Energy Coop \\
\hline Public Services and Procurement Canada & QUEST \\
\hline RND Construction & Smarter Shift \\
\hline Transport Canada & Tucker House \\
\hline University of Ottawa & VRTUCAR \\
\hline Windmill Development Group Ltd. & \\
\hline \multicolumn{2}{|c|}{ Workshop Participants } \\
\hline Bullfrog Power & Burritts Rapids Renewable Energy Association \\
\hline Canadian Geoexchange Coalition & CanmetENERGY \\
\hline CH Four Biogas & $\begin{array}{c}\text { City of Ottawa (various departments and } \\
\text { branches) }\end{array}$ \\
\hline $\begin{array}{c}\text { City of Hamilton (Office of Energy } \\
\text { Departments) }\end{array}$ & EcoGen Energy Inc. \\
\hline Econogics Inc. & EDF Renewable Energies \\
\hline Enbridge & Energy Ottawa \\
\hline Enwave & FVB Energy Inc. \\
\hline Greater Ottawa Home Builders' Association & Healthy Transportation Coalition \\
\hline $\begin{array}{l}\text { Hydraulic Energy and Renewable Energy } \\
\text { Technologies }\end{array}$ & Hydro Ottawa \\
\hline Innovative Hydro Controls & iSolara Solar Power \\
\hline
\end{tabular}




\begin{tabular}{|c|c|}
\hline JAZZ Solar Solutions & Master Group \\
\hline Minto Group & National Research Council \\
\hline Natural Resources Canada & Norsun Energy \\
\hline $\begin{array}{c}\text { Ontario Ministry of Agriculture, Food and } \\
\text { Rural Affairs }\end{array}$ & Ottawa Community Housing \\
\hline Ottawa Renewable Energy Co-operative & Plug 'N Drive \\
\hline Public Services and Procurement Canada & Windmill Development Group Ltd. \\
\hline
\end{tabular}


Appendix B: List of community stakeholders involved in overall Sounding Board discussions and technical workshops in "Energy Evolution: Ottawa's Community Energy Transition Strategy" (City of Ottawa 2020b, p. 7-8)

\begin{tabular}{|c|c|}
\hline Arborus Consulting & $\begin{array}{l}\text { Association of Energy Engineers - Eastern } \\
\text { Canada Conference }\end{array}$ \\
\hline Aspen Solar Management & Atmospheric Energy Systems \\
\hline BGIS & Building Owners and Managers Association \\
\hline Bullfrog Power & Burritts Rapids Renewable Energy Association \\
\hline Canada Green Building Council & Canadian Association for Renewable Energies \\
\hline Canadian Biogas Association & Canadian Geoexchange Coalition \\
\hline $\begin{array}{c}\text { Canada Science and Technology Museum } \\
\text { Corporation }\end{array}$ & $\begin{array}{l}\text { Canadian Urban Transit Research and } \\
\text { Innovation Consortium }\end{array}$ \\
\hline CanmetENERGY & Carbon Impact Consultants \\
\hline Carleton University & Centretown Citizens Ottawa Corporation \\
\hline Chamber of Commerce & CH Four Biogas \\
\hline $\begin{array}{c}\text { City of Ottawa (various departments and } \\
\text { branches) }\end{array}$ & $\begin{array}{c}\text { City of Hamilton (Office of Energy } \\
\text { Departments) }\end{array}$ \\
\hline City of Markham (Solid Waste) & City of Toronto (Planning Department) \\
\hline Clean Air Partnership & Clean Energy Canada \\
\hline $\begin{array}{c}\text { Community Associations for Environmental } \\
\text { Sustainability }\end{array}$ & Communauto \\
\hline Domicile Development Inc. & Eastern Ontario Landlords Organization \\
\hline EcoGen Energy Inc. & Ecology Ottawa \\
\hline Econogics Inc. & EDF Renewable Energies \\
\hline Electric Vehicle Council of Ottawa & Enbridge Gas Distribution Inc. \\
\hline Energy Ottawa & Envari \\
\hline Envirocentre & Enwave \\
\hline Federation of Canadian Municipalities & FVB Energy Inc. \\
\hline GHD Limited & Gloucester Housing Corporation \\
\hline Greater Ottawa Home Builders' Association & Green Communities Canada \\
\hline Healthy Transportation Coalition & $\begin{array}{l}\text { Hydraulic Energy and Renewable Energy } \\
\text { Technologies }\end{array}$ \\
\hline Hydro One & Hydro Ottawa \\
\hline Independent Electricity System Operator & Innovative Hydro Controls \\
\hline Invest Ottawa & iSolara Solar Power \\
\hline JAZZ Solar Solutions & JJ McNeil Commercial Inc \\
\hline J. Michael Wiggin Consulting & JL Richards \\
\hline Ken Church Consulting & Leidos Canada \\
\hline Lumos Energy & Master Group \\
\hline Minto Group & National Capital Commission \\
\hline National Research Council & Natural Resources Canada \\
\hline Norsun Energy & Nova Bus \\
\hline Ontario Biogas Association & $\begin{array}{c}\text { Ontario Ministry of Agriculture, Food and } \\
\text { Rural Affairs }\end{array}$ \\
\hline Ontario Energy Board & Ottawa Carleton District School Board \\
\hline
\end{tabular}




\begin{tabular}{|c|c|}
\hline Ottawa Centre EcoDistrict & Ottawa Climate Action Fund \\
\hline Ottawa Community Foundation & Ottawa Community Housing \\
\hline Ottawa Gatineau Hotel Association & Ottawa Macdonald Cartier International Airport \\
\hline Ottawa Renewable Energy Co-operative & Ottawa Regional Society of Architects \\
\hline Ottawa Student Transportation Authority & Passive House Canada \\
\hline Peak Power Energy & Plug 'N Drive \\
\hline Pollution Probe & Public Services and Procurement Canada \\
\hline QUEST & Regional Group \\
\hline RND Construction & Sustainability Solutions Group \\
\hline Smarter Shift & Treasury Board of Canada \\
\hline Transport Canada & University of Ottawa \\
\hline Tucker House Treasury Board of Canada & Wastewatch Ottawa \\
\hline VRTUCAR & Windmill Development Group Ltd \\
\hline whatIf? Technologies Inc & ZEBx \\
\hline WSP & \\
\hline Zibi & \\
\hline
\end{tabular}


Appendix C: List of sample interview questions for Sounding Board members (with prompts below questions)

1. Please tell me a little about yourself, your organization, and your involvement in the process surrounding Ottawa's Energy Evolution Strategy.

Prompts:

- When did you get involved and how long were you involved in the process?

2. Why does the future of the Ottawa energy system matter to your organization?

Prompts:

- What issues do you think are most important when defining the future of Ottawa's energy system?

3. How were you contacted and/or recruited into this process?

Prompts:

- Did you or your organization have a prior relationship with the office and/or person that contacted you, or was it a 'cold contact'?

\section{How would you define Energy Evolution?}

Prompts:

- If participant does not have a definition, can provide the city's definition and ask: Is this how you would define Energy Evolution?

5. What did your 'participation' look like in the Energy Evolution process?

Prompts:

- What opportunities were provided for you or your group to participate?

- Were there any specific processes or technologies used?

- How was your input collected and shared?

6. During consultations, which of the topics or themes raised resonated the most for your organisation, and what sort of considerations informed discussions on these topics?

Prompts:

- What was important about these themes/topics for you and your organizations?

- Whose needs and interests were considered in discussions? 
- What environmental, social and/or economic considerations informed the discussions?

7. Were your views welcome in the participatory process of Ottawa's Energy Evolution strategy?

Prompts:

- Do you recall specific proposals you made? How were these proposals dealt with?

- Did you ever feel like your perspective was not welcome, or ignored?

- Do you recall a proposal to have the City as an equal partner with Sounding Board members in the Strategy?

8. How were decisions made on contentious topics or issues?

Prompts:

- What tools were used to make decisions?

- How were opposing viewpoints dealt with?

- Do you feel Energy Evolution documents reflect a 'consensus'? Why or why not?

9. To what extent do you feel the input you or other individuals/groups provided made a difference in influencing outcomes via either decisions or overall policy?

10. To what extent do you feel this process was accountable to the public?

- How would you characterise the Sounding Board as a group?

11. Looking at the overall process and outcomes, to what extent did this Energy Evolution process address the initial issues or concerns your organization had about Ottawa's energy future? 
Appendix D: List of sample interview questions for City of Ottawa staff (with prompts below questions)

1. Please tell me a little about yourself and your role in the process of Ottawa's Energy Evolution Strategy.

Prompts:

- When did you get involved and how long were you involved in the process?

2. How did you contact and/or recruit Sounding Board members into this process?

Prompts:

- How did you decide on which Sounding Board members to recruit and why were they chosen?

- Did the majority of Sounding Board members have a prior relationship with the office, or did you 'cold contact' individuals/organizations?

3. How did city staff decide on defining or outlining the parameters of 'Energy Evolution'?

Prompts:

- What role did Sounding Board members have in defining the parameters of the issue of Energy Evolution?

4. How was participation conducted in the Energy Evolution process?

Prompts:

- How did you decide to divide individuals/organizations into specific working groups?

- How did you decide to conduct participation?

- Did you find your methods of conducting participation effective?

5. After the Sounding Board provided input, feedback and ideas, how were decisions made on what to include and exclude?

Prompts:

- How was input collected and shared?

- How were decisions made on contentious topics?

- Do you recall a proposal made to have the City as an equal partner with Sounding Board members in the Strategy? 
6. To what extent do you feel the input that the Sounding Board provided made a difference in influencing outcomes via either decisions or overall policy?

Prompts:

- Do you think Energy Evolution was made successful by the input of Sounding Board members?

- Many interviewees I have spoken to praised the staff, but noted constraints in the process. What constraints did you find along the process?

- Do you feel Energy Evolution documents reflect a 'consensus' amongst the Sounding Board members? Why or why not?

7. To what extent do you feel this process was accountable to the public?

Prompts:

- How would you characterise the Sounding Board as a group?

8. Looking at the overall process and outcomes, to what extent do you think this Energy Evolution process addresses the initial issues or concerns that the City had about Ottawa's energy future?

Prompts:

- Looking at the overall process and outcomes, to what extent did you feel the Energy Evolution process was successful in influencing City Council?

- Do you think the governance structure and political processes in the City of Ottawa are adequate in addressing climate change initiatives such as Energy Evolution? 
Appendix E: List of individuals/organizations that provided support for Energy Evolution: Ottawa's Community Energy Transition Strategy Final Report (EPWWM, 2020a)

\begin{tabular}{|c|c|}
\hline \multicolumn{2}{|c|}{$\begin{array}{l}\text { Public delegations that provided presentations at the October 20, } 2020 \text { Standing } \\
\text { Committee Environmental Protection, Water and Waste Management }{ }^{6}\end{array}$} \\
\hline Name & Role/Organization \\
\hline Robb Barnes & Executive Director, Ecology Ottawa \\
\hline Dick Bakker* & Ottawa Renewable Energy Co-operative \\
\hline Jason Burggraaf* & $\begin{array}{l}\text { Executive Director, Greater Ottawa Home } \\
\text { Builders' Association }\end{array}$ \\
\hline Steve Winkelman* & $\begin{array}{l}\text { Executive Director, Ottawa Climate Action } \\
\text { Fund }\end{array}$ \\
\hline Angela Keller-Herzog & $\begin{array}{l}\text { Community Associations for Environmental } \\
\text { Sustainability }\end{array}$ \\
\hline Colleen Glass & None recorded \\
\hline \multicolumn{2}{|c|}{ Individuals/organizations that provided correspondence largely in support of the report } \\
\hline Name & Role/Organization \\
\hline Malini Giridhar* & $\begin{array}{l}\text { Vice President, Business Development and } \\
\text { Regulatory, Enbridge }\end{array}$ \\
\hline Jonathan Westeinde* & $\begin{array}{l}\text { Chief Executive Officer, Windmill } \\
\text { Development Corporation }\end{array}$ \\
\hline Sharon Coward* & Executive Director, EnviroCentre \\
\hline Marco Pagani* & $\begin{array}{l}\text { President and Chief Executive Officer, Ottawa } \\
\text { Community Foundation }\end{array}$ \\
\hline S. Lisa Lee* & $\begin{array}{l}\text { Director, Customer Solutions, Hydro One } \\
\text { Networks Incorporated }\end{array}$ \\
\hline Jennifer Green* & $\begin{array}{l}\text { Executive Director, Canadian Biogas } \\
\text { Association }\end{array}$ \\
\hline Nicholas Gall* & $\begin{array}{l}\text { Director, Distributed Energy Resources, } \\
\text { Canadian Renewable Energy Association }\end{array}$ \\
\hline Adnan Khokhar* & $\begin{array}{l}\text { Chief Energy and Infrastructure Services } \\
\text { Officer, Envari Energy Solutions Incorporated }\end{array}$ \\
\hline Greg Clarke* & $\begin{array}{l}\text { Chief Electricity Generation Officer, Portage } \\
\text { Power/Energie }\end{array}$ \\
\hline Guy Cormier* & $\begin{array}{l}\text { President, J.L. Richards Engineers, Architects } \\
\text { and Planners }\end{array}$ \\
\hline Joan Haysom & $\begin{array}{l}\text { Associate, J.L. Richards Engineers, Architects } \\
\text { and Planners }\end{array}$ \\
\hline Julie (Gaudet) Lupinacci* & Chief Customer Officer, Hydro Ottawa \\
\hline Mark Hutchinson* & $\begin{array}{l}\text { Vice President, Green Building Programs and } \\
\text { Innovation, Canada Green Building Council }\end{array}$ \\
\hline Sueling Ching* & $\begin{array}{l}\text { President and Chief Executive Officer, Ottawa } \\
\text { Board of Trade }\end{array}$ \\
\hline
\end{tabular}

\footnotetext{
${ }^{6}$ Individuals marked with an asterisk either provided comments in writing or by e-mail.
} 


\begin{tabular}{|c|c|}
\hline Nick Xenos* & $\begin{array}{c}\text { Executive Director, Centre for Greening } \\
\text { Government, Treasury Board Secretariat of } \\
\text { Canada }\end{array}$ \\
\hline Stanley Leinwand* & $\begin{array}{c}\text { Acting Director, Sustainable Development and } \\
\text { Environmental Services, National Capital } \\
\text { Commission }\end{array}$ \\
\hline David McNicoll* (with caveats) & None recorded \\
\hline Angela Coleman* & $\begin{array}{c}\text { General Manager / Secretary-Treasurer, South } \\
\text { Nation Conservation Authority }\end{array}$ \\
\hline
\end{tabular}




\section{List of Interviews}

City Staff A. (2021, January 12). Interview by Daniel Atlas. Digital Recording. Ottawa, $\mathrm{ON}$

City Staff B. (2021, January 15). Interview by Daniel Atlas. Digital Recording. Ottawa, $\mathrm{ON}$

Energy Subject A. (2020, November 2). Interview by Daniel Atlas. Digital Recording. Ottawa, ON

Energy Subject B. (2020, November 9). Interview by Daniel Atlas. Digital Recording. Ottawa, ON

Energy Subject C. (2020, November 9). Interview by Daniel Atlas. Digital Recording. Ottawa, ON

Environmental Non-Government Organization Subject. (2020, October 6). Interview by Daniel Atlas. Digital Recording. Ottawa, ON

Government Subject. (2020, October 27). Interview by Daniel Atlas. Digital Recording. Ottawa, ON

Industry Subject A. (2020, October 6). Interview by Daniel Atlas. Digital Recording. Ottawa, ON

Industry Subject B. (2020, October 20). Interview by Daniel Atlas. Digital Recording. Ottawa, ON

Journalist Subject. (2020, November 5). Interview by Daniel Atlas. Digital Recording. Ottawa, ON

Quasi-Governmental Organization Subject A. (2020, September 11). Interview by Daniel Atlas. Digital Recording. Ottawa, ON

Quasi-Governmental Organization Subject B. (2020, November 5). Interview by Daniel Atlas. Digital Recording. Ottawa, ON

University Subject A. (2020, August 25). Interview by Daniel Atlas. Digital Recording. Ottawa, ON

University Subject B. (2020, September 1). Interview by Daniel Atlas. Digital Recording. Ottawa, ON 


\section{References}

A People's Official Plan. (n.d.). About POP. https://www.ottawaclimatesolutions.net/about

Avelino, F., Grin, J., Pel, B., \& Jhagroe, S. (2016). The politics of sustainability transitions. Journal of Environmental Policy \& Planning, 18(5), 557-567. https://doi.org/10.1080/1523908X.2016.1216782

Avelino, F., \& Wittmayer, J. (2016). Shifting power relations in sustainability transitions: A multi-actor perspective. Journal of Environmental Policy \& Planning: The Politics of Transition, 18(5), 628-649. https://doi.org/10.1080/1523908X.2015.1112259

Balest, J., Secco, L., Pisani, E., \& Garegnani, G. (2019). Municipal transitions: The social, energy, and spatial dynamics of sociotechnical change in South Tyrol, Italy. Energy Research \& Social Science, 54, 211-223. https://doi.org/10.1016/j.erss.2019.04.015

Bashmakov I. A., Bruckner, T., Chum, A., de la Vega Navarro, A., Edmonds, J., Faaji A., Fungtammasan, B., Garg, E., Hertwich, E., Honnery, D., Infield, D., Kainuma, M., Khennas, S., Kim, S., Mulugetta, Y., Nimir, H. B., Riahi, K., Strachan, N., Wiser, R., \& Zhang, X. (2014). Energy systems. In A. Adler, B. Kriemann, C. von Stechow, E. Farahani, I. Baum, J.C. Minx, J. Savolainen, K. Seyboth, P. Eickemeier, O. Edenhofer, R. Pichs-Madruga, S. Brunner, S. Kadner, S. Schlömer, T. Zwickel \& Y. Sokona (Eds.), Climate change 2014: Mitigation of climate change. contribution of working Group III to the Fifth Assessment Report of the Intergovernmental Panel on Climate Change (pp. 511-598). Cambridge University Press. https://www.ipcc.ch/site/assets/uploads/2018/02/ipcc_wg3_ar5_chapter7.pdf

Barnes, R. (2018). Barnes: To help save the climate, elect a greener Ottawa City Council. Ottawa Citizen. https://ottawacitizen.com/opinion/columnists/barnes-to-helpsave-the-climate-elect-a-greener-ottawa-city-council

Berger, P., \& Luckmann, T. (1966). The social construction of reality: A treatise in the sociology of knowledge. Anchor Books.

Bjerkan, K., Ryghaug, M., \& Skjølsvold, T. (2021). Actors in energy transitions: Transformative potentials at the intersection between Norwegian port and transport systems. Energy Research \& Social Science, 72, 1-11. https://doi.org/10.1016/j.erss.2020.101868

Bridgman, A., \& Gakhal, J. (2019). City of Ottawa Public Engagement Strategy. https://participedia.net/case/5438 
Bulkeley, H. (2010). Cities and the governing of climate change. Annual Review of Environment and Resources, 35(1), 229-253. https://doi.org/10.1146/annurevenviron-072809-101747

Callon, M., Lascoumes, P., \& Barthe, Y. (2009). Acting in an uncertain world: An essay on technical democracy. MIT Press.

Chianello, J. (2021). Unravelling the mystery behind sewer line warranty packages. $C B C$ News. https://www.cbc.ca/news/canada/ottawa/sewer-line-insurance-canadaottawa-staff-council-1.5956395

Chilvers, J., \& Longhurst, N. (2016). Participation in transition(s): Reconceiving public engagements in energy transitions as co-produced, emergent and diverse. Journal of Environmental Policy \& Planning, 18(5), 585-607. https://doi.org/10.1080/1523908X.2015.1110483

Chilvers, J., Pallett, H., \& Hargreaves, T. (2018). Ecologies of participation in sociotechnical change: The case of energy system transitions. Energy Research \& Social Science, 42, 199-210. https://doi.org/10.1016/j.erss.2018.03.020

City of Ottawa. (n.d.-a). Climate change and energy. https://ottawa.ca/en/livingottawa/environment/climate-change-and-energy\#climate-emergency

City of Ottawa. (n.d.-b). Public engagement. https://ottawa.ca/en/city-hall/publicengagement/projects/public-engagement

City of Ottawa. (n.d.-c). 2021 budget highlights. https://ottawa.ca/en/cityhall/budget/2021-budget-highlights

City of Ottawa. (n.d.-d). Statistics and demographics. https://ottawa.ca/en/livingottawa/statistics-and-demographics\#growth-projections-ottawa-2014-2036

City of Ottawa. (2014). Air Quality \& Climate Change Management Plan [PDF File]. http://ottwatch.ca/meetings/file/193382/Document 1 EN_Full_Rpt Update_of AQCCMP docx Item UPDATE OF THE AIR QUALITY AND CLIMATE CHANGE_MANAGEMENT_PLAN_Meeting_City_Council_Date_2014_05_28 $10 \_00 \quad 00$

City of Ottawa. (2015a). City of Ottawa 2015-2018 Strategic Plan [PDF file]. https://documents.ottawa.ca/sites/documents/files/documents/2015 2018 strategi c plan en.pdf

City of Ottawa. (2015b). Public Engagement Strategy: Guidelines and Toolkit [PDF file]. http://ottwatch.ca/meetings/file/273915/Document_2_EN_Public_Engagement_G 
uidelines and Toolkit pdf Item COMMUNITY AND SOCIAL SERVICES DEPARTMENT IMPLEMENTATION OF PUBLIC ENGAGEMENT STRA TEGY_Meeting_Community_and_Protective_Services_Committee_Date_2015_0

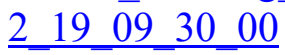

City of Ottawa. (2018). Equity \& Inclusion Lens Handbook [PDF file]. https://documents.ottawa.ca/sites/documents/files/ei_lens_hb_en.pdf

City of Ottawa. (2019). Project status update on Energy Evolution: Ottawa's Community Energy Transition Strategy [PDF file]. https://app05.ottawa.ca/sirepub/agdocs.aspx?doctype=agenda\&itemid=395101

City of Ottawa. (2020a). Climate Change Master Plan (draft) [PDF file]. https://documents.ottawa.ca/sites/documents/files/climate_change_mplan_en.pdf

City of Ottawa. (2020b). Energy Evolution: Ottawa's Community Energy Transition Strategy [PDF file]. https://app05.ottawa.ca/sirepub/agdocs.aspx?doctype=agenda\&itemid $=402848$

City of Ottawa. (2020c, November 20). New Official Plan (preliminary draft) [PDF file]. https://engage.ottawa.ca/the-new-official-plan/news feed/draft-new-official-plan

City of Ottawa News. (2019, July 25). City of Ottawa launches Engage Ottawa - a new way to have your say on City projects. https://ottawa.ca/en/news/city-ottawalaunches-engage-ottawa-new-way-have-your-say-city-projects

City of Ottawa News. (2020a, October 20). Committee approves $\$ 2.6$ million for Energy Evolution. https://ottawa.ca/en/news/committee-approves-26-million-energyevolution

City of Ottawa News. (2020b, November 20). City seeks public input on New Official Plan and how Ottawa will grow. https://ottawa.ca/en/news/city-seeks-publicinput-new-official-plan-and-how-ottawa-will-grow

City of Ottawa Planning, Infrastructure and Economic Development. (2017). Energy Evolution: Ottawa's Community Energy Transition Strategy: Phase 1 [PDF file]. https://documents.ottawa.ca/sites/documents/files/energy_evol_phase1_en.pdf

De Landa, M. (2006). A new philosophy of society assemblage theory and social complexity. Continuum.

Deleuze, G., \& Guattari, F. (1987). A thousand plateaus: Capitalism and schizophrenia. University of Minnesota Press. 
Dryzek, J. (1990). Green reason: Communicative ethics for the biosphere. Environmental Ethics, 12(3), 195-210. https://doi.org/10.5840/enviroethics19901231

Dryzek, J. (2009). Democratization as deliberative capacity building. Comparative Political Studies, 42(11), 1379-1402. https://doi.org/10.1177/0010414009332129

Dryzek, J. (2010). Foundations and frontiers of deliberative governance. Oxford University Press.

Dryzek, J. (2013). The politics of the earth: Environmental discourses (3rd ed.). Oxford University Press.

Dryzek, J., \& Pickering, J. (2017). Deliberation as a catalyst for reflexive environmental governance. Ecological Economics, 131, 353-360. https://doi.org/10.1016/j.ecolecon.2016.09.011

Eckersley, R. (2004). The green state: Rethinking democracy and sovereignty. MIT Press.

Eckersley, R. (2005). Ecocentric discourses: Problems and future prospects for nature advocacy. In D. Schlosberg \& J. S. Dryzek (Eds.), Debating the earth: The environmental politics reader (pp. 364-381). Oxford: Oxford University Press.

Eckersley, R. (2020). Ecological democracy and the rise and decline of liberal democracy: looking back, looking forward. Environmental Politics, 29(2), 214234. https://doi.org/10.1080/09644016.2019.1594536

Ecology Ottawa. (n.d.). About. https://ecologyottawa.ca/about/

Ecology Ottawa. (2017). For immediate release: Ecology Ottawa statement on 2018 City of Ottawa draft budget. https://ecologyottawa.ca/2017/11/08/for-immediaterelease-ecology-ottawa-statement-on-2018-city-of-ottawa-draft-budget/

Ecology Ottawa. (2019a). Budget 2020 - What does it mean for Ottawa's environment? https://ecologyottawa.ca/2019/11/07/budget-2020-what-does-it-mean-for-ottawasenvironment/

Ecology Ottawa. (2019b). Building a greener Ottawa - A welcome package for Ottawa City Council [PDF file]. https://ecologyottawa3.files.wordpress.com/2019/01/190131climatewelcomepackage.pdf

Elder, P. (1982). Project approval, environmental assessment and public participation. Environmentalist, 2(1), 55-71. https://doi.org/doi.org/10.1016/S0251$\underline{1088(82) 91622-9}$ 
Engage Ottawa. (n.d.). Energy Evolution: Ottawa's Community Energy Transition Strategy. https://engage.ottawa.ca/energy-evolution?tool=news feed\#tool tab

Environment and Climate Protection Committee. (2017, February 21). Report 427140 [PDF file]. http://ottwatch.ca/meetings/file/427140

Environment and Climate Protection Committee. (2018, June 27). Report 21 [PDF File]. http://ottwatch.ca/meetings/file/537519

Environment Committee. (2014, May 20). Report EN - Air Quality and Climate Change Management Plan. http://ottwatch.ca/meetings/EC/6198

Farla, J., Markard, J., Raven, R., \& Coenen, L. (2012). Sustainability transitions in the making: A closer look at actors, strategies and resources. Technological Forecasting \& Social Change, 79(6), 991-998. https://doi.org/10.1016/j.techfore.2012.02.001

Feindt, P., \& Weiland, S. (2018). Reflexive governance: exploring the concept and assessing its critical potential for sustainable development. Introduction to the special issue. Journal of Environmental Policy \& Planning, 20(6), 661-674. https://doi.org/10.1080/1523908X.2018.1532562

Flyvbjerg, B. (2001). Making social science matter: Why social inquiry fails and how it can succeed again. Oxford, UK: Cambridge University Press.

Flyvbjerg, B. (2006). Five misunderstandings about case-study research. Qualitative Inquiry, 12(2), 219-245. https://doi.org/10.1177/1077800405284363

Fritz, L., \& Binder, C. (2018). Participation as relational space: A critical approach to analysing participation in sustainability research. Sustainability, 10(8), 1-29. https://doi.org/10.3390/su10082853

For Our Kids. (2020). Tell City Council that a green and just recovery can't be put off! https://www.forourkids.ca/ottawa budget

Gariepy, M. (1991). Toward a dual-influence system: Assessing the effects of public participation in environmental impact assessment for hydro-Quebec projects. Environmental Impact Assessment Review, 11(4), 353-374 https://doi.org/10.1016/0195-9255(91)90006-6

Geels, F. (2012). A socio-technical analysis of low-carbon transitions: Introducing the multi-level perspective into transport studies. Journal of Transport Geography, 24, 471-482. https://doi.org/10.1016/j.jtrangeo.2012.01.021 
Geels, F. (2018). Low-carbon transition via system reconfiguration? A socio-technical whole system analysis of passenger mobility in Great Britain (1990-2016).

Energy Research \& Social Science, 46, 86-102. https://doi.org/10.1016/j.erss.2018.07.008

Green, D. (2002). Constructivist comparative politics: Foundations and framework. In D. Green (Eds.), Constructivism and comparative politics (pp. 3-59). M.E. Sharpe.

Halperin, S., \& Heath, O. (2017). Political research: Methods and practical skills (Second ed.). New York, NY: Oxford University Press.

Hendriks, C. (2008). On inclusion and network governance: The democratic disconnect of Dutch energy transitions. Public Administration, 86(4), 1009-1031. https://doi.org/10.1111/j.1467-9299.2008.00738.x

Hess, D., \& Sovacool, B. (2020). Sociotechnical matters: Reviewing and integrating science and technology studies with energy social science. Energy Research \& Social Science, 65, 1-17. https://doi.org/10.1016/j.erss.2020.101462

Hoedeman, A. (2014, October 15). 100\% renewable Ottawa [PDF File]. https://ecologyottawa3.files.wordpress.com/2015/01/100-renewable-ottawa-_david-chernushenko.pdf

Hoff, J., Gausset, Q., \& Lex, S. (2020). The role of non-state actors in the green transition: Building a sustainable future. Routledge. https://doi.org/10.4324/9780429280399

International Energy Agency. (2019). World energy outlook 2019, OECD Publishing. https://doi-org/10.1787/caf32f3b-en.

Intergovernmental Panel on Climate Change. (2018). Summary for policymakers. In A. Pirani, C. Péan, D. Roberts, E. Lonnoy, H.-O. Pörtner, J.B.R. Matthews, J. Skea, M.I. Gomis, M. Tignor, P.R. Shukla, P. Zhai, R. Pidcock, S. Connors, T. Maycock, T. Waterfield, V. Masson-Delmotte, W. Moufouma-Okia, X. Zhou \& Y. Chen (Eds.), Global Warming of $1.5^{\circ} \mathrm{C}$. An IPCC Special Report on the impacts of global warming of $1.5^{\circ} \mathrm{C}$ above pre-industrial levels and related global greenhouse gas emission pathways, in the context of strengthening the global response to the threat of climate change, sustainable development, and efforts to eradicate poverty (pp. 2-24). World Meteorological Organization. https://www.ipcc.ch/sr15/chapter/spm/

Irwin, A. (1995). Citizen science a study of people, expertise, and sustainable development. Routledge. 
Irwin, A. (2006). The politics of talk: Coming to terms with the "new" scientific governance. Social Studies of Science, 36(2), 299-320.

https://doi.org/10.1177/0306312706053350

Irwin, A., \& Michael, M. (2003). Science, social theory and public knowledge. Open University Press.

Jaccard, M., Murphy, R., Zuehlke, B., \& Braglewicz, M. (2019). Cities and greenhouse gas reduction: Policy makers or policy takers? Energy Policy, 134, 1-11. https://doi.org/10.1016/j.enpol.2019.07.011

Kemp, R., \& Loorbach, D. (2006). Transition management: A reflexive governance approach. In J.-P., Voß, D. Bauknecht \& R. Kemp (Eds.), Reflexive Governance for Sustainable Development (pp. 103-130). Edward Elgar.

Köhler, J., Geels, F., Kern, F., Markard, J., Onsongo, E., Wieczorek, A., Alkemade, F., Avelino, F., Bergek, A., Boons, F., Fünfschilling, L., Hess, D., Holtz, G., Hyysalo, S., Jenkins, K., Kivimaa, P., Martiskainen, M., McMeekin, A., Mühlemeier, M., ... Wells, P. (2019). An agenda for sustainability transitions research: State of the art and future directions. Environmental Innovation and Societal Transitions, 31, 1-32. https://doi.org/10.1016/j.eist.2019.01.004

Latour, B. (1987). Science in action: How to follow scientists and engineers through society. Open University Press.

Lawhon, M., \& Murphy, J. (2011). Socio-technical regimes and sustainability transitions: Insights from political ecology. Progress in Human Geography, 36(3), 354-378. https://doi.org/10.1177/0309132511427960

Leidos Canada Inc. (2017, October 17). Pathway study on solar power in Ottawa [PDF file]. https://documents.ottawa.ca/sites/documents/files/energy_pathway_phase1_en.PD $\underline{F}$

Lennon, B., Dunphy, N., \& Sanvicente, E. (2019). Community acceptability and the energy transition: A citizens' perspective. Energy, Sustainability and Society, 9(1), 1-18. https://doi.org/10.1186/s13705-019-0218-z

Loorbach, D. (2010). Transition management for sustainable development: A prescriptive, complexity-based governance framework. Governance (Oxford), 23(1), 161-183. https://doi.org/10.1111/j.1468-0491.2009.01471.x

Loorbach, D., \& Rotmans, J. (2010). The practice of transition management: Examples and lessons from four distinct cases. Futures, 42(3), 237-246.

https://doi.org/10.1016/j.futures.2009.11.009 
Lynch, D., Klaassen, P., Wassenaer, v, \& Broerse, J. (2020). Constructing the public in roadmapping the transition to a bioeconomy: A case study from the Netherlands. Sustainability, 12(8), 1-18. https://doi.org/10.3390/su12083179

Lynch, M. (2016). Social constructivism in science and technology studies. Human Studies, 39(1), 101-112. https://doi.org/10.1007/s10746-016-9385-5

Lyytimäki, J., Vikström, S., \& Furman, E. (2019). Voluntary participation for sustainability transition: Experiences from the "Commitment to Sustainable Development 2050." International Journal of Sustainable Development and World Ecology, 26(1), 25-36. https://doi.org/10.1080/13504509.2018.1460632

Markard, J., Raven, R., \& Truffer, B. (2012). Sustainability transitions: An emerging field of research and its prospects. Research Policy, 41(6), 955-967. https://doi.org/10.1016/j.respol.2012.02.013

Meadowcroft, J. (2004). Participation and sustainable development: modes of citizen, community, and organizational involvement. In W. Lafferty (Ed.), Governance for sustainable development: The challenge of adapting form to function (pp. 162190). Edward Elgar.

Meadowcroft, J. (2007). Who is in charge here? Governance for sustainable development in a complex world. Journal of Environmental Policy \& Planning, 9(3-4), 299314. https://doi.org/10.1080/15239080701631544

Meadowcroft, J. (2011). Engaging with the politics of sustainability transitions. Environmental Innovation and Societal Transitions, 1(1), 70-75. https://doi.org/10.1016/j.eist.2011.02.003

Miller, C., Richter, J., \& O’Leary, J. (2015). Socio-energy systems design: A policy framework for energy transitions. Energy Research \& Social Science, 6, 29-40. https://doi.org/10.1016/j.erss.2014.11.004

Müller, M. (2015). Assemblages and actor-networks: Rethinking socio-material power, politics and space. Geography Compass, 9(1), 27-41. https://doi.org/10.1111/gec3.12192

National Capital Commission. (n.d.). Greenbelt. https://ncc-ccn.gc.ca/places/greenbelt

Nominating Committee. (2014, December 9). Agenda 1. http://ottwatch.ca/meetings/meeting/6386

Ottawa City Council. (2014, May 28). Appendix E: Energy supply and demand in Ottawa [PDF file]. 
http://ottwatch.ca/meetings/file/193390/Appendix E Energy Supply and Dema nd in Ottawa docx Item UPDATE OF THE AIR QUALITY AND CLIMA TE_CHANGE_MANAGEMENT_PLAN_Meeting_City_Council_Date_2014_05 $28 \quad 10 \quad 00 \quad 00$

Ottawa City Council. (2019, April 24). Minutes 12. https://app05.ottawa.ca/sirepub/mtgviewer.aspx?meetid=7553\&doctype=minutes \&itemid $=387062$

Ottawa City Council. (2020a, January 29). Minutes 26. https://app05.ottawa.ca/sirepub/mtgviewer.aspx?meetid=7868\&doctype=agenda\& itemid $=397817$

Ottawa City Council. (2020b, October 28). Minutes 42. https://app05.ottawa.ca/sirepub/mtgviewer.aspx?meetid=7861\&doctype=SUMM $\underline{\mathrm{ARY}}$

Ottawa Public Health. (n.d.). Socio-demographic data and population projections. https://www.ottawapublichealth.ca/en/reports-research-andstatistics/sociodemographics.aspx\#Origin-and-Identity

Petts, J. (2001). Evaluating the effectiveness of deliberative processes: Waste management case-studies. Journal of Environmental Planning and Management, 44(2), 207-226. https://doi.org/10.1080/09640560120033713

Petts, J. (2007). Learning about learning: Lessons from public engagement and deliberation on urban river restoration. The Geographical Journal, 173(4), 300311. https://doi.org/10.1111/j.1475-4959.2007.00254.x

Plumwood, V. (2005). Inequality, ecojustice and ecological rationality. In D. Schlosberg \& J. S. Dryzek (Eds.), Debating the earth: The environmental politics reader (pp. 608-632). Oxford: Oxford University Press.

Policy Options. (2007). Cities in Canadian federalism. https://policyoptions.irpp.org/magazines/the-mood-of-canada/cities-in-canadianfederalism/

Reevely, D. (2017, June 20). Reevely: City hall's advisory committees are still a disaster. Ottawa Citizen. https://ottawacitizen.com/news/local-news/reevely-city-hallsadvisory-committees-are-still-a-disaster

Renn, O., Ulmer, F., \& Deckert, A. (Eds.). (2020). The role of public participation in energy transitions. Academic Press. https://doi.org/10.1016/C2018-0-02096-4 
Rittel, H., \& Webber, M. (1973). Dilemmas in a general theory of planning. Policy Sciences, 4(2), 155-169. https://doi.org/10.1007/BF01405730

Roelich, K., Bale, C. S. E., Turner, B., \& Neall, R. (2018). Institutional pathways to municipal energy companies in the UK: Realising co-benefits to mitigate climate change in cities. Journal of Cleaner Production, 182, 727-736. https://doi.org/10.1016/j.jclepro.2018.02.002

Schirmer, J., Dare, M., \& Ercan, S. A. (2016). Deliberative democracy and the Tasmanian forest peace process. Australian Journal of Political Science, 51(2), 288-307. https://doi.org/10.1080/10361146.2015.1123673

Senate of Canada Standing Committee on Energy, the Environment and Natural Resources. (2013). Federal, provincial and territorial energy jurisdiction (appendix 5) [PDF file]. https://sencanada.ca/Content/SEN/Committee/411/enev/DPKEnergy/appendices/Appendix05-EN.pdf

Sharp, E., Fagan, J., Kah, M., McEntee, M., \& Salmond, J. (2021). Hopeful approaches to teaching and learning environmental "wicked problems." Journal of Geography in Higher Education, 1-19. https://doi.org/10.1080/03098265.2021.1900081

Smedby, N., \& Quitzau, M. (2016). Municipal governance and sustainability: The role of local governments in promoting transitions. Environmental Policy and Governance, 26(5), 323-336. https://doi.org/10.1002/eet.1708

Sovacool, B. K., Burke, M., Baker, L., Kotikalapudi, C. K., \& Wlokas, H. (2017). New frontiers and conceptual frameworks for energy justice. Energy Policy, 105, 677691. https://doi.org/10.1016/j.enpol.2017.03.005

Standing Committee on Environmental Protection, Water and Waste Management. (2019, December 17). Report 620386 [PDF file]. http://ottwatch.ca/meetings/file/620386

Standing Committee on Environmental Protection, Water and Waste Management. (2020a, October 20). Minutes 11. https://app05.ottawa.ca/sirepub/mtgviewer.aspx?meetid=7925\&doctype=MINUT $\underline{\mathrm{ES}}$

Standing Committee on Environmental Protection, Water and Waste Management. (2020b, October 20). Report 662707 [PDF file]. http://ottwatch.ca/meetings/file/662707

Statistics Canada. (n.d.). Census profile, 2016 census Ottawa, city [census subdivision], Ontario and Canada [country]. https://www12.statcan.gc.ca/census- 
recensement/2016/dp-

$\mathrm{pd} /$ prof $/$ details $/$ page.cfm?Lang $=\mathrm{E} \&$ Geo1 $=\mathrm{CSD} \&$ Code $1=3506008 \& \mathrm{Geo} 2=\mathrm{PR} \& \mathrm{C}$ ode $2=01 \&$ SearchText $=$ ottawa $\&$ SearchType $=$ Begins $\&$ SearchPR $=01 \& B 1=$ All\&T $\underline{\mathrm{ABID}=1 \& \text { type }=0}$

Statistics Canada. (2018, January 17). Government. https://www150.statcan.gc.ca/n1/pub/11-402-x/2011000/chap/gov-gouv/govgouv-eng.htm

Strand, K. J., Marullo, S., Cutforth, N., Stoecker, R. \& Donohue, P. (2003). Communitybased research and higher education: Principles and practices (1st ed.). San Francisco, CA: Jossey-Bass.

Sustainability Solutions Group. (2019). Pathway study on demand side management and energy storage in Ottawa [PDF file].

https://documents.ottawa.ca/sites/documents/files/energy pathway phase2 en.PD $\underline{F}$

Szulecki, K. (2018). Conceptualizing energy democracy. Environmental Politics, 27(1), 21-41. https://doi.org/10.1080/09644016.2017.1387294

Uittenbroek, C., Mees, H., Hegger, D., \& Driessen, P. (2019). The design of public participation: Who participates, when and how? Insights in climate adaptation planning from the Netherlands. Journal of Environmental Planning and Management, 62(14), 2529-2547. https://doi.org/10.1080/09640568.2019.1569503

Webler, T., Tuler, S., \& Krueger, R. (2001). What is a good public participation process? Five perspectives from the public. Environmental Management, 27(3), 435-450. https://doi.org/10.1007/s002670010160 